Universidade de São Paulo

Instituto de Física

\title{
Estudo de Casadores de Impedância Mecânicos para Transdutores Paramétricos de Microondas em Detectores Esféricos de Ondas Gravitacionais
}

Fábio da Silva Bortoli

ORIENTADOR: Prof. Dr. Carlos Frajuca (CEFET-SP)

Dissertação de Mestrado apresentada ao Instituto de Física para a obtenção do título de Mestre em Ciências.

Banca Examinadora:

Prof. Dr. Carlos Frajuca (CEFET-SP)

Prof. Dr. Emerson José Veloso de Passos (IFUSP)

Prof. Dr. Odylio Denys de Aguiar (INPE) 
FICHA CATALOGRÁFICA

Preparada pelo Serviço de Biblioteca e Informação do Instituto de Física da Universidade de São Paulo

Bortoli, Fábio da Silva

"Estudo de casadores de impedância mecânicos para transdutores paramétricos de microondas em detectores esféricos de ondas gravitacionais". São Paulo, 2006.

Paulo.

Dissertação (Mestrado) - Universidade de São

Instituto de Física, Depto. de Física dos Materiais e Mecânica

Orientador: Prof. Dr. Carlos Frajuca

Área de Concentração: Física

Unitermos:

1.Detetores; 2.Ondas gravitacionais; 3.Método dos elementos finitos.

USP/IF/SBI-066/2006 


\section{AGRADECIMENTOS}

Ao meu orientador Prof. Dr. Carlos Frajuca pela oportunidade em pesquisar em uma área tão importante, e pela atenção e incentivo nos momentos em que foram necessários.

Aos professores do IFUSP, em especial aos professores Profs. Drs. Emerson Passos, Josif Frenkel, Élcio Abdala e Iberê Luiz Caldas, com os quais tive a chance de aprender e a honra de conviver.

Ao Prof. Dr. Odylio D. Aguiar e ao Prof. Dr. Nei F. Oliveira Jr. pela luta contagiante em favor da ciência.

A Profa. Dra. Nadja Magalhães pelo apoio e parceria nos artigos. Ao Me. Sérgio Turano de Souza por sempre disponibilizar as informações que dispunha. Aos colegas do projeto Gráviton pela colaboração sempre que esta foi necessária.

Ao colega, físico e mestrando da Escola Politécnica Marco Brizzoti, com quem pude trocar experiências sobre programas de MEF, sempre com muito entusiasmo.

À professora Profa. Dra. Larissa Diemeier e ao Prof. Dr. Marcílio Alves da Escola Politécnica, por permitirem a minha participação nas aulas iniciais da disciplina "Fundamentos do MEF não linear aplicados a Sistemas Mecânicos”.

Aos funcionários da CPG, em especial a Cláudia, Francilene, Hebert e Rodolfo pelo atendimento sempre eficiente e cortês.

Ao CEFETSP pelo apoio dado, através da licença semestral concedida, que em muito colaborou em meus trabalhos.

Aos professores e amigos do CEFETSP que dedicaram palavras de incentivo e apoio a este projeto, em especial a Paulo Gilberto Zépter, Almir Fernandes, Silvana Bueno, Nanci Romero e Marcelo Bonetti.

Aos colegas da GTI do CEFETSP que sempre colaboraram. Agradeço especialmente ao Sérginho pela sua intervenção sem a qual muitos arquivos de trabalho seriam perdidos, e ao Hélio pela consultoria on-line. 


\section{Dedicatória}

Aos meus amados pais que me ensinaram a prosseguir.

À Carla, pelo amor e o seu melhor fruto.

Ao Victor, por ser este fruto.

Ao Sr. Luiz e a Sra. Sônia que sempre apoiaram este projeto. 


\section{Resumo}

Através de várias simulações em um programa de elementos finitos fez-se uma série de estudos de uma esfera conectada a casadores de impedância mecânicos com dois formatos diferentes: "bico de passsarinho", criado nesta pesquisa, e “cogumelo”. Por limitação de tempo de processamento computacional escolheu-se trabalhar com casadores de impedância mecânicos com formatos mais simples que os utilizados no detector Mário Schenberg. Constatou-se que os modos normais do sistema acoplado não são exatamente degenerados. Fica clara a dificuldade em se encontrar um grupo de casador de impedância mecânico que possa ser calibrado da mesma forma em todos os diferentes modos de detecção. Para o casador de impedância com formato de cogumelo foi identificado um conjunto de dimensões que permite que todos os transdutores sejam calibrados da mesma forma. 


\section{Abstract}

Using simulation in Finite Element Modeling software a series of studies of a sphere connected to mechanical impedance mantchers with two different shapes: beak shape na mushroom shape. For computer processing limitation time, the work was done with simpler shapes than the one used in Mário schenberg Detector. It was shown that the system vibration normal modes are not exactly degenerated. It's clear the dificcult in finding a set of mehanical macthers that can be calibrated in the same way in all the different detector modes. 


\section{Índice}

Estudo de Casadores de Impedância Mecânicos para Transdutores Paramétricos de Microondas em Detectores Esféricos de Ondas Gravitacionais .................. I

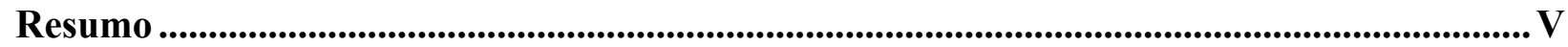

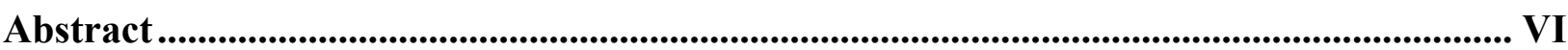

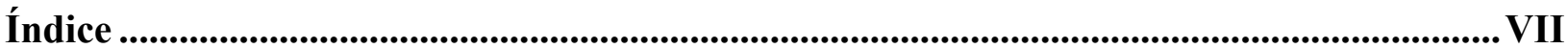

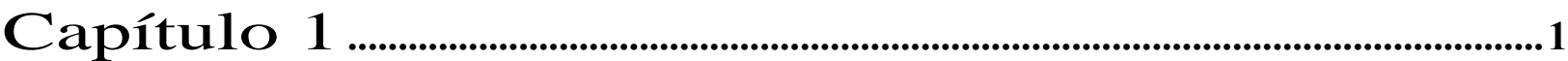

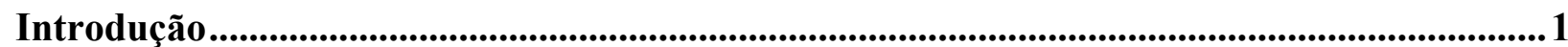

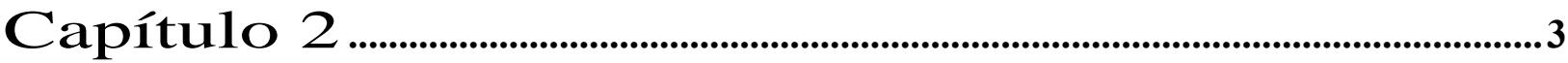

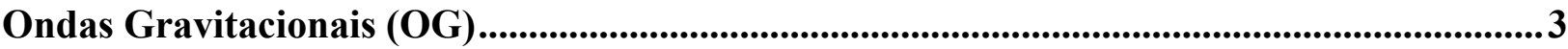

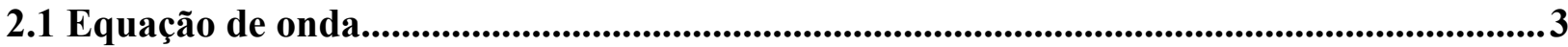

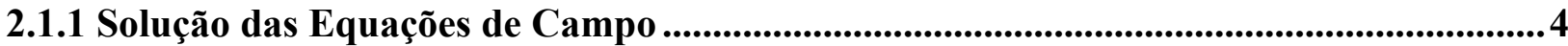

2.1.2 Equação de movimento ....................................................................................................................5

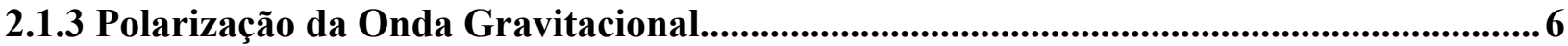

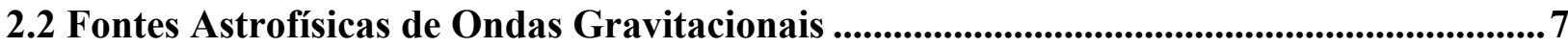

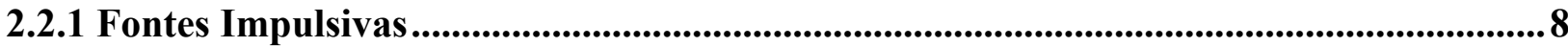

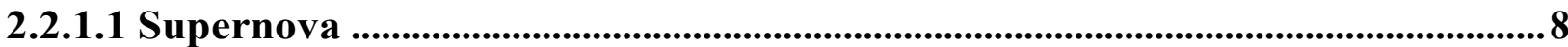

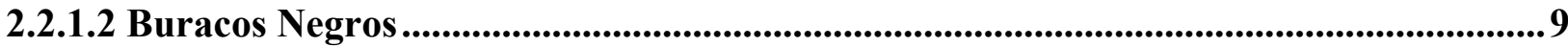

2.2.1.3 Coalescência de Binárias Compactas ...............................................................................99

2.1.4 Queda de Estrelas e Pequenos Buracos Negros no Interior de Buracos Negros Supermassivos........................................................................................................................................... 10

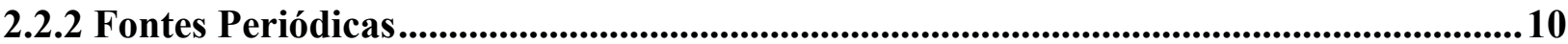

2.2.2.1 Estrelas de Nêutrons em Rotação …...........................................................................11

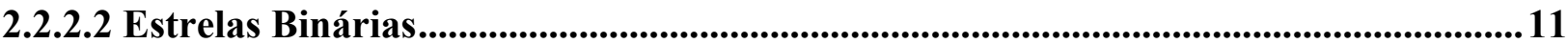

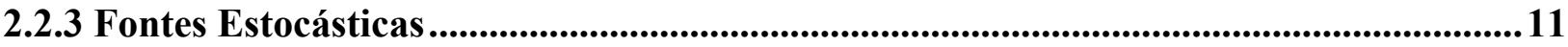

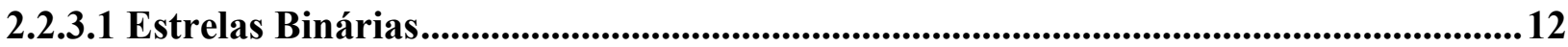

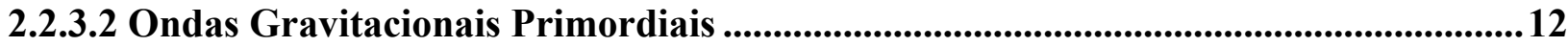

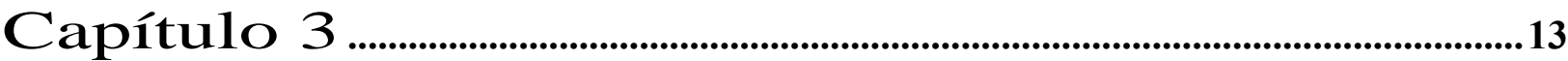

Tecnologia Existente para a Detecção de Ondas Gravitacionais ........................................... 13

3.1 Interação das Ondas Gravitacionais com a Matéria........................................................13

3.2 Previsão, Evidência e Tentativas de Detecção de Ondas Gravitacionais .......................... 14

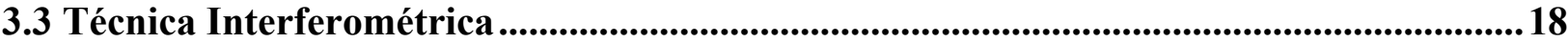

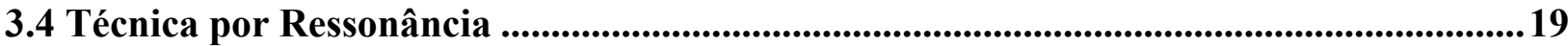


3.5 Princípios Relativos à Detecção com Detectores de Massa Ressonante ............................20

3.5.1 Comparando Detectores Esféricos com os do Tipo Barra...............................................21

3.6 Utilizando Detectores Esféricos.................................................................................22

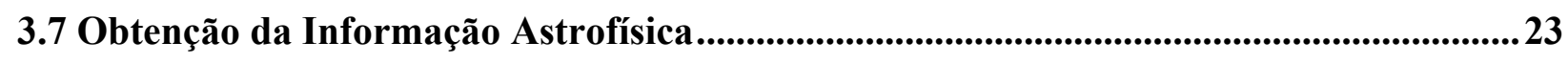

3.8 Ruídos e Atenuação de seus Efeitos na Sensibilidade do Detector ...................................23

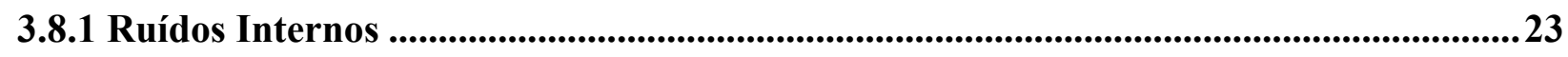

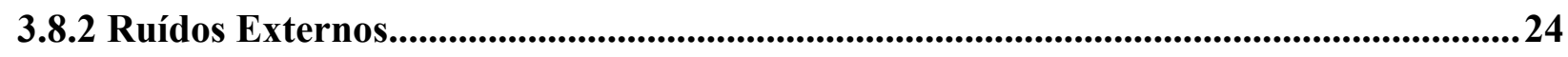

3.9 Influência do Fator de Qualidade Mecânico Q na Sensibilidade do Detector..................26

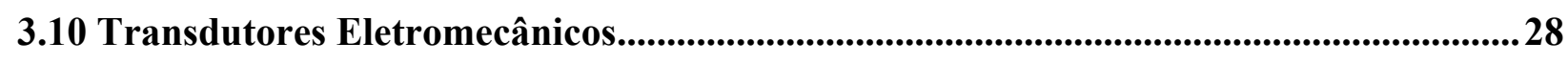

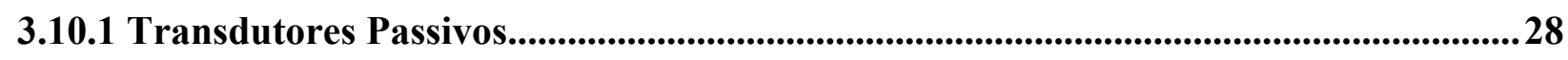

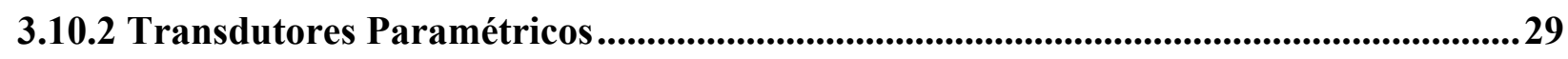

3.10.3 Vantagens dos Transdutores Paramétricos sobre Transdutores Passivos .................30

3.10.4 Desvantagens dos Transdutores Paramétricos sobre Transdutores Passivos ............30

3.10.5 Equações de Manley-Rowe..................................................................................

3.10.6 Transdutor Paramétrico do Tipo Cavidade Reentrante ..............................................32

3.10.7 Ruídos no Transdutor do Tipo Cavidade Reentrante ...............................................33

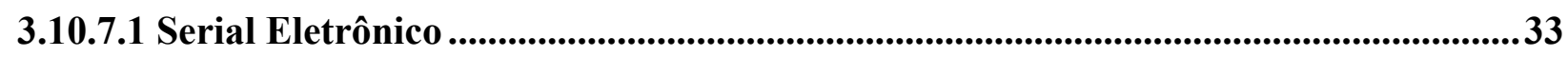

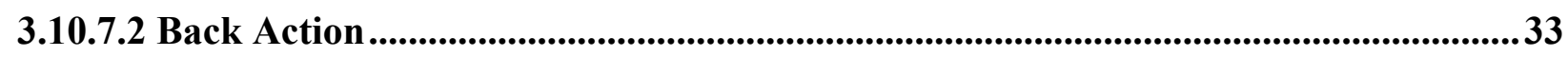

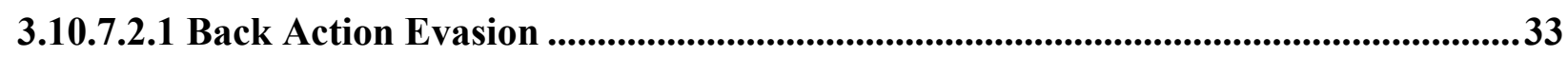

3.10.7.3 Ruído de Amplitude e Fase.......................................................................................35

3.10.7.4 Implicações do Ruído de Fase em Detecção de Ondas Gravitacionais......................38

Capítulo 4 ....................................................................................................................39

Oscilações Mecânicas no Detector ............................................................................................39

4.1 Dinâmica de Sistemas Rígidos..............................................................................40

4.2 Oscilações Acopladas .............................................................................................................4 41

4.2.1 Acoplamento de dois Osciladores Harmônicos ..........................................................42

4.2.2 Coordenadas e Modos Normais ................................................................................47

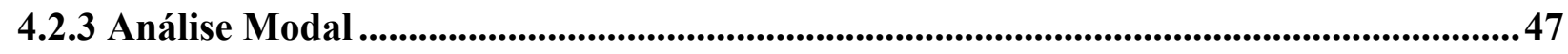

4.2.4 Análise Modal de Dois Osciladores Harmônicos Acoplados......................................52

4.2.5 Modos de Vibração Degenerados.............................................................................................56

4.2.6 Modos de Vibrações e Freqüências Naturais em Sistemas Contínuos ............................56

4.2.6.1 Sistemas Contínuos Regulares ...................................................................................................56

4.2.6.2 Sistemas Contínuos Quaisquer .............................................................................................55

4.3 Método de Elementos Finitos (MEF) ...........................................................................59

4.3.1 Resumo da Teoria......................................................................................................................59

4.3.2 Análise Modal Utilizando MEF ......................................................................62 


\section{Capítulo 5 Estudo dos Casadores Mecânicos de Impedância

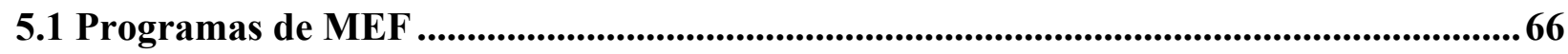

5.2 Calibração do MEF Através da Simulação da Esfera do Schenberg................................66

5.3 Modelagem e Simulação com os Casadores de Impedância...............................................68

5.3.1 Formatos Inicialmente Pesquisados ............................................................................68

5.3.2 Casadores de Impedância com Formato "Bico de Passarinho" ("beak shape")......... 71

5.3.3 As Simulações da Esfera com um Casador de Impedância "Bico de Passarinho" ...... 72

5.3.3.1 Primeira Estratégia ..................................................................................................................73

5.3.3.2 Segunda Estratégia....................................................................................................................73

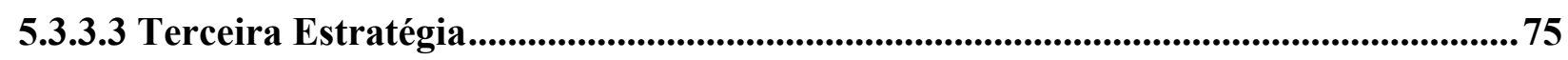

5.3.4 Duas Simulações da Esfera com Três Casadores de Impedância "Bico de Passarinho"

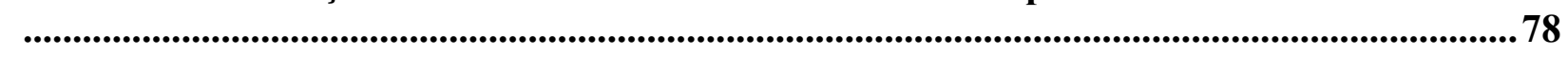

5.3.5 Simulação da Esfera com Seis Casadores de Impedância "Bico de Passarinho".........80

5.3.6 As Simulações da Esfera com um Casador de Impedância com Formato "Cogumelo" ("mushroom shape")...............................................................................................................................8 83

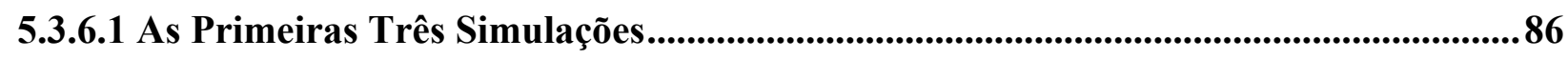

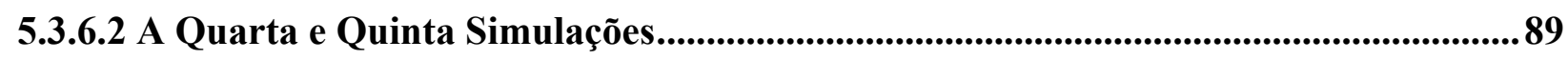

5.3.6.3 A Sexta Simulação ...................................................................................................................91

5.3.7 Simulação da Esfera com Seis Casadores de Impedância “Cogumelo"'.........................92

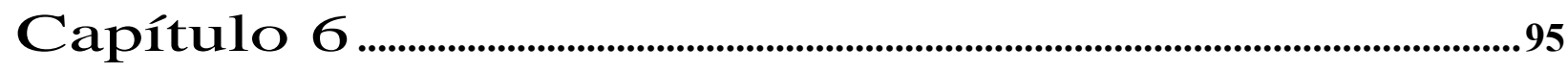

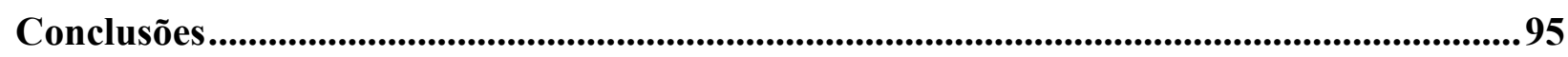

6.1 Sugestões para Trabalho Futuro …...............................................................................97

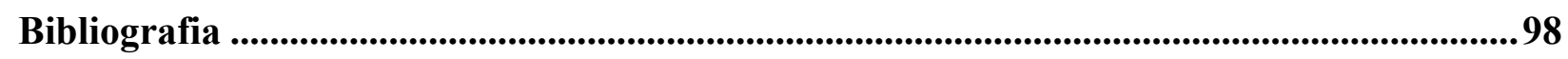




\section{Capítulo 1}

\section{Introdução}

Podem-se produzir e detectar ondas eletromagnéticas em laboratório, já a tentativa de se produzir OG (ondas gravitacionais) em laboratório, com a tecnologia disponível, resulta em ondas com intensidade muito baixa para serem detectadas. Apesar da atenuação pela enorme distância das fontes astrofísicas é melhor tentar observar as OG produzidas no universo.

A comparação entre as radiações eletromagnética e gravitacional conduz a duas diferenças importantes:

- As OG interagem fracamente com a matéria tornando-se extremamente difícil de serem detectadas. Contudo é exatamente esta característica que torna possível sondar astros ou eventos astrofísicos escondidos por nuvens de poeiras ou gases, desde que tais eventos produzam OG com intensidade alta o suficiente para serem detectadas.

- Para que as OG sejam geradas é necessário que haja aceleração relativa entre massas, ou mais precisamente, que haja uma mudança na distribuição “quadrupolar” de massas, enquanto as ondas eletromagnéticas são emitidas quando uma carga elétrica acelera.

Até o presente momento não existe evidencia direta da existência de OG, embora seja possível a sua verificação experimental indireta através da observação da taxa de decaimento do período orbital do Pulsar Binário PSR 1913+16 [1] [2], que é mostrada na Figura 1.1 . A verificação experimental direta confirmará a existência de OG e permitirá a medição de sua velocidade de propagação, validando possivelmente assim a TRG (Teoria Geral da Relatividade) de Einstein, além de permitir uma investigação direta da interação gravitacional sob condições extremas [2]. Vencido o desafio de detectar OG oriundas de fontes astrofísicas teremos um novo instrumento para a pesquisa, que possibilitará uma nova maneira de estudar a astronomia.

A detecção de OG vem envolvendo vários grupos de pesquisas em todo o mundo, que vêm desenvolvendo detectores cada vez mais sensíveis para tentar estudar e compreender a interação destas ondas com a matéria. Será, provavelmente, um dos eventos mais importantes da pesquisa física nas próximas décadas. 


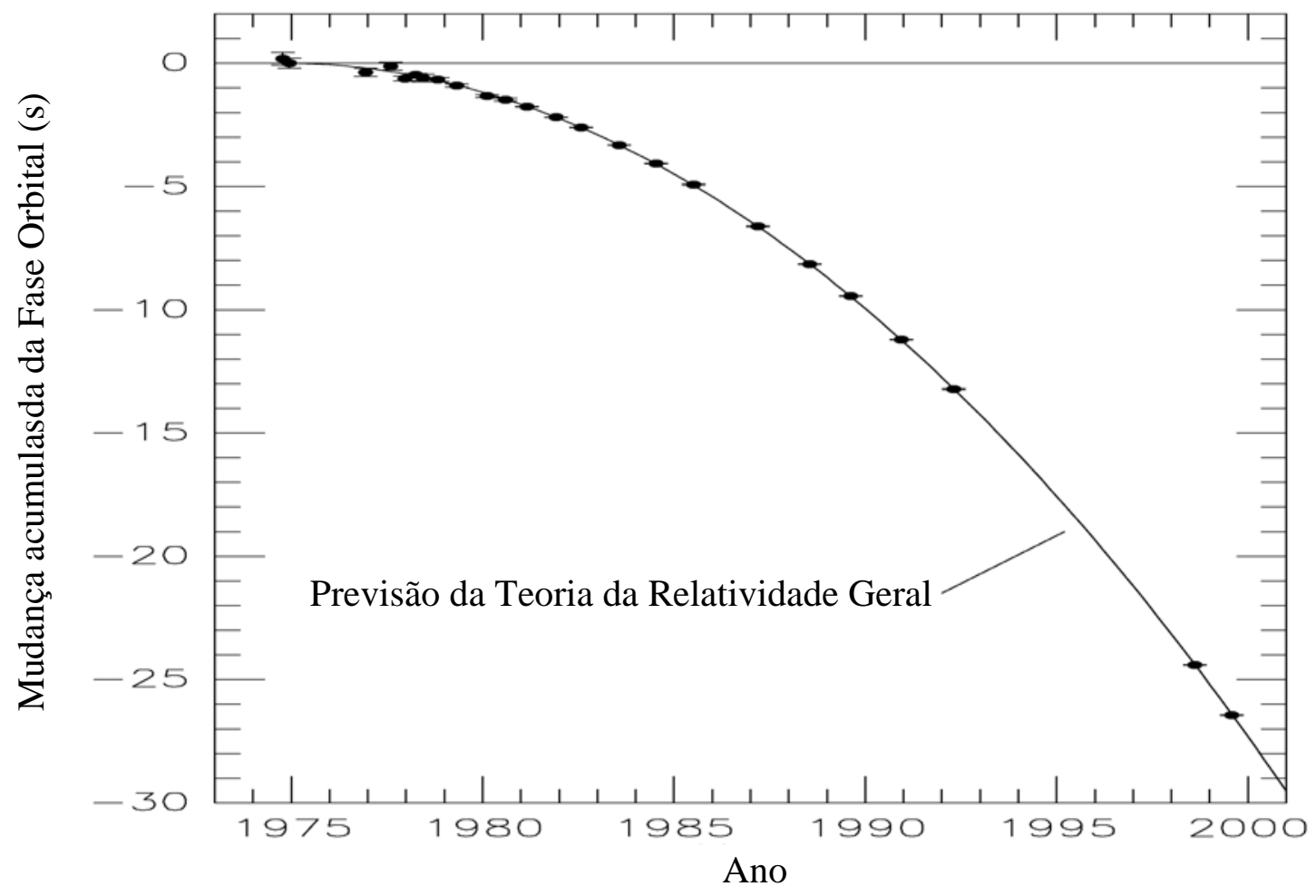

Figura 1.1: Taxa de decaimento do período orbital do Pulsar Binário PSR 1913+16 [30]. 


\section{Capítulo 2}

\section{Ondas Gravitacionais (OG)}

São bem conhecidas as alterações que o movimento acelerado de uma carga elétrica provoca em um sistema envolvendo outras cargas. Em muitas situações é possível se descrever as mudanças nos campos elétricos e magnéticos devidas ao movimento de tais cargas e se produzir e avaliar estes comportamentos em laboratório.

De forma semelhante, quando um corpo inicia um deslocamento a distribuição de massas do sistema Terra-corpo se altera, provocando uma súbita mudança no campo gravitacional da Terra que tem que se adaptar a esta mudança. Esta mudança no campo gravitacional se propaga. Esta propagação, com velocidade comparável à da luz e longe da fonte, é chamada de onda gravitacional (OG). A sua existência foi prevista na Teoria da Relatividade Geral (TRG) de Einstein em 1916 [2] , mas ainda não se obteve observação direta de sua existência.

\subsection{Equação de onda}

Em 1916 Einstein previu a existência de OG a partir da solução das equações de campo da Teoria da Relatividade Geral (TRG) [2], que é reproduzida abaixo:

$$
R_{\mu \nu}-\frac{1}{2} g_{\mu v} R=8 \pi \frac{G}{c^{4}} T_{\mu \nu}+\lambda
$$

onde,

$R_{\mu v}$ representa a curvatura do espaço-tempo (tensor de Ricci)

$T_{\mu \nu}$ é o tensor momento-energia

$g_{\mu \nu}$ é a métrica do espaço-tempo

$R$ é o escalar de curvatura

$G$ é a constante universal da gravitação

$c$ é a velocidade de propagação da luz no vácuo

$\lambda$ é o termo da constante cosmológica.

Desprezando a constante cosmológica $\lambda$, e sabendo-se, que no vácuo o tensor momento-energia $T_{\mu v}=0$ (ausência de matéria), podemos reescrever as equações de campo (2.1) de forma mais simples: 
$R_{\mu \nu}-\frac{1}{2} g_{\mu \nu} R=G_{\mu \nu}=0$

no qual, $G_{\mu \nu}$ é o tensor de Einstein.

As equações (2.2) são diferenciais de $2^{\mathrm{a}}$ ordem, isto torna difícil obter uma solução analítica para elas. Entretanto, soluções aproximadas podem ser obtidas a partir de métodos numéricos computacionais (relatividade numérica). Existem alguns métodos, empregados na resolução destas equações, tais como: formalismo Slow-motion, Pós-Minkoswkiano e Pós-Newtoniano que nos permite obter soluções aproximadas para as equações da TRG [2].

\subsubsection{Solução das Equações de Campo}

A aproximação de campo gravitacional fraco é empregada em regiões suficientemente longe das fontes [2]. Nestes casos, o espaço é aproximadamente plano e o tensor métrico pode ser escrito como:

$g_{\mu \nu}=\eta_{\mu v}+h_{\mu \nu}$

nas quais, $\eta_{\mu \nu}$ é a métrica de Minkowisky e $h_{\mu \nu}<<1$ é uma perturbação da métrica do espaçotempo que corresponde à amplitude da onda gravitacional.

Definindo,

$\bar{h}_{\mu \nu}=h_{\mu \nu}-\frac{1}{2} \eta_{\mu \nu} h$ (condição de Lorentz),

e substituindo na equação (2.2) obtemos:

$\square^{2} \bar{h}_{\mu \nu}=0$

na qual, $\square^{2} \equiv\left(\frac{-1 \partial^{2}}{c^{2} \partial t^{2}}+\nabla^{2}\right)$, é o operador d'Alambertiano. 
O tensor $h_{\mu \nu}$ possui divergência nula (gauge de Lorentz), não têm traço e é transverso a direção de propagação da onda.

A equação (2.5) admite uma solução da forma: $\bar{h}=A_{\mu \nu} e^{[i k(z-c t)]}$, a qual representa uma onda monocromática propagando-se ao longo da direção z, à velocidade da luz $c$ (outras teorias de gravitação podem obter resultados diferentes para a velocidade de propagação), com freqüência $\omega=k c$, transportando momento e energia.

A energia irradiada por uma onda gravitacional é obtida através de uma expansão multipolar da solução tipo potencial retardado das equações de campo (2.2). A expansão é feita a distâncias suficientemente grandes, comparadas à dimensão da fonte. O termo de dipolo obtido é nulo, devido à conservação do momento linear e a inexistência de massas negativas. O primeiro termo não nulo da expansão multipolar é o de quadrupolo, dado por,

$$
W=\frac{1}{5} \frac{G}{c^{5}}\left(\dddot{I}_{j k}\right)^{2}
$$

nas quais, $W$ é a energia irradiada pelas OG e $\dddot{I}_{j k}$ é a terceira derivada temporal do momento de quadrupolo.

Desta forma, OG são emitidas quando a terceira derivada do momento quadrupolar da distribuição de massas é diferente de zero. Fazendo-se uma analogia entre as radiações gravitacional e eletromagnética, nota-se que o fator $c^{5}$ do denominador da expressão de emissão quadrupolar, comparado ao fator $c^{3}$ do termo de emissão dipolar eletromagnética [3], explica a pequena amplitude das OG. Portanto, espera-se que apenas eventos catastróficos no universo, envolvendo objetos de grande massa, ou com grande velocidades, ou raios da ordem $2 G M / c^{2}$, produzam ondas com amplitudes detectáveis. Isto é, eventos astrofísicos.

\subsubsection{Equação de movimento}

Na Teoria da Relatividade Geral uma OG é descrita por um campo adimensional $h_{i j}(i j=1,2,3)$

[1]. Se as OG forem a única fonte de curvatura no espaço-tempo num sistema de coordenadas de um observador em queda livre, um deslocamento $\delta x_{i}$, pode ser relacionado com $h_{i j}$ pela equação de movimento:

$$
m \frac{d^{2} \delta x_{i}}{d t^{2}}=\frac{m}{2} \frac{\partial^{2} h_{i j}}{\partial t^{2}} x^{j}
$$


Na aproximação de OG muito fraca tal que $\partial x^{i}<<x^{i}, x^{i}$ pode ser considerado constante no lado direito da equação (2.7), que integrada fornece a seguinte relação:

$\frac{1}{2} h_{i j}=\frac{\partial x_{i}}{x^{j}}$

O campo da OG é transverso e com traço nulo. E se orientarmos o eixo $z$ do nosso sistema de coordenadas na direção de propagação da onda, as únicas componentes não nulas do tensor serão:

$h_{x x}=-h_{y y} \mathrm{e}$

$h_{x y}=h_{y x}$.

O campo tem, portanto, somente dois estados de polarização, que são chamados de polarização “mais” (plus) e “xis” (cross), os quais em termos das componentes do campo são:

$$
\begin{aligned}
& h_{+}=h_{x x}=-h_{y y} \quad \mathrm{e} \\
& h_{x}=h_{x y}=h_{y x} .
\end{aligned}
$$

Elas possuem divergência nula (Gauge de Lorentz), não têm traço e são transversas à direção de propagação da onda.

\subsubsection{Polarização da Onda Gravitacional}

O desvio geodésico na direção transversa à direção de propagação da onda nos fornece um meio de estudar e caracterizar a polarização das ondas planas [2]. O tensor $h_{\mu v}$, representa os dois estados de polarização da onda. Na forma canônica, $h_{\mu \nu}$ é descrito por:

$$
h_{\mu \nu}=\left[\begin{array}{cccc}
0 & 0 & 0 & 0 \\
0 & 0 & 0 & 0 \\
0 & 0 & h_{+} & h_{x} \\
0 & 0 & h_{x} & -h_{+}
\end{array}\right],
$$

o qual é definido em termos das duas amplitudes de polarização $h_{+}$e $h_{x}$ definidos acima em (2.9a) e (2.9b). 


\subsection{Fontes Astrofísicas de Ondas Gravitacionais}

Conforme [1], [2], [4], e [6].

Geralmente as OG são classificadas segundo critérios relacionados ao seu comportamento temporal ou a sua freqüência de emissão. Segundo o critério referente ao comportamento temporal do sinal tem-se que:

$\Delta f=\frac{f_{c}}{q}$,

onde $q$ é o número de ciclos coerentes apresentados pelo sinal, $\Delta f$ é a largura de banda e $f_{c}$ é a freqüência característica de emissão da fonte.

Ainda de acordo com o critério temporal as fontes astrofísicas são classificadas em:

- fontes impulsivas, emitem sinais que apresentam poucos ciclos coerentes $q$, e conseqüentemente uma largura de banda $\Delta f$ grande. Neste caso os sinais emitidos mantêm a coerência durante um tempo correspondente a poucos ciclos da onda;

- fontes periódicas, emitem sinais continuamente e mantêm a coerência durante um tempo longo (q grande);

- fontes estocásticas, emitem sinais que correspondem à somatória de uma distribuição aleatória de sinais, portanto não coerente $(q \rightarrow 0)$.

De acordo com Thorne [1], as OG mais intensas são esperadas em freqüências abaixo de $10 \mathrm{kHz}$. Thorne [1] estimou a amplitude característica de uma OG como:

$h_{c}=2,7 \times 10^{-20}\left[\frac{\Delta E_{O G}}{M_{S} c^{2}}\right]^{1 / 2}\left[\frac{1 \mathrm{kHz}}{f_{c}}\right]^{1 / 2}\left[\frac{10 M p c}{r_{0}}\right]$,

onde $\Delta E_{O G}$ é a energia total emitida na forma de OG em massas solares, $M_{S}$ é a massa do sol, $r_{0}$ é a distância da fonte e $10 \mathrm{Mpc}$ é a distância estimada do centro do aglomerado de Virgo. Como exemplo, o colapso de uma estrela para uma estrela de nêutrons a uma distância de 10 Kpc produziria uma amplitude da ordem de $10^{-20}$ a $10^{-18}$.

Essa amplitude é suficientemente alta pata ser detectada pelos detectores atuais, mas o problema é que a taxa de supernovas em nossa galáxia é estimada em cerca de uma a cada 30 anos. Para atingirmos um alcance comparável ao centro do aglomerado de Virgo é necessário um aumento na sensibilidade em 3 ordens de magnitude na amplitude ou em 6 ordens de magnitude na 
energia. De acordo com um catálogo feito por Fouqué [1], baseado em estudos óticos [1], o aglomerado de Virgo contém 2096 galáxias, e, entre estas 105 são galáxias que possuem uma alta taxa de supernovas.

Uma fonte não convencional de OG seria a coalescência de sistemas binários constituídos de objetos escuros (matéria escura) no halo de nossa galáxia [1].

\subsubsection{Fontes Impulsivas}

Potenciais candidatas a fontes impulsivas são: colapso de estrelas no processo de formação de estrelas de nêutrons ou buracos negros, coalescência de sistemas binários compactos constituídos de estrelas de nêutrons e/ou buracos negros, e choques de estrelas ou pequenos buracos negros com buracos negros massivos ou supermassivos.

Como já foi mencionado: os pulsos mais intensos são esperados para OG com freqüências abaixo de $10 \mathrm{kHz}$. .

A seguir é feita uma breve descrição das candidatas a fontes impulsivas de OG.

\subsubsection{Supernova}

A produção de OG durante o colapso de uma estrela no processo de formação de uma estrela de nêutrons, ou supernova, depende do grau de não esfericidade do colapso e também da velocidade do mesmo. Colapsos perfeitamente esféricos não produzem ondas gravitacionais, já que a taxa de variação do momento de quadrupolo é nula.

Dependendo de como se originou e das características do colapso (sua instabilidade quanto a deformação e a perturbações, sua simetria esférica, suas velocidade e velocidade de rotação) são previstas emissões de OG com as seguintes características:

Se a estrela permanecer axi-simétrica durante o colapso, são previstas as emissões mais fortes em duas diferentes regiões espectrais:

$f_{c} \approx 10^{3} \mathrm{~Hz}$, onde $\Delta E_{O G} \cong 10^{-7} M_{S} c^{2}$ e $h_{c} \approx 10^{-23}\left(10 \mathrm{Mpc} / r_{0}\right)$, devido ao colapso inicial, e
$f_{c} \approx 10^{4} \mathrm{~Hz}$ onde $\Delta E_{O G} \cong 10^{-6} M_{S} c^{2}$ e $h_{c} \approx 10^{-23}\left(10 \mathrm{Mpc} / r_{0}\right)$ devido às pulsações de uma EN (Estrela de Neutrons).

Se a estrela se tornar instável à deformação e se tornar um elipsóide, foi prevista uma emissão monocromática com $f_{c} \approx 10^{3} \mathrm{~Hz}$, terminando em 30 ciclos e produzindo $\Delta E_{O G} \cong 10^{-4} M_{S} c^{2}$ e $h_{c} \approx 5 \times 10^{-22}\left(10 \mathrm{Mpc} / r_{0}\right)$.

Se a estrela colapsante tornar-se muito instável a perturbações não axi-simétricas, de maneira que rompa em duas ou mais massas deformadas, neste caso, serão produzidas as ondas mais fortes: $\Delta E_{O G} \cong 10^{-2} M_{S} c^{2}, f_{c} \approx 10^{3} H z$ e $h_{c} \approx 4 x 10^{-21}\left(10 M p c / r_{0}\right)$. 


\subsubsection{Buracos Negros}

No colapso para formar um buraco negro, a intensidade das OG produzidas é altamente dependente do grau de não esfericidade deste colapso, mas este grau é desconhecido. A freqüência de ocorrência destes colapsos também é desconhecida.

A taxa de formação de buracos negros de baixa massa é de aproximadamente $1 / 3$ da taxa de formação de estrelas de nêutrons na nossa galáxia, e, considerando o aglomerado de Virgo não deve passar de um por ano. Buracos negros com massa da ordem de $10^{6} M_{S}$ são formados apenas em núcleos galácticos e a uma pequena taxa (poucos buracos negros por ano) dentro do universo observado.

Como um Buraco negro é o objeto final mais simples, as OG irradiadas por sua vibração são melhores entendidas se elas forem produzidas pelas acelerações envolvidas no colapso.

Assim, enquanto detalhes iniciais de sinais impulsivos dependem de fatores desconhecidos do colapso, a característica posterior deve ter uma forma estabilizada na qual é possível se determinar a massa com alta precisão.

Supondo que o buraco negro irradie OG com uma eficiência $\Delta E / m c^{2}=\varepsilon$, que está a uma distância $r_{0}$, e que tem uma massa $M_{1}$, tem-se que:

$h_{c}=1,0 \times 10^{-20}\left[\frac{\varepsilon}{0,01}\right]^{\frac{1}{2}}\left[\frac{1 k H z}{f_{c}}\right]^{\frac{1}{2}}\left[\frac{10 M p c}{r_{0}}\right]$,

onde $f_{c}$ é a freqüência característica da fonte dada por:

$$
f_{c}=\frac{1}{56 M_{S}}=\left(1,3 \times 10^{4} \mathrm{~Hz}\right)\left[\frac{M_{x}}{M_{1}}\right] .
$$

Se o colapso é axi-simétrico, então a eficiência $\varepsilon$ provavelmente não excede $7 \times 10^{-4}$. E para buracos negros com algumas massas solares os colapsos ocorridos até uma distância de $10 \mathrm{Mpc}$ apresentariam uma amplitude da ordem de $10^{-21}$ na Terra.

\subsubsection{Coalescência de Binárias Compactas}

Durante a espiralação a freqüência varia, tendendo a atingir no seu estágio final um valor máximo para estrelas de nêutrons de:

$f_{\max } \approx 1 \mathrm{kHz}$ 
e para buracos negros

$f_{\max } \approx \frac{10 \mathrm{kHz}}{\mathrm{M}_{1} / M_{S}}$

onde $M_{1}$ é a massa do objeto mais massivo. A amplitude da onda pode ser calculada por:

$$
h_{c}=4,1 \times 10^{-22}\left(\frac{M}{M_{S}}\right)^{\frac{1}{3}}\left(\frac{\mu}{M_{S}}\right)^{\frac{1}{2}}\left(\frac{100 M p c}{r}\right)\left(\frac{100 H z}{f_{c}}\right)^{\frac{1}{6}},
$$

onde $M$ é a massa total, $M_{S}$ é a massa do sol, $\mu$ é a massa reduzida do sistema, $r$ é a distância da fonte e $f_{c}$ é a freqüência característica da fonte.

\subsubsection{Queda de Estrelas e Pequenos Buracos Negros no Interior de Buracos} Negros Supermassivos

Acredita-se que buracos negros supermassivos com massa $M \geq 10^{5} M_{S}$ ocupem o centro das galáxias e que os mesmos possam aumentar de tamanho por acresção. Para $r_{0} \approx 10 M p c$ tem-se uma taxa de eventos razoável. A freqüência máxima de emissão da onda é dada por:

$$
f_{c} \cong \frac{1}{20} M_{1}=10^{-4}\left(\frac{10^{8} M_{S}}{M_{1}}\right)
$$

E a amplitude da onda pode ser calculada por:

$$
h_{c} \cong \frac{M_{2}}{2 r_{0}}=2 \times 10^{-21}\left(\frac{M_{2}}{M_{S}}\right) \cdot\left(\frac{10 M p c}{r_{0}}\right),
$$

onde $M_{1}$ é a massa do buraco negro supermassivo e $M_{2}$ é a massa do corpo em queda.

\subsubsection{Fontes Periódicas}

São fontes que emitem sinais que se repetem periodicamente, mantendo coerência durante muitos ciclos e permitindo a sua integração durante longos períodos. Como exemplos de fontes periódicas têm-se: rotação de estrelas de nêutrons axialmente assimétricas, rotação de sistemas binários e rotação de pulsares axialmente assimétricos.

As fontes periódicas apresentam um valor de estabilidade em freqüência extremamente alto permitindo a integração do sinal durante longos períodos. Desse modo valores de amplitude muitos pequenos tornam-se detectáveis. Este tipo de fonte apresenta um sinal com largura de banda pequena, emitindo as ondas numa freqüência bem característica. 


\subsubsection{Estrelas de Nêutrons em Rotação}

Um pulsar (estrela de nêutrons em rotação) emite ondas gravitacionais com amplitude proporcional à assimetria ao redor do seu eixo de rotação, e com freqüência igual ao dobro da freqüência de rotação. Quanto mais rápido girar e maior a assimetria, mais forte deverá ser a emissão.

A amplitude adimensional da OG na Terra pode ser calculada pela expressão:

$$
h=8,1 \times 10^{-28}\left(\frac{I\left(\mathrm{gcm}^{2}\right)}{3 \times 10^{44}}\right)\left(\frac{\varepsilon_{r a d}}{10^{-6}}\right)\left(\frac{100}{R(p c)}\right)\left(\frac{f(H z)}{10}\right)^{2},
$$

onde $I$ é o momento de quadrupolo, $\varepsilon$ é a assimetria da estrela, $R$ é a distância em parsec e $f$ é a freqüência em Hz. O fator de assimetria $\varepsilon$ é difícil de ser estimado e não há como determinálo à partir da observação. Mas ele pode ser previsto teoricamente, quando se obtém valores entre $10^{-6}$ e $10^{-2}$. Entretanto, pode-se obter a amplitude da emissão gravitacional de pulsares a partir da medida da variação do período de rotação $(d P / d t)$, assumindo que essa variação corresponda à perda de momento angular devido à emissão gravitacional.

\subsubsection{Estrelas Binárias}

Devido à excentricidade da órbita, binárias ordinárias emitem OG igualmente espaçadas (linhas espectrais), e a sua amplitude característica pode ser dada por:

$$
h_{c}=8,7 \times 10^{-21} \cdot\left(\frac{\mu}{M_{\oplus}}\right)\left(\frac{M}{M_{\oplus}}\right)^{\frac{2}{3}}\left(\frac{100 p c}{r}\right)\left(\frac{f}{10^{-3} H z}\right)^{\frac{2}{3}}
$$

onde $\mu$ é a massa reduzida do sistema, $M_{\oplus}$ é a massa do sol, $M$ é massa do corpo mais massivo, $r$ é a distância da fonte e $f$ é a freqüência. Para baixa excentricidade da órbita ( $\varepsilon \leq$ $0,2)$ o harmônico dominante da emissão gravitacional ocorre em $f=2 \cdot f_{\text {orb }}$.

\subsubsection{Fontes Estocásticas}

Fontes estocásticas incluem uma potencial radiação gravitacional de fundo com origem cosmológica ou de uma sobreposição da radiação de uma grande população de sistemas binários em nossa galáxia e nas galáxias próximas.

São emissões, oriundas de uma distribuição estatística (aleatória) de fontes que resultam num ruído de fundo gravitacional. São exemplos de fontes: sistemas binários na Via Láctea ou em galáxias próximas, ondas gravitacionais primordiais, transições de fase e cordas cósmicas. 
São emissões que resultam num ruído de fundo gravitacional com origem:

- cosmológica (OG promordiais),

- na sobreposição da radiação de uma grande população de sistemas binários, distribuídos aleatoriamente na Via Láctea, ou em galáxias próximas,

- nas transições de fase,

- nas cordas cósmicas.

A detecção deste ruído de fundo poderia ser feita fazendo-se a correlação entre o ruído detectado em diversas antenas.

\subsubsection{Estrelas Binárias}

Muitas estrelas binárias, em nossa e em outras galáxias, emitem radiação gravitacional na região de freqüência $f \leq 10^{-2} \mathrm{~Hz}$, havendo uma grande superposição destas emissões e a produção de um "background” muito intenso. A contribuição de todas as outras galáxias deve ser menor que 15\% da contribuição da Via Láctea. O “background” produzido por vários tipos de binárias representam um sério obstáculo para a busca de outros tipos de ondas na banda de freqüências entre $10^{-5} \mathrm{~Hz}$ e $0,03 \mathrm{~Hz}$.

\subsubsection{Ondas Gravitacionais Primordiais}

Estima-se que os grávitons se desacoplaram da matéria em um intervalo de tempo de $10^{-43} \mathrm{~s}$ (igual ao tempo de Planck) após o “Big-Bang”, quando o espaço-tempo era quantizado e o Universo se comportava de uma maneira bem diferente do que é descrito pelas leis físicas conhecidas hoje. O estudo das OG primordiais (ondas criadas no "Big-Bang”) pode ignorar subseqüentes interações com a matéria, porém interações com a curvatura do espaço-tempo não podem ser ignoradas. Estas interações podem gerar amplificações e desta maneira pequeníssimas variações iniciais podem resultar numa quantidade mais significativa. A quantidade de energia produzida como radiação gravitacional depende crucialmente de aspectos da singularidade inicial da equação de estado que descreve aquela situação e da taxa de expansão dependente do vácuo do Universo muito primitivo. 


\section{Capítulo 3}

\section{Tecnologia Existente para a Detecção de Ondas Gravitacionais}

\subsection{Interação das Ondas Gravitacionais com a Matéria}

A ação de um campo gravitacional sobre diferentes massas situadas em um único lugar é a de fornecer a mesma aceleração a estas massas (princípio da equivalência). Assim o único efeito observável produzido por uma OG são acelerações relativas entre massas situadas em lugares diferentes, ao mesmo tempo [1]. Ou seja, OG podem ser detectadas a partir da variação temporal induzida por elas [4]. OG podem ser consideradas como distorções do espaço, que é dependente do tempo, e, como foi visto (seções 2.1 .2 e 2.1.3) tendo duas polarizações: $h_{+}$e $h_{x}$.

Uma das formas de estudar a interação da OG com a matéria é medir a aceleração relativa entre duas partículas testes num plano ${ }^{1}$. A Figura 3.1 mostra a interação, com o decorrer do tempo, de um anel de massas teste situado, em um plano x-y com uma onda gravitacional com polarização $(+)$ e $(x)$, propagando-se na direção z. O efeito de ambas polarizações lineares é mostrado. A medida em que a onda se propaga no eixo z, passado um quarto do ciclo, distorce o anel circular de partículas para uma elipse. Meio período de onda mais tarde distorce o anel de partículas para uma elipse perpendicular à anterior. Após a passagem da onda o anel de partículas volta ao seu estado inicial. As duas polarizações são equivalentes, exceto por uma rotação de $45^{\circ}$ em torno do eixo de propagação [1].
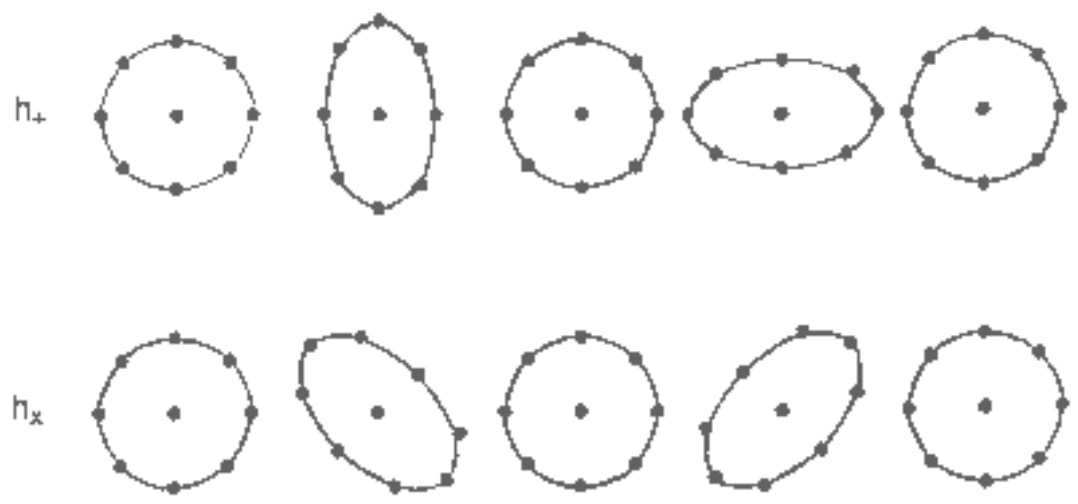

0 $\pi / 2$ $\pi$ $3 \pi / 2$ $2 \pi$

Figura 3.1: A distorção de um anel de partículas teste durante um ciclo de uma onda propagandose na direção $\mathrm{z}$.

\footnotetext{
${ }^{1}$ O princípio da equivalência não permite que essas acelerações sejam absolutas.
} 
Com a passagem da OG as massas teste, localizadas neste espaço-tempo, têm suas distâncias relativas alteradas, sendo:

$$
h_{i j} / 2=\partial x_{i} / x^{j}
$$

a medida deste deslocamento (ver seção 2.1.2), e

$h \approx \Delta l / l$

a medida da OG [4].

Conforme mostrado por Weber [5], o termo de quadrupolo de massa de um oscilador harmônico pode ser excitado por uma OG. Este fato justifica a investigação de sistemas que apresentem este termo quadrupolar, e que possam ser montados em laboratório.

Os casos mais simples de um quadrupolo de massa são aqueles em que: (i) dois corpos de massa M estão ligados por uma mola, ou (ii) um corpo sólido possui freqüência de ressonância igual à freqüência de oscilação do sistema massa-mola. Estes sistemas são conhecidos como de massas ressonantes. A diferença básica entre eles é que, geralmente, um corpo sólido possui outros modos de oscilação (modos de ordem superior ou inferior) além daqueles apresentados pelo sistema massa-mola.

Outra forma de se obter um termo de quadrupolo de massa para a detecção de OG é a utilização de sistemas de massas com espelhos vinculados e monitorados por interferômetros laser [4].

Na atualidade as duas principais técnicas existentes para a detecção de OG são:

- Interferométrica: está fundamentada na característica ondulatória das OG [1].

- Por ressonância: está fundamentada na característica corpuscular, ou seja, se utiliza o quantum das OG (gráviton) [1] .

Nas seções 3.2 e 3.3 são descritas estas duas técnicas de detecção, enfatizando a por ressonância. Serão apresentadas as vantagens e desvantagens entre elas. Antes porém, será feito um breve resumo histórico da detecção de OG, referindo-se a sua previsão, as evidências de sua existência e as tentativas feitas.

\subsection{Previsão, Evidência e Tentativas de Detecção de Ondas Gravitacionais}

Em 1916, Einstein, a partir de uma solução de radiação das equações de campo da Relatividade Geral no vácuo, previu formalmente a existência de OG. Somente em 1960, 44 anos depois, 
Joseph Weber propôs um método para a medição do tensor de Riemann e uma possível detecção de OG. Em 1965 ele construiu o primeiro detector de massa ressonante, que consistia de um cilindro de alumínio pesando 1,5 tonelada, com freqüência fundamental longitudinal de 1,6 kHz, operando a temperatura ambiente e isolado vibracionalmente em uma câmara de vácuo. A detecção de possíveis OG se daria através da medida das deformações longitudinais, ocorridas no cilindro na sua freqüência fundamental, e monitorada através de vários cristais piezoelétricos ligados em série, cristais estes colados na forma de um cinturão sobre a superfície lateral na região central do cilindro [6].

As antenas de massa ressonante são classificadas, de acordo com algumas de suas características, em gerações, conforme a Tabela 3.1 .

Tabela 3.1: Classificação das antenas de massa ressonante

\begin{tabular}{|l|l|l|}
\hline Geração & Massa Ressonante / Vácuo & Temperatura \\
\hline $1^{\text {a }}$ & Cilíndrica sob vácuo & Ambiente \\
\hline $2^{\mathrm{a}}$ & Cilíndrica sob vácuo & $4 \mathrm{~K}$ \\
\hline $3^{\mathrm{a}}$ & Cilíndrica sob vácuo & Menor que $0,1 \mathrm{~K}$ \\
\hline $4^{\mathrm{a}}$ & Esférica sob vácuo & Menor que $0,1 \mathrm{~K}$ \\
\hline
\end{tabular}

Durante os anos 70 foram construídos diversos detectores de massa ressonante, todos de primeira geração, como o de Weber.

Com o objetivo de aumentar a sensibilidade dos detectores, foram idealizados na década de 70, detectores de massa ressonante criogênicos, nos quais a barra metálica é resfriada na temperatura do hélio líquido (4,2 K). No início da década de 80 entra em operação o primeiro detector deste tipo, dando início à segunda geração de detectores de massa ressonante, na Universidade de Stanford. Da primeira para a segunda geração de detectores houve um aumento da sensibilidade em energia da ordem de dez mil vezes. Isto foi possível graças às melhorias obtidas nos sistema de isolamento vibracional, ao uso de transdutores mais sofisticados, ao uso de transformadores mecânicos de amplitude, além das temperaturas criogênicas alcançadas.

Os detectores de massa ressonante de OG de terceira geração utilizam barras cilíndricas e são resfriados a temperaturas ultra-criogênicas (o objetivo é, utilizando refrigeradores por diluição, atingir temperaturas termodinâmicas da ordem de 50mK). Como exemplo de detectores de terceira geração tem-se: NAUTILUS (Frascati) e AURIGA (Legnaro), ambos na Itália. Estes detectores estão em operação e a meta é atingir $h=10^{-20}$.

Os detectores de segunda e terceira geração (ver Tabela 3.2) são sensíveis o bastante para detectar OG oriundas de um colapso gravitacional em nossa galáxia, se a energia convertida em 
OG for da ordem de um por cento da massa solar [7].

No início dos anos 90 foi retomada a idéia de se construir uma antena de massa ressonante esférica. Proposta inicialmente por Forward em 1971 e depois estudada por Wagoner e Paik [1], a antena de massa ressonante esférica voltou a ser estudada por Merkowitz e Johnson [1] [6] que apresentaram a configuração TIGA (Truncated Icosahedron Gravitational Wave Antena), uma antena que tem o formato de um icosaedro truncado (volume semelhante a uma bola de futebol, composto por 32 faces, sendo 20 hexagonais e 12 pentagonais,).

Os detectores de quarta geração utilizam massas ressonantes de forma esférica ou esferoidal, além de um eficiente sistema de isolamento vibracional e temperaturas ultra-criogenicas. Detectores com estas características são sensíveis o bastante para detectar instabilidades hidrodinâmicas em estrelas de nêutrons em nossa galáxia (2 a 3 eventos por século).

Detectores de quarta geração estão em desenvolvimento no Brasil e Holanda. A tabela 3.2 também mostra os detectores de quarta geração (esferoidais) em fase de implementação.

O grupo Gráviton do INPE (S. J. dos Campos, Brasil) pretende construir, em colaboração com outras instituições nacionais e internacionais, uma antena ressonante icosaedral truncada de três metros de diâmetro, que se chamará EINSTEIN. Numa fase anterior serão construídos dois protótipos: MÁRIO SCHENBERG (esfera de 0,65 m de diâmetro, em colaboração com a USP), já em fase de testes criogênicos; e NEWTON (icosaedro truncado de 1,0 m de diâmetro). Com estes protótipos serão testadas técnicas de construção e análise de dados. 
Tabela 3.2: Características dos Detectores de Massa Ressonante de Segunda e Terceira Geração em Operação [1] [2] [4] [6].

\begin{tabular}{|c|c|c|c|c|c|c|c|c|c|}
\hline $\begin{array}{l}\text { Detector, Localização e } \\
\text { Classificação (Geração) }\end{array}$ & 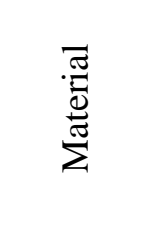 & 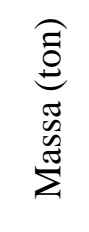 & 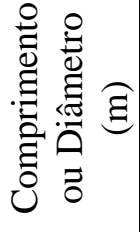 & 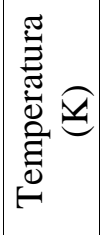 & 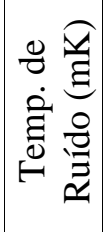 & 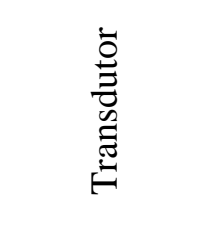 & 莺 & 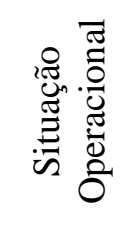 & 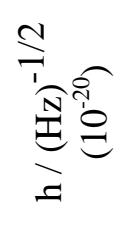 \\
\hline \begin{tabular}{|c|} 
ALLEGRO \\
(LSU, Baton Rouge, \\
Louisiana, EUA) 2 ${ }^{\mathrm{a}}$ Ger.
\end{tabular} & Al 5056 & 2,3 & 3 & 4,2 & 6 & $\begin{array}{l}\text { Ressonante } \\
\text { Indutivo }\end{array}$ & 900 & Ativo & 70 \\
\hline \begin{tabular}{|l|} 
EXPLORER \\
(CERN, Genebra, \\
Suiça) $2^{\text {a }}$ Ger.
\end{tabular} & Al 5056 & 2,3 & 3 & 2,0 & 6 & $\begin{array}{l}\text { Ressonante } \\
\text { Capacitivo }\end{array}$ & 900 & Ativo & 70 \\
\hline \begin{tabular}{|c|} 
NIOBE \\
(UWA, Perth, Austrália) \\
$2^{\mathrm{a}}$ Ger. \\
\end{tabular} & $\mathrm{Nb}$ & 1,5 & 2,5 & 5,0 & 1 & $\begin{array}{l}\text { Ressonante } \\
\text { Paramétrico } \\
\text { Microondas }\end{array}$ & 700 & Inativo & 50 \\
\hline \begin{tabular}{|c|} 
NAUTILUS \\
(INFN, Frascati, Itália ) \\
$3^{\text {a }}$ Ger. \\
\end{tabular} & Al 5056 & 2,5 & 3 & 0,9 & 4 & $\begin{array}{l}\text { Ressonante } \\
\text { Capacitivo }\end{array}$ & 900 & Ativo & 60 \\
\hline \begin{tabular}{|c|} 
AURIGA \\
(Legnaro, Itália) $4^{\mathrm{a}}$ Ger.
\end{tabular} & Al 5056 & 2,5 & 3 & 0,9 & 1 & $\begin{array}{l}\text { Ressonante } \\
\text { Capacitivo }\end{array}$ & 900 & Ativo & 30 \\
\hline $\begin{array}{c}\text { MÁRIO } \\
\text { SCHENBERG } \\
\text { (USP, São Paulo, } \\
\text { Brasil) } 4^{\text {a }} \text { Ger. }\end{array}$ & $\begin{array}{l}\mathrm{CuAl} \\
(6 \%)\end{array}$ & 1,15 & 0,65 & 4,2 & & $\begin{array}{l}\text { Ressonante } \\
\text { Microondas }\end{array}$ & 3200 & Teste & \\
\hline $\begin{array}{c}\text { MINI-GRAIL } \\
\text { (Laiden, Holanda) } 4^{\text {a }} \\
\text { Ger. }\end{array}$ & $\begin{array}{l}\text { CuAl } \\
(6 \%)\end{array}$ & 1,15 & 3 & 0,050 & & $\begin{array}{l}\text { Ressonante } \\
\text { Capacitivo }\end{array}$ & 2900 & Teste & \\
\hline
\end{tabular}

Também na década de 80 começaram a ser projetados os grandes detectores interferométricos a laser. Hoje detectores interferométricos com braços de alguns quilômetros encontram-se em estágio final de construção. Além dos projetos baseados em solo, existe um projeto que prevê a construção de um detector interferométrico no espaço, o LISA. Ver tabela 3.3 [2] [4] [6].

Tabela 3.3: Detectores de Ondas Gravitacionais Interferométricos [2] [6].

\begin{tabular}{|l|c|c|c|c|}
\hline \multicolumn{1}{|c|}{ Detector e Localização } & $\begin{array}{c}\text { Tamanho dos } \\
\text { braços } \\
(\mathrm{m})\end{array}$ & $\begin{array}{c}\text { Banda } \\
(\mathrm{Hz})\end{array}$ & $\begin{array}{c}\text { Previsão para } \\
\text { Inicio de } \\
\text { Operação }\end{array}$ & $\mathrm{h} /(\mathrm{Hz})^{-1 / 2}$ \\
\hline LIGO I (Hanford, USA) & 4000 & $10^{1}-10^{4}$ & Em operação & $\sim 6 \times 10^{-22}$ \\
\hline LIGO II (Livingston, USA) & 4000 & $10^{1}-10^{4}$ & 2007 & $\sim 5 \times 10^{-23}$ \\
\hline VIRGO (Piza, Itália) & 3000 & $10^{0}-10^{4}$ & Em operação & $\sim 6 \times 10^{-23}$ \\
\hline TAMA (Japão) & 300 & $10^{1}-10^{4}$ & Em operação & $\sim 8 \times 10^{-22}$ \\
\hline GEO 600 (Hannover, Alemanha) & 600 & $10^{0}-10^{4}$ & Em operação & $\sim 10^{-22}$ \\
\hline AIGO (Perth, Australia) & 80 a 4000 & & & \\
\hline LISA (ESA) & $5 \times 10^{9}$ & $10^{-4}-10^{0}$ & 2014 & $\sim 5 \times 10^{-24}$ \\
\hline
\end{tabular}


A evolução dos detectores citados acima tem como objetivo aumentar a sensibilidade das antenas, para permitir a detecção de eventos cada vez mais distantes e, portanto, com taxa de ocorrência maior.

A primeira evidência observacional da existência de OG, mesmo que indireta, foi obtida a partir da observação, por mais de uma década, do comportamento orbital do pulsar PSR $1913+16$, descoberto por Hulse e Taylor em 1976. Este pulsar apresenta uma variabilidade no seu período que só pode ser explicada pela emissão de OG (concordantes com a TRG). Hulse e Taylor receberam o Prêmio Nobel por este trabalho em 1993. [6].

\subsection{Técnica Interferométrica}

Esta técnica utiliza interferometria laser para detectar OG, idéia estudada inicialmente por Forward [4] na década de 70. A construção e o funcionamento de um detector deste tipo podem ser estudados a partir do interferômetro de Michelson, representado na Figura 3.2.

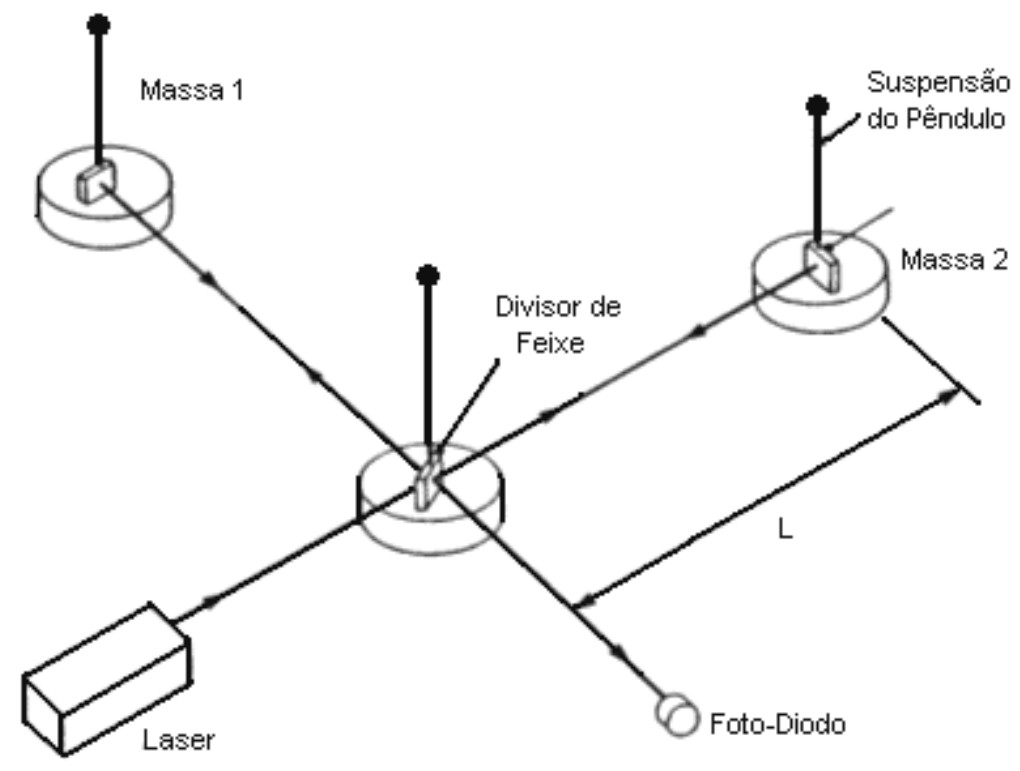

Figura 3.2: Diagrama esquemático de um detector de OG do tipo interferométrico, utilizando um interferômetro de Michelson. [2].

O funcionamento de um interferômetro laser se dá pela medição da mudança na distância entre duas massas separadas por uma grande distância. O que possibilita que as acelerações diferenciais nas direções definidas pelos braços do interferômetro sejam monitoradas diretamente [1].

Os detectores deste tipo possuem dois braços ortogonais não rígidos. Cada braço possui em uma de suas extremidades, vibracionalmente isoladas, uma massa suspensa com um espelho vinculado. As massas são separadas por uma grande distância uma da outra.

Um laser de alta potência incide sobre um divisor de feixe (beam spliter) situado na origem dos 
dois braços, onde é dividido em dois. Cada um destes feixes percorre um dos braços ortogonais do interferômetro, é refletido por um dos espelhos colocado sobre uma das massas, e se reencontra no divisor com o outro feixe (vindo do outro braço) onde são recombinados [4]. Os caminhos ópticos são ajustados de maneira que ocorra uma interferência destrutiva da luz e se produza como resultado um mínimo sobre o foto-detector [2].

Quando uma OG atinge a antena com direção e polarizações favoráveis, os comprimentos dos braços variam, produzindo uma diferença de fase proporcional à amplitude da onda, alterando o padrão de interferência sobre o foto-detector. Essa alteração no padrão de interferência corresponde à detecção da OG [6].

A sensibilidade destes interferômetros é diretamente proporcional ao comprimento de seus braços e à raiz quadrada da potência do laser.

Os detectores interferométricos apresentam a seguinte vantagem sobre os de massa ressonante: detectores interferométricos são de banda larga, podendo varrer uma grande faixa de freqüências. Por outro lado estes detectores apresentam algumas desvantagens sobre os de massa ressonante:

- são muito mais caros;

- eles não podem responder sobre a quantização das ondas gravitacionais, enquanto os de massa ressonante podem.

- os detectores interferométricos, assim como os de massa ressonante tipo barra, são cegos para certas direções e polarizações das OG.

\subsection{Técnica por Ressonância}

Esta técnica utiliza uma massa metálica sólida, cilíndrica ou esferoidal, como antena. Quando atingida por uma OG com a mesma freqüência de seu modo quadrupolar a antena é excitada e oscila. Transdutores eletromecânicos montados na superfície da antena convertem estas oscilações em sinais elétricos. Em seguida os sinais elétricos são amplificados e armazenados para análise posterior. A detecção consiste em medir as vibrações mecânicas induzidas pela OG [2] [4].

As primeiras antenas de massa ressonante eram cilíndricas, funcionavam à temperatura ambiente e não possuíam um sistema de isolamento vibracional muito desenvolvido. Utilizavam como transdutor cristais piezoelétricos colados sobre a sua superfície. A partir da segunda geração estes detectores passaram a ser isolados vibracionalmente e a serem resfriados a temperaturas criogênicas, começaram a utilizar transdutores mais sofisticados e transformadores mecânicos de amplitude. Estas alterações resultaram em uma melhora considerável na sensibilidade destas antenas [2].

As antenas evoluíram até chegarem a sua quarta geração. A massa metálica passa a ser esférica, 
possuem um ótimo isolamento vibracional, são resfriadas até temperaturas próximas do zero absoluto (zero Kelvin), são feitas de materiais com um bom fator de qualidade mecânico Q, e utilizam sistemas eletrônicos com uma baixa temperatura de ruído. Caso contrário os diversos tipos de ruído (térmico, ambiental e sísmico) impediriam a detecção [6].

Basicamente os detectores que utilizam a técnica por ressonância são formados por três partes principais, que são:

- Corpo sólido com freqüência de ressonância em torno de 0,7 a 3,2kHz,

- Transdutores eletromecânicos,

- Sistema de amplificação e armazenamento de dados.

$\mathrm{Na}$ abordagem feita nesta dissertação se dará ênfase as antenas do tipo massa ressonante esferoidais por ser o objeto de trabalho deste grupo de pesquisa. Assim, serão omitidas considerações sobre antenas cilíndricas, a não ser quando isto for relevante ou para efeito de comparações.

\subsection{Princípios Relativos à Detecção com Detectores de Massa}

\section{Ressonante}

Como foi visto (seções 2.1.2 e 2.1.3) OG podem ser consideradas como distorções do espaço. Por isso, em princípio, elas podem ser detectadas a partir da variação temporal que induzem no espaço [4]. O efeito da interação de uma OG propagando-se é deformar o espaço de acordo com a sua polarização $\left(h_{+}\right.$e $\left.h_{x}\right)$. Ela pode excitar o termo de quadrupolo de massa de um oscilador harmônico (seção 3.1). Um corpo sólido que possui freqüência de ressonância igual à freqüência do sistema massa-mola, e que é conhecido como sistema de massa ressonante, apresenta este termo de quadrupolo de massa e pode ser montado em laboratório.

Quando uma OG atinge uma antena do tipo massa ressonante realiza trabalho sobre a mesma. A energia transferida é depositada somente nos seus modos fundamentais ou normais (freqüências características de oscilação do sistema) quadrupolares, fazendo com que ela vibre, o que produz uma deformação neste sistema.

Contudo se a OG excitar a antena na freqüência de um de seus modos ressonantes (modos normais quadrupolares), a antena continuará a vibrar mesmo depois da onda ter passado. O que permite que haja uma integração do sinal sobre um longo período de tempo (se este for comparado com a duração de uma OG proveniente de uma fonte impulsiva) e se possam observar variações na amplitude ou na fase do detector, o que faz com que parte do ruído randômico se cancele, aumentando a sensibilidade da medida [1].

Os ressonadores, ou transformadores mecânicos de amplitude, associados aos transdutores 
eletromecânicos, são utilizados para amplificar os deslocamentos produzidos pelas deformações ocorridas como conseqüência da interação com a OG.

Supondo-se a conservação de energia entre as massas intermediárias do ressonador, a amplificação mecânica das amplitudes $x_{2} / x_{1}$, obtida entre sua última massa e sua primeira massa (antena), é dada por:

$$
\frac{\left|x_{2}\right|}{\left|x_{1}\right|}=\sqrt{\frac{M_{1}}{M_{2}}}=\sqrt{\mu}
$$

onde $M_{1} / M_{3}$ é a razão entre as massas efetivas, da primeira com a última massa do ressonador. Estes ressonadores são dimensionados (calibrados) de maneira que um de seus modos normais de vibração seja ressonante com a freqüência de trabalho da antena (freqüência que excita os modos de vibração normais quadrupolares da massa esférica). Esta calibração deve levar em conta que tanto os ressonadores como a esfera são osciladores, e que, pelo fato de estarem conectados, a energia pode passar de um para o outro em ambos os sentidos. Como conseqüência ocorre o efeito da realimentação, que produz o acoplamento das oscilações destes osciladores [8]. Estes aspectos serão discutidos no próximo capítulo.

Os ressonadores possibilitam utilizar uma massa final mais leve para a operação de transdutância, aumentam o acoplamento eletromecânico e a banda de freqüência de detecção [2], funcionando como casadores de impedância: filtrando as freqüências que não são de interesse na detecção.

A banda de freqüência de detecção é dada pela equação [9],

$$
\Delta f \approx 2 f_{0} \sqrt{\mu}
$$

na qual, $f_{0}$ é a freqüência do modo e $\mu$ é a razão entre a massa efetiva de um modo de vibração e o seguinte.

Análises teóricas mostram que a largura da banda aumenta rapidamente com o número de modos indo de um até três, mas há um pequeno incremento se o número de modos for aumentado acima de três [2].

\subsubsection{Comparando Detectores Esféricos com os do Tipo Barra}

Os detectores esféricos possuem uma série de vantagens sobre os detectores do tipo barra:

1. Uma esfera tem cinco modos quadrupolares degenerados. Cada modo livre age como 
uma antena orientada em uma direção, ou polarização, diferente. Portanto, um detector esférico pode ser imaginado como cinco detectores em um único instrumento.

2. Um detector esférico é onidirecional. Ele é capaz de determinar a polarização de ondas monocromáticas, ou seja, ele é igualmente sensível a OG vindas de qualquer direção do espaço.

3. Um esferóide tem uma massa muito maior que uma barra equivalente (barra com a mesma freqüência de ressonância). E uma massa maior implica em uma maior seção de choque, com o que se obtém uma melhoria na sensibilidade da antena. Estudos realizados com este tipo de antena mostram que é obtido um aumento de sensibilidade em energia em torno de 56 vezes em relação a uma barra ressonante de mesma freqüência.

4. Duas antenas esféricas situadas nas proximidades uma da outra, podem ser usadas para detectar sinais gravitacionais estocásticos.

5. Uma única antena esférica é suficiente para determinar a direção da origem de uma OG. A vibração da antena pode ser decomposta nos cincos modos do sistema de referência do laboratório, e assim se resolver o problema inverso, isto é, a determinação da direção, polarização e amplitude da OG a partir da resposta de amplitude de cinco diferentes pontos na superfície da esfera. Obtendo-se assim a direção da onda.

Em contrapartida, os quatro modos extras que se acoplam fortemente a uma OG introduzem um conjunto de complexidade ao sistema. Além disso, os ressonadores mecânicos conectados ao esferóide para monitorar os modos de vibrações que interagem fortemente com as OG, acoplarão aos modos resultantes da esfera mais seis/doze modos (seis ou doze, dependendo de quantos modos tem o transdutor).

\subsection{Utilizando Detectores Esféricos}

Basicamente, um detector esférico de OG consiste de um esferóide, cujas oscilações produzidas pelas OG serão sempre uma superposição dos seus cinco modos quadrupolares degenerados [2]. No mínimo cinco transdutores eletromecânicos deverão monitorar os modos normais das vibrações quadrupolares da esfera.

No detector Mário Schenberg serão utilizados seis transdutores eletromecânicos, em conseqüência disto a operação da antena consistirá em monitorar seus modos de vibração normais, em especial os modos quadrupolares, por meio dos seis transdutores eletromecânicos. O processamento destes dados permitirá recompor os deslocamentos e as deformações da esfera, decorrentes de sua interação com a OG. Os cinco modos de vibração normais quadrupolares da esfera com os seis (ou doze) modos de vibração normal dos seis ressonadores, correspondentes aos seus primeiros (ou primeiros e segundos) modos de vibração, formarão uma base a partir da 
qual serão medidos os modos de vibração da esfera. Todas as informações sobre as OG sairão desta base formada por estes onze (ou dezessete) modos vibracionais normais compostos.

\subsection{Obtenção da Informação Astrofísica}

À partir dos cinco modos degenerados (modos quadrupolares) da esfera ressonante, pode-se determinar os cinco parâmetros que fornecem toda a informação física necessária sobre a OG pelo exame do movimento da antena [4]. A determinação da direção, polarização e amplitude da OG, a partir da resposta de amplitude de cinco diferentes pontos na superfície da esfera, é chamado de problema inverso. Este problema pode ser resolvido supondo que a antena, em um determinado sistema de coordenadas, é atingida por uma OG com amplitude h, polarização “+” e “x”, e direção $(\theta, \phi)$. Estuda-se, então, o efeito desta onda sobre a antena, determinando-se o acoplamento onda-antena (amplitude de vibração da antena e acoplamento entre os modos de vibração). Finalmente, a partir da determinação do movimento da antena (que é monitorada por transdutores eletromecânicos), obtém-se a informação sobre a onda incidente [4].

\subsection{Ruídos e Atenuação de seus Efeitos na Sensibilidade do Detector}

A existência de várias fontes de ruídos intrínsecas (ruídos internos) e extrínsecas (ruídos externos) aos detectores do tipo massa ressonante podem excitar seus modos ressonantes, colocando em dúvida se o que foi detectado foi proveniente de uma OG ou de um ruído, limitando desta forma a sensibilidade do detector. Por isso, ao se analisar sinais impulsivos é necessário verificar as coincidências com outros detectores, para se ter certeza de que o que foi medido foi realmente um sinal [2].

Os ruídos internos são flutuações estatísticas de variáveis físicas do próprio sistema de detecção. Não podem ser eliminados, porém podem ser minimizados. Os ruídos externos são produzidos por eventos externos ao sistema de detecção e podem resultar em interferência no sistema se não for tomada a devida precaução [2].

Além disto, os ruídos são classificados quanto ao seu comportamento temporal: como estacionários (quando a sua probabilidade de ocorrência é constante no tempo) e não estacionários; e quanto à sua distribuição espectral: como gaussianos (quando a sua distribuição apresenta média nula e desvio padrão) e não gaussianos [2].

\subsubsection{Ruídos Internos}

Entre os ruídos internos temos: 
- ruídos térmicos: os principais tipos de ruídos térmicos que afetam um detector de OG do tipo massa ressonante são:

o ruído térmico da suspensão: são forças decorrentes do movimento Browniano que podem fazer oscilar as partes mecânicas da suspensão. Pode ser minimizado abaixando-se a temperatura termodinâmica e construindo-se um sistema de isolamento vibracional,

o ruído térmico da antena: é causado pela agitação térmica da estrutura cristalina. É definido pela temperatura termodinâmica e pelo tempo de relaxação da massa ressonante. Os efeitos dos ruídos térmicos podem ser minimizados resfriando-se a antena a temperaturas baixíssimas, utilizando-se um material de alto fator de qualidade mecânico Q na confecção da antena (o que torna mais lenta a transferência de energia entre um modo de vibração mecânica qualquer e outro modo que seja de interesse), e finalmente, mantendo pequeno o tempo de integração das observações realizadas. (Ruídos Brownianos são ruídos associados à dissipação de energia térmica. Todo corpo sólido vibra quando está a uma temperatura finita.)

- ruídos da câmara de mistura (Mixer Chamber): é produzido durante o processo de resfriamento por diluição (mistura de $\mathrm{He}^{3}$ e $\mathrm{He}^{4}$ líquidos para obter temperaturas da ordem de mK). O borbulhamento do He introduz um ruído de baixa freqüência, que, através de fenômenos não lineares, pode ser convertido em ruídos na faixa de detecção. Este ruído pode ser evitado fazendo-se um contato térmico entre o refrigerador e a antena através de um módulo antivibratório, permitindo ao mesmo tempo o resfriamento e o isolamento do ruído.

- ruídos eletrônicos do transdutor: são provenientes do movimento dos sensores. Estes ruídos (gaussianos e não estacionários) são de dois tipos: ruído serial eletrônico e ruído de “back action” (ruído de amplitude e fase do oscilador). (Ver seção 3.6.1)

Para reduzir os efeitos dos ruídos térmicos e elétricos na detecção, geralmente, a saída do sinal elétrico é filtrada com um filtro linear [4].

\subsubsection{Ruídos Externos}

Estes ruídos são produzidos por eventos externos ao detector e podem resultar em interferência nos sinais.

Entre os ruídos externos tem-se:

- ruídos sísmicos e vibracionais: o ruído sísmico é causado pelo movimento da crosta terrestre e o vibracional pela construção civil, estado da estrutura devido às mudanças de 
temperatura, vibrações devido ao trafego de automóveis, trens etc. São ruídos, gaussianos e não estacionários, que produzem movimentos na estrutura do laboratório. Caso não sejam eliminados podem produzir efeitos de "Up Conversion", isto é, sinais de baixa freqüência excitando os modos de alta freqüência da antena. Estes efeitos são devido à fricção de juntas, tensão excessiva em conexões, etc. Eles podem ser minimizados com um sofisticado sistema de isolamento vibracional, que utiliza $\mathrm{N}$ filtros mecânicos passa baixa; ou vetados, utilizando monitores de vibração em baixas freqüências no laboratório e na base do detector, os quais geram sinais que vetam a presença de pulsos, caso estes ocorram no mesmo instante de eventos relacionados na saída do detector.

- ruídos sonoros: são ruídos devido a buzinas, trovões, conversas e qualquer outro tipo de poluição sonora. São ruídos não estacionários e não necessariamente gaussianos. Para minimizar estes ruídos também é necessário um sistema bem projetado de isolamento vibracional, que inclui um alto vácuo ao redor da antena.

- ruídos devido a ondas eletromagnéticas: são ruídos (não estacionários e não necessariamente gaussianos) causados por: ondas eletromagnéticas geradas por emissoras de televisão, rádio, telefonia celular, quedas de raios e relâmpagos, indução eletromagnética devido ao ato de ligar e desligar equipamentos eletrônicos do próprio laboratório e qualquer outro tipo de emissão eletromagnética. Podem ser minimizados através dos seguintes recursos: i) utilizando uma gaiola de Faraday ou isolando a antena com as camadas de metal com que são feitas as câmaras criogênicas, ii) vetando as ondas eletromagnéticas que conseguem transpor esta blindagem utilizando um conjunto de antenas que monitoram o ambiente do laboratório, iii) com filtros de RF (rádio freqüência) instalados na fiação que conecta os transdutores aos amplificadores externos.

- ruídos devidos à interferência de Raios Cósmicos: os raios cósmicos são partículas de alta energia que entram freqüentemente na atmosfera terrestre. Eles são considerados ruídos gaussianos e estacionários (quando não acontecem chuveiros). Eles podem, portanto, excitar os modos ressonantes da antena. Contudo, são quase impossíveis de serem blindados. Uma alternativa é circundar o detector de OG com detectores de raios cósmicos e utilizar um sistema de veto, descartando os sinais detectados pelo detector de OG que sejam coincidentes com os detectados pelo detector de raios cósmicos. Além do sistema de vetos é necessária a utilização dos testes de coincidência com outros detectores que operem na mesma faixa de freqüência. Uma pequena blindagem com espessura em torno de $4 \mathrm{~m}$ de concreto pode reduzir significantemente o número de partículas incidentes, o que possibilita uma menor perda de tempo morto no processo de vetagem [2]. 


\subsection{Influência do Fator de Qualidade Mecânico Q na}

\section{Sensibilidade do Detector}

Como a amplitude das vibrações térmicas normalmente excede a amplitude esperada para as fontes astrofísicas, e não há como suprimir este ruído, a detecção de OG por massa ressonante seria improvável. Entretanto, Weber observou que em uma antena com alto fator de qualidade mecânica Q, e conseqüentemente com baixa perda acústica, o ruído efetivo de energia seria reduzido por um fator de $\tau_{i} / \tau_{a}$, onde $\tau_{i}$ é tempo de variação do sinal medido e $\tau_{a}$ é o tempo de decaimento da vibração da antena [4]. O que se espera detectar é uma mudança maior na amplitude de vibração da antena, do que a variação causada apenas pelo banho térmico, num certo intervalo de tempo [1].

Assim, o que se procura fazer é construir a antena com um material que tenha um alto fator de qualidade mecânico Q $\left(\geq 10^{6}\right)$, para assegurar uma menor taxa de transferência de energia entre o detector e o banho térmico [1], e um tempo maior de relaxação da perturbação induzida pela OG. O fator de qualidade mecânico corresponde à razão entre a energia mecânica armazenada num modo de vibração e a energia que é dissipada em cada ciclo. Um alto fator de qualidade mecânico Q corresponde, portanto, a um modo de vibração de maior amplitude e duração [6].

O fator de qualidade mecânico é definido como:

$Q=\tau_{n} . \omega_{n}$

onde $\tau_{n}$ é o tempo de relaxação, e $\omega_{n}$ é a freqüência de ressonância.

A antena é dimensionada (no caso da antena de massa esférica é determinado o seu diâmetro) de modo que os seus modos de vibração normais quadrupolares ocorram na freqüência em que se espera detectar a OG. Ou seja, a antena é calibrada para que seus modos quadrupolares sejam excitados pela freqüência de trabalho da antena. A freqüência de ressonância da antena é determinada pelo tamanho do corpo e pela velocidade do som $\mathrm{v}_{S}$ no material utilizado [4]. A Figura 3.3 ilustra os 5 modos quadrupolares de uma esfera excitados pela OG. 


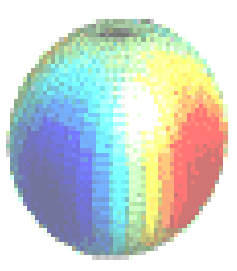

lingtos 1

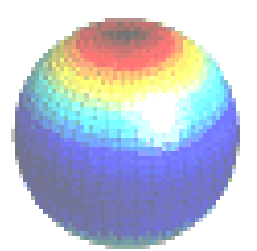

limes 5

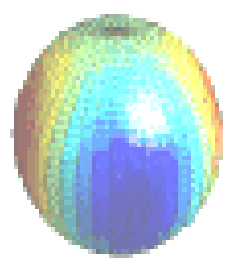

Imota 1.

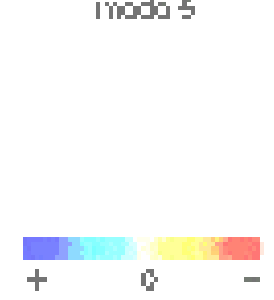

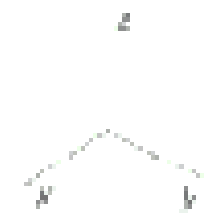

$\operatorname{lims} 2$

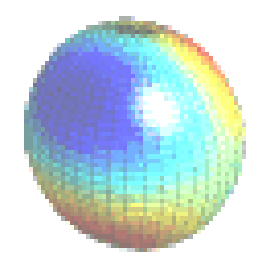

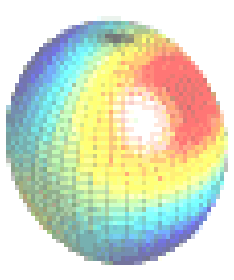

Iñut 4

Figura 3.3: Modos Quadrupolares da esfera excitados pela OG [31].

As freqüências normais (ou fundamentais) de ressonância $\omega_{n}$ de um corpo rígido, nas quais a energia de um sinal gravitacional será depositada, podem ser calculadas [6] a partir da razão entre a velocidade do som e uma dimensão linear do sólido.

$\omega_{n}=\frac{Q}{\tau_{n}}=\frac{n \cdot \pi \cdot \mathrm{v}_{S}}{L}$

onde $\mathrm{L}$ é a dimensão linear do sólido, que depende de sua forma geométrica, e $\mathrm{v}_{S}$ é a velocidade do som no material da antena, obtida de:

$$
\mathrm{v}_{S}=\sqrt{\frac{\mathrm{E}}{\rho}}
$$

onde E é o módulo de elasticidade do material da antena e $\rho$ é a densidade deste material [6]. Para uma freqüência particular, o material da antena deve ter o maior valor possível para o produto $\mathrm{Q} \rho \mathrm{v}_{\mathrm{S}}^{3}$, onde $\mathrm{Q}$ é o fator de qualidade mecânico, $\rho$ é a densidade do material da antena e $\mathrm{v}_{S}$ é a velocidade do som neste material. Dos três parâmetros relacionados na quantidade citada somente o fator Q pode ser modificado durante a preparação e suspensão da 
antena [4].

Quanto maior a antena, maior a sua massa, e também a sua seção de choque para os grávitons e, portanto, maior a sensibilidade do detector. Já o nível de ruído térmico é inversamente proporcional ao fator de qualidade mecânico $\mathrm{Q}$ do material e diretamente proporcional à temperatura da antena. O material de que é feito um detector de massa ressonante deve ter as seguintes características [6]:

- alto fator de qualidade mecânico Q,

- alta velocidade do som no seu próprio meio,

- alta densidade,

\subsection{Transdutores Eletromecânicos}

Transdutores eletromecânicos são dispositivos utilizados para converter sinais mecânicos em elétricos, ou vice-versa [2].

Como já discutido nas seções anteriores, a detecção consiste em se medir as vibrações induzidas pela OG ao excitar o modo quadrupolar da massa ressonante que constitui a antena. Transdutores eletromecânicos, montados na superfície da antena, são usados para converter estas vibrações em sinais elétricos.

Inicialmente as antenas utilizavam como transdutores cristais piezoelétricos montados próximos ao sistema de suspensão da barra cilíndrica (a massa ressonante). Posteriormente eles foram substituídos por transdutores ressonantes passivos ou ativos (paramétricos), os quais se mostraram muito mais sensíveis.

\subsubsection{Transdutores Passivos}

Os transdutores passivos não utilizam fonte externa de potência. O seu ganho é menor do que uma unidade e, geralmente, podem ser utilizados com baixo ruído de amplificação na freqüência característica da antena $\omega_{0}$. Eles são polarizados com sinal DC, podendo ser uma corrente (indutivo) ou uma tensão (capacitivo), o que é determinado por características de sua construção. Uma outra característica dos transdutores passivos é que a freqüência do sinal de saída é a mesma do sinal mecânico de entrada, ou seja, não ocorre amplificação do sinal no processo de transdução. Desta forma, os transdutores passivos devem utilizar amplificadores que operam na mesma freqüência da antena. Tanto os transdutores indutivos quanto os capacitivos utilizam amplificadores SQUIDS (Super-conducting Quantum Interference Device), para amplificar o sinal antes da conexão com a eletrônica convencional. 


\subsubsection{Transdutores Paramétricos}

Os transdutores paramétricos (ou ativos) são "bombeados” com sinal AC através de uma fonte externa de sinal AC e $\omega_{\mathrm{p}}$, que é utilizada para ativar o circuito que relaciona, de forma não linear, uma variável mecânica com uma variável elétrica. Estes transdutores utilizam a variação de um parâmetro deste circuito.

O ganho de potência é obtido no processo de transdução, e dentro do transdutor, pela conversão do sinal da antena para uma freqüência muito maior do que a freqüência de ressonância $\omega_{0}$. Uma característica deste tipo de transdutor, no processo de transdução, é a amplificação paramétrica da freqüência do sinal de saída.

A Figura 3.4 mostra o esquema básico de um transdutor paramétrico. As vibrações da antena modulam a freqüência de um circuito ressonante com grande $Q_{e}$ (fator de qualidade elétrica), o qual, por sua vez, modula o sinal da bomba produzindo bandas laterais. A modulação da bomba é amplificada utilizando, como referência, parte do seu sinal original. Todos os transdutores paramétricos em desenvolvimento operam modulando a capacitância de um circuito com alto $Q_{e}$ e, geralmente, utilizam cavidades reentrantes (ou capacitivamente carregadas) ressonantes em

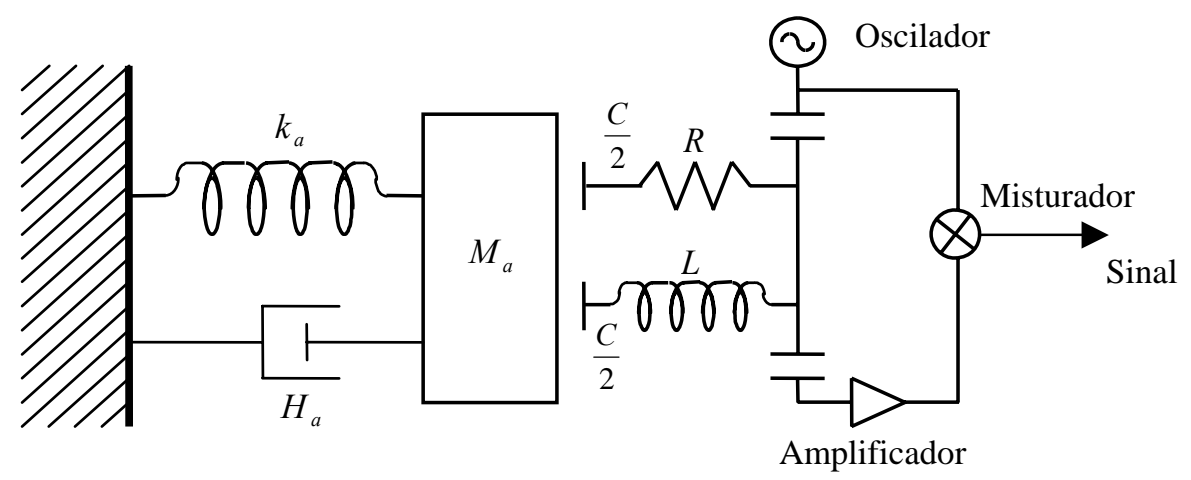

alta freqüência, combinadas com amplificadores de alta freqüência com baixo ruído.

Figura 3.4: Modelo simplificado de uma antena do tipo massa ressonante com um transdutor paramétrico.

Na Figura 3.4, $M_{a}$ representa a massa efetiva da antena. Os parâmetros $k_{a}=M_{a} \omega_{a}^{2}$ e $H_{a}=\frac{M_{a} \omega_{a}}{Q_{a}}$ são, respectivamente, a constante de mola e o fator de amortecimento da massa efetiva da antena. Os parâmetros $C$ (capacitância), $L$ (indutância) e $R$ (resistência) são determinados pela geometria, freqüência de ressonância e $Q_{e}$ do transdutor, respectivamente. 


\subsubsection{Vantagens dos Transdutores Paramétricos sobre Transdutores}

\section{Passivos}

1. Por utilizarem uma fonte externa de potência, os transdutores paramétricos tem um ganho de potência intrínseco, desde que se garanta que a temperatura de ruído do transdutor seja suficientemente pequena.. Este ganho de potência é obtido pela conversão do sinal da antena para freqüências mais altas. Os transdutores passivos não utilizam fonte de potência.

2. Com o uso de transdutores paramétricos a freqüência de operação pode ser escolhida, permitindo a escolhe bombas e amplificadores em freqüências que ofereçam um desempenho ótimo. Já os transdutores passivos estão restritos a utilizarem amplificadores na freqüência de ressonância da antena.

3. Transdutores paramétricos não aumentam o ruído da antena, pois os ruído elétrico do transdutor e pré-amplificador não apresentam “back action” significativo. Os transdutores paramétricos “colddamp”, atuam reativamente a antena e degradam levemente o Q acústico. Enquanto que os transdutores passivos amortecem resistivamente a antena, diminuindo o seu $Q$, e aumentando a contribuição do movimento browniano.”

4. O transdutor paramétrico possui um grande coeficiente de acoplamento eletromecânico obtido devido à ação paramétrica.

5. Os transdutores paramétricos poderão ser utilizados para burlar o limite quântico, através de técnicas, conhecidas como “Back Action Evasion” [2], enquanto que os passivos não podem.

\subsubsection{Desvantagens dos Transdutores Paramétricos sobre}

\section{Transdutores Passivos}

1. Os amplificadores de baixos ruídos disponíveis no mercado na faixa de interesse só apresentam baixíssimo ruído para potências de entrada iguais ou menores a $10^{-11} \mathrm{~W}$. Deste modo, o sinal da bomba ou portadora deve ser suprimido antes de ser amplificado.

2. A principal desvantagem sobre os transdutores passivos é o uso de uma fonte externa (oscilador). O sinal deste oscilador deverá ter níveis de ruídos de amplitude e fase baixíssimos, pois o ruído de fase do oscilador é processado juntamente com uma grande quantidade desse ruído. A solução deste problema requer o desenvolvimento de novos osciladores em freqüências de microondas [2]. 


\subsubsection{Equações de Manley-Rowe}

Se dois sinais com freqüências $\omega_{1}$ e $\omega_{2}$, respectivamente, são aplicados a uma reatância não linear, então a conversão em freqüência pela reatância produzirá sinais em todos os harmônicos inteiros $\pm\left|m \omega_{1}+n \omega_{2}\right|$ [2]. Usando $P_{m, n}$ para denotar a potência média fluindo na reatância nestas freqüências, as equações de Manley-Rowe podem ser escritas na forma:

$$
\begin{aligned}
& \sum_{m=0}^{\infty} \sum_{n=-\infty}^{\infty} \frac{m P_{m, n}}{m \omega_{1}+n \omega_{2}}=0 \\
& \sum_{m=-\infty}^{\infty} \sum_{n=0}^{\infty} \frac{m P_{m, n}}{m \omega_{1}+n \omega_{2}}=0 .
\end{aligned}
$$

1) Considere as bandas laterais "up converter" onde a potência é restrita a fluir em $\omega_{1}=\omega_{a}$ (freqüência da antena), $\omega_{2}=\omega_{p}$ (freqüência da bomba), $\omega_{2}+\omega_{1}=\omega_{+}$e $\omega_{2}-\omega_{1}=\omega_{-}$ pelo uso de filtros (circuito ressonante de alto $Q$ por exemplo). Denotando $P_{1,0}=P_{a}, P_{0,1}=P_{P}$, $P_{1,1}=P_{+}$e $P_{-1,1}=P_{-}$, as equações (3.7) podem ser escritas na forma:

$$
\begin{aligned}
& \frac{P_{a}}{\omega_{a}}+\frac{P_{+}}{\omega_{+}}-\frac{P_{-}}{\omega_{-}}=0 \\
& \frac{P_{P}}{\omega_{P}}+\frac{P_{+}}{\omega_{+}}+\frac{P_{-}}{\omega_{-}}=0
\end{aligned}
$$

A partir da equação (3.8a) podemos ver que:

- Se $P_{+} / \omega_{+}<P_{-} / \omega_{-}$, então $P_{a} / \omega_{a}>0$. Isto é, se mais potência é extraída pela banda lateral mais baixa do que pela mais alta, então a potência liquida é injetada na antena. Esta situação pode produzir instabilidade paramétrica, na qual o transdutor faz a antena oscilar se a potência injetada na antena excede as perdas acústicas. Este caso corresponde à freqüência da bomba acima da ressonância elétrica.

- Se $P_{+} / \omega_{+}>P_{-} / \omega_{-}$, então $P_{a} / \omega_{a}<0$. Isto é, a potência é absorvida a partir da antena se a freqüência da bomba está abaixo da ressonância. Nesta configuração a antena é "colddamped". 


\subsubsection{Transdutor Paramétrico do Tipo Cavidade Reentrante}

Um transdutor paramétrico do tipo cavidade reentrante (cavidade "cavada” na superfície) em freqüência de microondas, já se encontra em operação no detector NIOBE localizado na

“University of Western Australia” (UWA) [2]. A Figura 3.5 mostra um diagrama esquemático deste tipo de transdutor acoplado a uma barra ressonante.

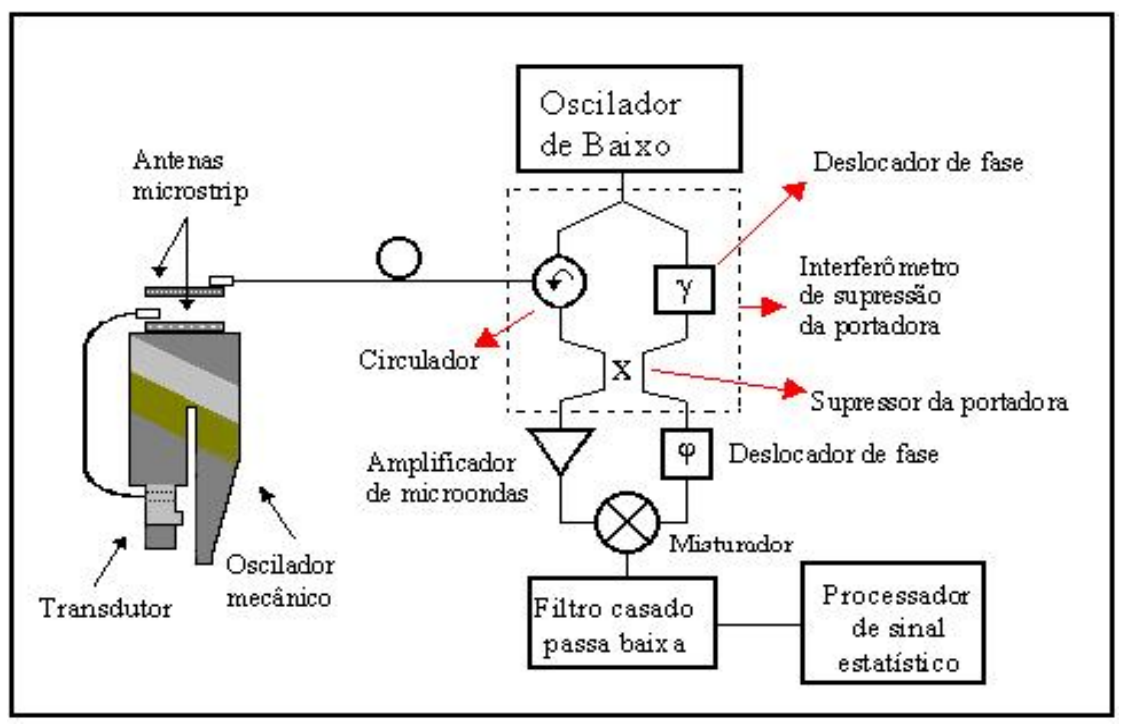

Figura 3.5: Diagrama esquemático do detector NIOBE da UWA, é mostrado o transdutor paramétrico do tipo cavidades reentrante, acoplado a antena ressonante [2].

O principio de transdução entre a antena e o transdutor é o seguinte: um sinal eletromagnético em freqüência $10 \mathrm{GHz}$, produzido por um oscilador de baixo ruído de fase é injetado no circulador, que o envia para a cavidade reentrante do transdutor através de antenas do tipo microlinhas. As vibrações na barra, provocadas pelas OG, modulam a freqüência ressonante do transdutor, o qual, por sua vez, modula a portadora produzindo bandas laterais. As bandas laterais e a portadora retornam para o circulador, e deste para o supressor da portadora. O sinal do oscilador é suprimido para evitar que o mesmo aumente o ruído do amplificador de microondas.

Após a supressão da portadora por interferometria destrutiva do sinal modulado com a própria portadora, restam apenas os sinais eletromagnéticos modulados pelo sinal mecânico. Estes sinais são amplificados pelo amplificador de microondas para aumentar as suas intensidades. Os sinais eletromagnéticos modulados puros são então misturados com o sinal do oscilador, após a amplificação. A fase do oscilador é ajustada para a obtenção do máximo sinal na saída do filtro passa baixa. Este filtra o sinal do oscilador e outros de alta freqüência. Apenas o sinal elétrico na freqüência do ressonador mecânico sobrevive. Este sinal é analisado, em busca da presença de OG. 


\subsubsection{Ruídos no Transdutor do Tipo Cavidade Reentrante}

Os principais tipos de transdutores paramétricos em operação e ou construção são: transdutor do tipo cavidade reentrante como o utilizado no detector NIOBE, na universidade de Western (Austrália), e o transdutor óptico em desenvolvimento na estrutura do experimento AURIGA, em Legnaro (Itália) [2].

As fontes de ruídos nos transdutores paramétricos são de natureza eletrônica. Estes ruídos eletrônicos de dividem em: serial eletrônico, "back action" e ruído de amplitude e fase do oscilador.

\subsubsection{Serial Eletrônico}

O ruído serial eletrônico é constituído pelo ruído elétrico do transdutor somado aos ruídos dos circuitos eletrônicos dos amplificadores [2]. Este ruído é de banda larga e não representa uma excitação na antena. Sua principal fonte é o ruído do amplificador. O ruído de série pode ser minimizado, reduzindo-se o ruído do amplificador. Já existe no mercado amplificador comercial com níveis de ruído suficientemente baixo para minimizá-lo a níveis aceitáveis.

\subsubsection{Back Action}

O ruído de "back action" [2] é o efeito mecânico causado na antena pela ação reversa do ruído eletrônico do transdutor sobre a antena através da transdutância reversa. Neste caso, existem técnicas, chamadas “back action evasion”, que o minimizam.

\subsection{Back Action Evasion}

Detectores de OG do tipo massa ressonante são modelados como osciladores harmônicos simples [2]. Na mecânica quântica, a incerteza na determinação da posição de osciladores pode ser estimada a partir do princípio da incerteza de Heisenberg:

$$
\Delta x \Delta p \geq \frac{\hbar}{2}
$$

onde $\hbar$ é a constante de Planck (usualmente denominada $h$ ) dividida por $2 \pi$, a qual vem da relação de não comutatividade dos operadores, posição $X$ e momento $P$ [2].

$$
[X, P]=i \hbar
$$

O limite quântico padrão pode ser encontrado assumindo que as incertezas no momento e 
posição são iguais $\Delta x=\Delta p / m \omega$, onde $p$ foi dividido por $m \omega$ para dar dimensões de comprimento, reescrevendo a equação (3.9) obtemos:

$$
\Delta x=\left(\frac{\hbar}{2 m \omega}\right)^{\frac{1}{2}}
$$

onde $m$ é a massa, $\omega$ é freqüência de oscilação e $\Delta x$ é o deslocamento do oscilador.

Entretanto, o princípio da incerteza proíbe o monitoramento da amplitude complexa de um oscilador mecânico com uma precisão maior do que $\Delta x$. Assim, para ser detectável, um sinal gravitacional deve ser capaz de deslocar o oscilador de uma quantidade maior do que $\Delta x$. Parametrizando a equação (3.11) para um detector de ondas gravitacionais obtemos:

$$
h \approx|\Delta x|_{Q L}=\left(\frac{\hbar}{2 m \omega}\right)^{\frac{1}{2}} \approx\left(3 x 10^{-19} \mathrm{~cm}\right)\left(\frac{1 \text { ton }}{m}\right)^{\frac{1}{2}}\left(\frac{10^{4} s^{-1}}{\omega}\right)^{\frac{1}{2}}
$$

na qual, $h$ é a amplitude adimensional de deformação da onda gravitacional na antena.

De acordo com a equação (3.12) é impossível medir com uma barra de comprimento $\ell$, ondas gravitacionais com uma amplitude menor que:

$$
h_{Q L} \approx \frac{|\Delta x|_{Q L}}{\ell} \approx\left(3 x 10^{-21}\right) \cdot\left(\frac{1 \text { ton }}{m}\right)^{\frac{1}{2}}\left(\frac{10^{4} \mathrm{~s}^{-1}}{\omega}\right)^{\frac{1}{2}}\left(\frac{100 \mathrm{~cm}}{\ell}\right),
$$

onde $h_{Q L}$ é a amplitude de deformação da onda gravitacional no limite quântico.

Entretanto, existe um método denominado “Back Action Evasion” (BAE) que pode ser utilizado para ultrapassar o limite quântico em $h$. Técnicas como estas, são chamadas "técnicas de não demolição quântica” porque elas tentam monitorar o oscilador sem demolir (perturbar) seu estado quântico.

A forma da relação de incerteza $\Delta X_{1} \Delta X_{2} \geq \hbar / 2 m \omega$, sugere uma possível maneira de ultrapassar o limite quântico na medida da amplitude de deformação da onda $\left(h_{Q L}\right)$. Em vez de se monitorar $X_{1}$ e $X_{2}$ com a mesma precisão (medição de fase e amplitude), seriam monitorados $X_{1}$ com uma alta precisão $\Delta X_{1}<<(\hbar / 2 m \omega)$ e $X_{2}$ com uma pequena precisão $\Delta X_{2}>>(\hbar / 2 m \omega)$, ou vice versa.

Medições com $\Delta X_{1} \ll \Delta X_{2}$, são chamadas "Back action Evading”" porque são cuidadosamente realizadas para permitir que $X_{1}$ elimine o efeito de "back action" do sistema medido. A Figura 


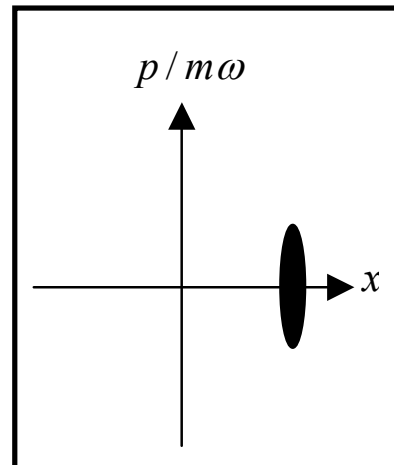

(a)

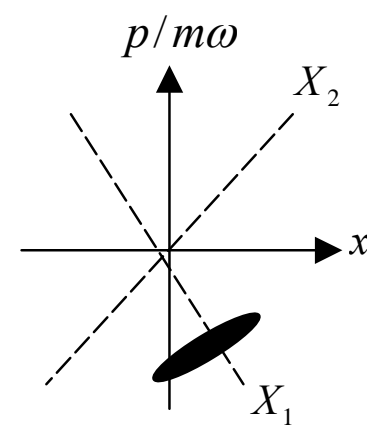

(b)

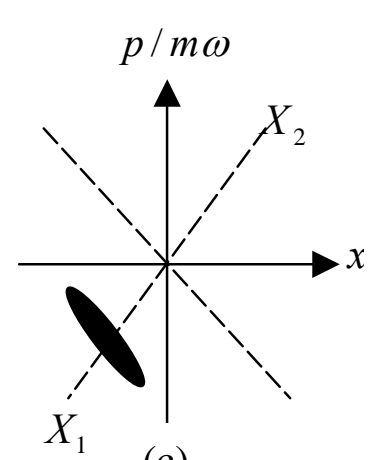

(c)

Figura 3.6: Caixa de erro, para uma medição de “back action evading” de $X_{1}$, vista no espaço de fase posição-momento [2].

Suponha que em um tempo $t=0$, tenha sido medida a posição $x$ do oscilador com alta precisão, produzindo desta forma uma grande incerteza no momento $p$ (Fig. 3.6a). Então, na ausência de medições posteriores ou forças externas, quando o tempo passa, as caixas de erro giram no espaço de fase, no sentido horário, com velocidade angular $\omega$ (evolução de um oscilador harmônico). Se, em um tempo posterior (Fig. 3.6b) se tentar medir novamente $x$ com alta precisão (técnica de amplitude e fase), obter-se-á um resultado imprevisível. Mas se em vez disto, se tentar medir $X_{1} \equiv$ [valor de $x$ no referencial de rotação] (técnica de "Back Action Evading”), obter-se-ía um resultado altamente previsível, um resultado com uma precisão tão boa quanto a medição original.

A questão é que $X_{1}$ é uma constante do movimento na ausência de forças externas, enquanto $x$ não é. Isto significa que, se $X_{1}$ é medido precisamente uma vez, ele permanecerá conhecido precisamente daí para frente, enquanto que se $x$ é medido precisamente, sua precisão é destruída posteriormente pelas misturas do momento modificado pelo ruído de "back action”.

\subsubsection{Ruído de Amplitude e Fase}

Ruídos de amplitude e fase em osciladores eletromagnéticos [2] são proveniente da falta de coerência do sinal no domínio do tempo, ou instabilidades no sinal no domínio das freqüências. A densidade espectral de ruído de fase de um sinal é definida matematicamente em termos da distribuição de energia em função da variância de fase por unidade de largura de banda como: 


$$
S_{\phi}\left(f_{m}\right) \equiv \frac{\Delta \phi_{r m s}^{2}}{\Delta f}\left[\frac{r^{2} d^{2}}{H z}\right],
$$

nas quais, $S_{\phi}\left(f_{m}\right)$ é a densidade espectral de ruído de fase, $\Delta \phi$ é o desvio de fase, $\Delta f$ é a largura de banda e $f_{m}$ é a freqüência de "offset" (deslocamento de freqüência a partir da portadora). A equação (3.14) é valida apenas quando $\Delta f$ é desprezível em relação a qualquer variação de $S_{\phi}$ versus $f_{m}$. A definição de flutuações de fase é ilustrada pela Figura 3.8.

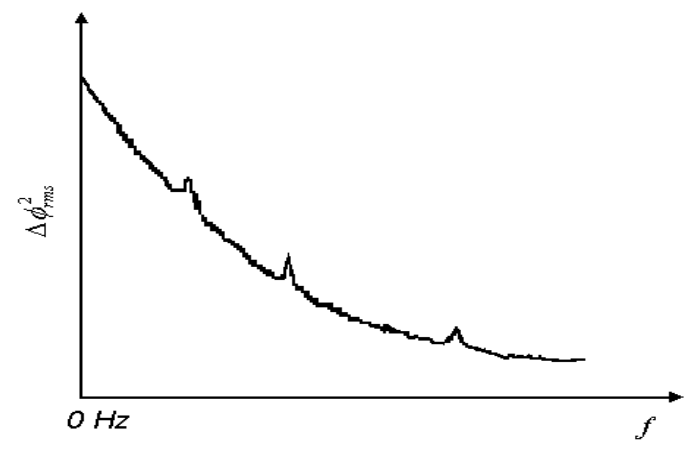

Figura 3.8: Banda lateral de ruído de fase do sinal [2].

O "U.S. National Institute of Standards and Technology” define ruído de fase como a razão entre a potência de uma banda lateral de modulação de fase e a potência total do sinal em uma freqüência de "offset" $f_{m}$, assim:

$$
£\left(f_{m}\right) \equiv \frac{P_{B L}}{P_{S}}\left[\frac{d B c}{H z}\right]
$$

nas quais, $£\left(f_{m}\right)$ é a banda lateral de ruído de fase em relação à portadora por $\mathrm{Hz}, P_{B L}$ é a densidade de potência numa banda lateral de modulação de fase e $P_{S}$ é a potência total do sinal. A definição de $£\left(f_{m}\right)$ é ilustrada pela Figura 3.9. 


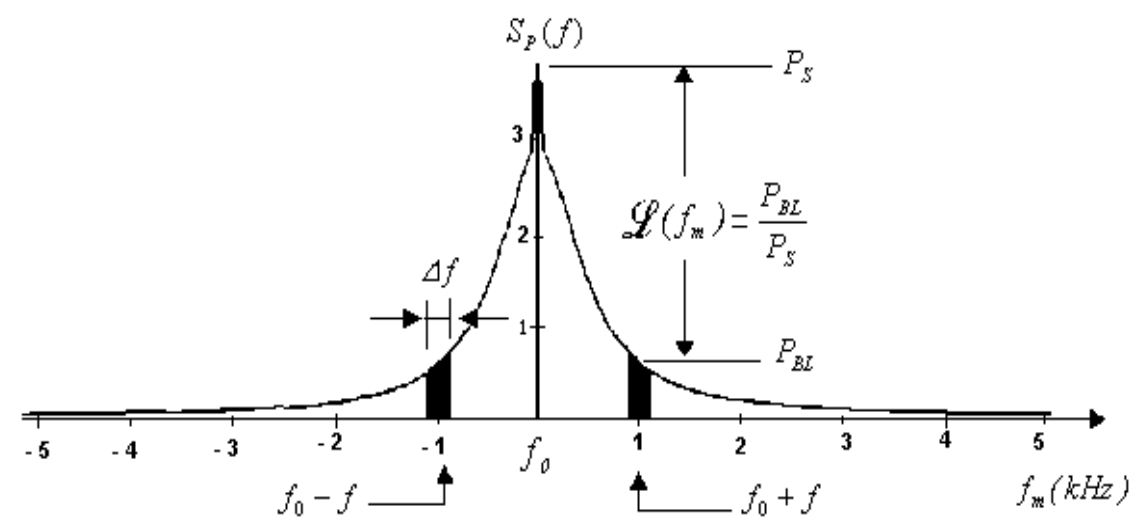

Figura 3.9: Derivação do ruído de fase $£\left(f_{m}\right)$, a partir da tela de um analisador de espectro [2].

O ruído de fase, $£\left(f_{m}\right)$ é uma medida indireta da energia de ruído, a qual está relacionada ao espectro de potência observado num analisador de espectro. O ruído de fase, $£\left(f_{m}\right)$ também está diretamente relacionado a densidade espectral das flutuações de fase, $S_{\phi}\left(f_{m}\right)$ pela aproximação:

$$
£\left(f_{m}\right) \cong \frac{1}{2} S_{\phi}\left(f_{m}\right)
$$

A aproximação é válida se o desvio de fase total é muito menor do que 1 radiano, isto é, se $(\Delta \phi<<1 \mathrm{rad})$. O ruído de fase $£\left(f_{m}\right)$ é geralmente apresentado em escala logarítmica, como uma densidade espectral das bandas laterais de modulação de fase numa representação no domínio da freqüência, expresso em (decibéis) relativo à potência da portadora por uma largura de banda por $\mathrm{Hz}(d B c / H z)$, como mostrado na Figura 3.10.

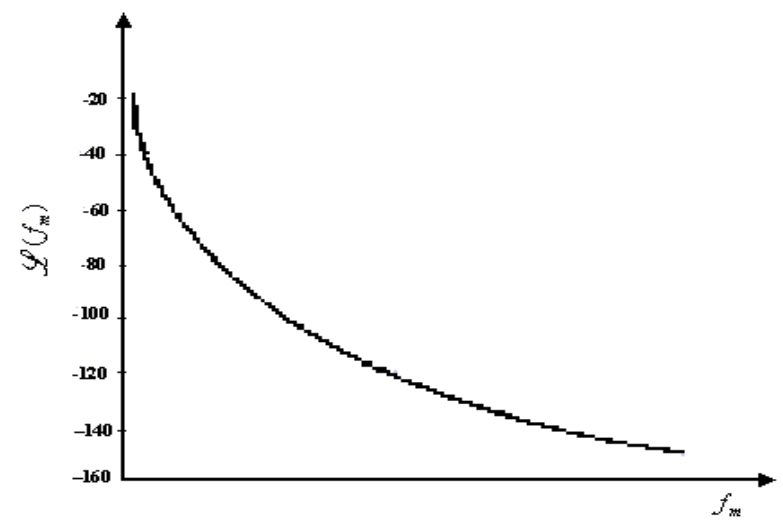

Figura 3.10: Ruído de fase $£\left(f_{m}\right)$ em função da freqüência de "offset” [2].

Entretanto, cuidados devem ser tomados quando é calculado $£\left(f_{m}\right)$ a partir da densidade espectral das flutuações de fase $S_{\phi}\left(f_{m}\right)$, porque o cálculo de $£\left(f_{m}\right)$ é independente do critério 
de pequeno ângulo [00].

\subsubsection{Implicações do Ruído de Fase em Detecção de Ondas Gravitacionais}

A sensibilidade de detectores [2] de OG é limitada pela quantidade de ruído no sistema. Pois, um sinal fraco gerado pela OG é processado juntamente com uma grande quantidade desse ruído.

No detector Mario Schenberg, o ruído de fase dos osciladores dos transdutores paramétricos, utilizados para alimentarem estes transdutores, é um dos principais limitantes da sensibilidade do sistema. A Figura 11 ilustra como será a operação de transdutância entre a antena e os transdutores paramétricos do detector Mario Schenberg, o qual operará dentro de uma banda de freqüência $\Delta f$, de $400 \mathrm{~Hz}$ centrada na freqüência de $\pm 3,2 \mathrm{kHz}$.

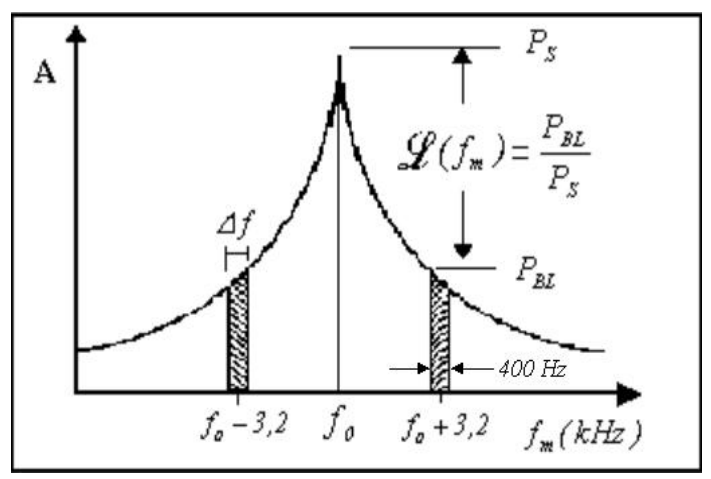

Fig. 3.11: Modulação do sinal eletromagnético $f_{0} \cong 10 \mathrm{GHz}$, por um sinal mecânico numa banda de freqüência de $~ 400 \mathrm{~Hz}$ centrada na freqüência de "offset" de $\pm 3,2 \mathrm{kHz}$ [2].

O sinal eletromagnético produzido pelo oscilador na freqüência de $f_{0} \cong 10 G H z$ será modulado por sinais mecânicos, dentro de uma banda de freqüência de $\Delta f \cong 400 \mathrm{~Hz}$, centrado na freqüência de "offset” de $\pm 3,2 \mathrm{kHz}$, produzindo bandas laterais de modulação do sinal. Caso o ruído de fase das bandas laterais da freqüência de "offset" de $\pm 3,2 \mathrm{kHz}$ seja maior do que o sinal dentro da banda de operação do detector, $\Delta f \cong 400 \mathrm{~Hz}$, não se tem como saber se o sinal medido foi induzido por vibrações mecânicas na antena devido a incidência de OG, ou se foram bandas laterais de ruído de fase do próprio oscilador, limitando, por isso, a sensibilidade do detector. Desta forma, para obtermos uma relação sinal/ruído boa é necessário construirmos osciladores com baixo nível de ruído de fase.

Estudos preliminares sugerem que um oscilador com ruído de fase de $-150 d B c @ \pm 1 k H z$ é suficiente para atingir o limite quântico de sensibilidade para o detector NIOBE da "University of Western Australia” (UWA) [2]. Estendendo esse estudo ao detector Mario Schenberg é esperado que um oscilador com ruído de fase de $-145 \mathrm{dBc} @ \pm 3,2 \mathrm{kHz}$ seja suficiente para atingir o limite quântico em sensibilidade para o detector Mario Schenberg. 


\section{Capítulo 4}

\section{Oscilações Mecânicas no Detector}

No detector esférico a detecção é feita a partir das deformações produzidas pela energia depositada na antena após ser atingida por uma OG. Contudo, as deformações esperadas, que servirão como base para a detecção, são muito menores que as dimensões atômicas. Por isso é necessária uma combinação de fatores que permitam a amplificação destas deformações para que possam ser medidas e monitoradas. Um dos meios que serão utilizados com este objetivo são os ressonadores mecânicos, casadores de impedância mecâicos conectados à superfície da massa esférica, que são sintonizados na mesma freqüência da antena de maneira que o movimento da superfície da antena excite o modo deste ressonador. Na antena será usado um sistema de dois modos. Um sistema de multimodos tem como vantagens: a possibilidade de usar uma massa final leve, o que possibilita uma maior amplificação mecânica, e propiciar uma maior separação entre os modos, o que aumenta a banda de detecção [1]. Estes casadores de impedância são construídos de maneira a obedecer a equação do oscilador harmônico simples unidirecional.

Mas, para o dimensionamento destes ressonadores é necessário, além de sintonizar o seu primeiro modo normal de vibração com a freqüência de trabalho da antena, levar em conta como eles se deformam e como eles afetam os modos normais degenerados da massa esférica, em particular os modos quadrupolares. A maneira como se deformam deve ser compatível com o tipo de transdutor a ser utilizado para a conversão das deformações em sinais elétricos. Como os modos de vibração dos ressonadores se acoplarão aos modos normais da massa esférica, e, como estes acoplamentos afetarão o funcionamento da antena, são questões que só poderão ser analisadas após se ter uma previsão de como serão os padrões das deformações e das freqüências do sistema massa esférica - ressonadores.

Com o estudo analítico de modelos massa-mola não se consegue alcançar a complexidade exigida para se fazer à análise necessária em tais casos. Por outro lado, formatos conhecidos de sólidos já estudados e analisados não atendem as necessidades existentes na antena, além do que nestes estudos tais sólidos são considerados vinculados a massas infinitas. Devido a estes fatores, na presente pesquisa foi necessária a utilização de um método numérico, o método de elementos finitos (MEF), para realizar as simulações necessárias à análise pretendida.

O desenvolvimento deste capítulo parte do estudo de osciladores harmônicos acoplados e da determinação de seus modos de vibração através de método analítico. A partir da análise modal são obtidas as equações desacopladas, descritas em coordenadas normais, que são a forma mais compacta possível de se descrever o sistema. Nesta forma, as equações de movimento do sistema encontram-se diagonalizadas ou linearizadas. 
São apresentadas as equações de movimento para alguns sistemas contínuos regulares.

O método de elementos finitos é então introduzido, como sendo um grande número de osciladores harmônicos acoplados. A sua resolução segue, basicamente, o mesmo método apresentado no início do capítulo para estes osciladores. Deste modo os programas de elementos finitos utilizados na análise modal, obtém as soluções desacopladas do sistema modelado a partir das equações de movimento linearizadas. Como o objetivo principal no MEF é o cálculo das freqüências modais, das amplitudes, dos formatos e do movimento resultantes da oscilação, as equações de movimento obtidas não são exibidas de forma explícita.

\subsection{Dinâmica de Sistemas Rígidos}

Por definição, um sistema rígido é todo conjunto de partículas obrigadas a permanecer a distâncias relativas absolutamente fixas. Por esta definição, não existem na natureza sistemas deste tipo, já que as últimas partículas constituintes, e que formam todos os corpos (os átomos), estão sempre submetidas a algum movimento relativo. Este movimento, contudo, é de natureza microscópica, razão pela qual, em geral, pode se ignorar o seu efeito na descrição do movimento macroscópico do sistema. Por outro lado, pode existir entre os deslocamentos macroscópicos, como é o caso das deformações elásticas, mas para muitos dos corpos que nos interessam podemos desprezar sem perigo as variações de tamanho e forma produzidas por tais deformações, obtendo equações de movimento válidas com alto grau de precisão.

Assim mesmo, é evidente que existe uma limitação relativista na idéia de sistema totalmente rígido. Por exemplo, consideremos uma barra comprida de um certo material. Aplicando um golpe em um dos extremos da mesma, se esta fosse absolutamente rígida, o efeito seria sentido imediatamente no extremo oposto. Mas isto corresponderia à transmissão de um sinal a velocidade infinita, coisa que pela relatividade sabemos que é impossível. (Realmente, a velocidade de transmissão de um sinal como este em uma barra metálica, da ordem de $10^{5} \mathrm{~cm} / \mathrm{s}$, é bem mais baixa que a velocidade da luz, e depende das propriedades elásticas do material.) .

Todo movimento finito de um sistema rígido, qualquer que seja, pode ser considerado a soma de dois movimentos independentes: uma translação linear de algum ponto do corpo com a rotação em torno do mesmo ponto. Quando este ponto for o centro de massa, esta decomposição em duas partes permitirá que seja levado em conta que o momento cinético e a energia cinética podem ser separados em duas partes responsáveis pelo movimento do centro de massa e do movimento ao redor do centro de massa. [8] .

Quando a energia potencial também for separável (como será sempre o caso, por exemplo, da energia potencial em um campo de forças uniforme), a Lagrangeana será por sua vez separável, e o problema inteiro se divide convenientemente em duas partes, uma das quais pertinente somente 
à translação e a outra somente à rotação, podendo se resolver cada uma delas com independência da outra. Esta separação é fundamental para uma descrição relativamente simples do movimento dos corpos rígidos.

\subsection{Oscilações Acopladas}

Quando se examina [8] o movimento de um oscilador harmônico submetido a uma força impulsora externa, é comum se considerar a ação do impulsor sobre o oscilador, mas não o efeito de realimentação do oscilador sobre o impulsor. Realmente, em muitos casos, isto carece de importância. Mas quando se conectam dois (ou mais) osciladores, como é o caso do detector Mário Schenberg, de tal forma que a energia possa passar de um ao outro (ou de uns aos outros) em um ou outro sentido, encontramo-nos diante de uma situação mais complexa, que corresponde ao caso das oscilações acopladas. Um movimento deste tipo pode ser muito complexo, inclusive podendo ser não periódico, mas, como será visto, sempre é possível descrever o movimento de um sistema oscilante qualquer em função de coordenadas normais, que tem a propriedade de, cada uma delas, oscilar com uma freqüência bem definida. Quer dizer, as coordenadas normais são construídas de forma a não existir acoplamento entre elas, ainda que haja acoplamento entre as coordenadas físicas que definem as posições das partículas. As condições iniciais do sistema podem ser sempre estabelecidas de forma que, no movimento subseqüente, só uma das coordenadas normais varie com o tempo; nestas circunstâncias diremos que foi excitado um dos modos normais do sistema. Se o sistema possui $n$ graus de liberdade (é formado por $\mathrm{n}$ osciladores monodimensionais ou $n / 3$ osciladores tridimensionais acoplados, por exemplo) haverá, em geral, n modos normais, alguns dos quais podendo ser idênticos ou degenerados. Mas, sempre se poderá determinar condições iniciais tais que se excite, independentemente, um dado modo qualquer. A identificação de cada um dos modos normais de um sistema, permite construir uma imagem reveladora do movimento, ainda que o movimento do sistema seja, em geral, uma combinação complicada de todos os modos normais de oscilação. No detector Mário Schenberg não há força impulsora externa atuando nos ressonadores (osciladores). Além disto, devido às escolhas e condições estabelecidas em projeto, no seu estudo será adotado um modelo de oscilador harmônico sem amortecimento. O uso de materiais com alto fator de qualidade mecânica $Q$ e as temperaturas criogênicas utilizadas em sua operação, entre outros fatores já mencionados, justificam esta consideração.

A análise de um sistema composto de dois osciladores harmônicos, que será feita a seguir, servirá para discutir questões relacionadas ao acoplamento, ao uso das coordenadas normais e como base para justificar a adequação do uso do método de elementos finitos (MEF) neste tipo de trabalho. 


\subsubsection{Acoplamento de dois Osciladores Harmônicos}

Nesta seção será analisado um sistema composto por dois osciladores harmônicos acoplados [8], para se discutir questões relacionadas ao acoplamento em si e ao uso de coordenadas normais como meio de desacoplar as equações de movimento resultante. (Posteriormente este estudo também comporá a base para o método numérico que será utilizado nesta pesquisa, qual seja, o método dos elementos finitos.). A Figura 4.1 representa dois osciladores harmônicos unidirecionais unidos entre si, um sistema análogo ao ressonador de dois modos utilizado na antena Mário Schenberg.

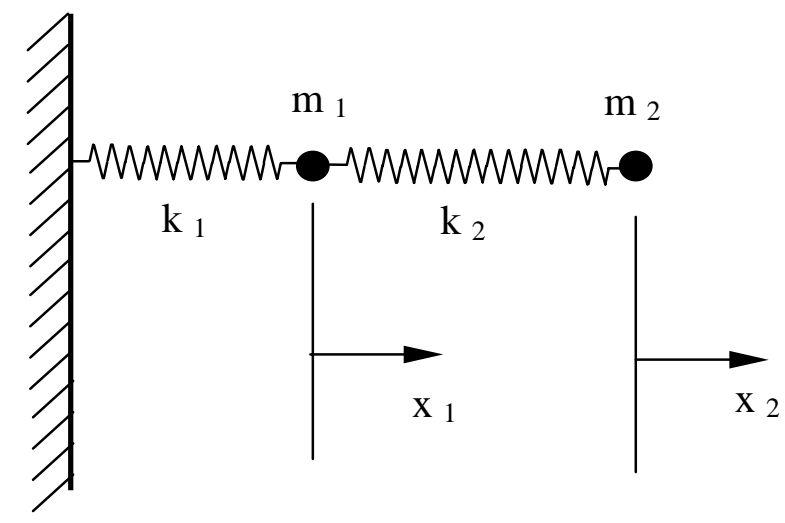

Figura 4.1 - Dois osciladores harmônicos iguais acoplados [10]

As constantes de mola em cada um dos osciladores acoplados são designadas por $k_{1}$ e $k_{2}$. O movimento é limitado à reta que une as massas $m_{1}$ e $m_{2}$. Este sistema possui dois graus de liberdade, representados pelas coordenadas $x_{1}$ e $x_{2}$, cada uma medida a partir da posição de equilíbrio da massa correspondente. Considerando que as massas $m_{1}$ e $m_{2}$ tenham se deslocado de $x_{1}$ e $x_{2}$ de suas posições de equilíbrio, respectivamente, as equações para as energias potencial e cinética para este sistema serão:

$V=\frac{k_{1}}{2} x_{1}^{2}+\frac{k_{2}}{2}\left(x_{2}-x_{1}\right)^{2}$

$T=\frac{m_{1}}{2} \dot{x}_{1}^{2}+\frac{m_{2}}{2} \dot{x}_{2}^{2}$

e, a Lagrangeana será:

$L=T-V=\frac{m_{1}}{2} \dot{x}_{1}^{2}+\frac{m_{2}}{2} \dot{x}_{2}^{2}-\frac{k_{1}}{2} x_{1}^{2}-\frac{k_{2}}{2}\left(x_{2}^{2}-2 x_{1} x_{2}+x_{1}^{2}\right)$

A partir das equações de Lagrange:

$\frac{\partial L}{\partial x_{i}}-\frac{d}{d t} \frac{\partial L}{\partial \dot{x}_{i}}=0$ 
obtêm-se as equações de movimento do sistema, que são dadas por:

$$
\begin{aligned}
& m_{1} \ddot{x}_{1}+\left(k_{1}+k_{2}\right) x_{1}-k_{2} x_{2}=0 \\
& m_{2} \ddot{x}_{2}-k_{2} x_{1}+k_{2} x_{2}=0
\end{aligned}
$$

que na forma matricial se escreve:

$\left|\begin{array}{cc}m_{1} & 0 \\ 0 & m_{2}\end{array}\right|\left|\begin{array}{l}\ddot{x}_{1} \\ \ddot{x}_{2}\end{array}\right|+\left|\begin{array}{cc}k_{1}+k_{2} & -k_{2} \\ -k_{2} & k_{2}\end{array}\right| \begin{aligned} & x_{1} \\ & x_{2}\end{aligned}|=| \begin{aligned} & 0 \\ & 0\end{aligned} \mid$

ou

$$
\mathbf{M} \ddot{\mathbf{X}}+\mathbf{K X}=\mathbf{0}
$$

onde $\mathbf{M}$ é a matriz de massa, $\mathbf{K}$ é a matriz de rigidez, $\mathbf{X}$ é o vetor deslocamento e $\ddot{\mathbf{X}}$ é o vetor aceleração. Esta equação é geral, ou seja, vale para sistemas com mais graus de liberdade, apesar de aqui ter sido desenvolvida à partir de um sistema de apenas dois graus de liberdade [8] [10] Para o caso em análise ou sempre que o movimento de um sistema ocorrer nas proximidades da configuração de equilíbrio, ou seja, quando as coordenadas são deslocadas de sua posição de equilíbrio, e logo no instante $t=0$ são deixadas livres, de tal modo que $x_{j}(0)=x_{j 0}, \dot{x}_{j}=0$ e $\ddot{x}_{j}=0$, tem-se das equações de Lagrange, e também no equilíbrio, que $\partial T / \partial x_{j}=0$ e, conseqüentemente que $\partial V / \partial x_{j}=0$. Esta conclusão [8] [10] leva em conta que não há força externa aplicada nas coordenadas do sistema e que os termos de ordem superior a dois, no desenvolvimento em série de Taylor para a energia potencial, podem ser desprezados. Como o interesse nesta pesquisa, são pelos modos de vibração livre do sistema e suas freqüências naturais, estas considerações são adequadas.

Então, considerando-se a energia potencial $V=0$ no equilíbrio, em geral, ela será $V \geq 0$. Evidentemente, a energia cinética também deverá ser $T \geq 0$. Quando as energias potencial e cinética de um sistema são como as especificadas acima, a equações de Lagrange para a j-ésima coordenada se torna

$\frac{d}{d t}\left(\frac{\partial T}{\partial \dot{x}_{j}}\right)+\frac{\partial V}{\partial x_{j}}=\mathbf{M} \ddot{\mathbf{X}}+\mathbf{K X}=\mathbf{0}$

para $j=1,2, \ldots, n$.

Para um sistema de dois graus de liberdade como o que está sendo analisado: 


$$
\begin{aligned}
& \left|\begin{array}{l}
\frac{d}{d t}\left(\frac{\partial T}{\partial \dot{x}_{1}}\right) \\
\frac{d}{d t}\left(\frac{\partial T}{\partial \dot{x}_{2}}\right)
\end{array}\right|=\mathbf{M} \ddot{\mathbf{X}} \\
& \left|\begin{array}{l}
\frac{\partial V}{\partial x_{1}} \\
\frac{\partial V}{\partial x_{2}}
\end{array}\right|=\mathbf{K X}
\end{aligned}
$$

Já que $T$ é função das velocidades generalizadas somente e $U$ é função das coordenadas generalizadas somente.

Para sistemas compostos por osciladores harmônicos acoplados são esperadas soluções da forma:

$x_{j}(t)=B_{j} e^{i w t}$

com

$\dot{x}_{j}(t)=i w B_{j} e^{i w t} \quad \mathrm{e}$

$\ddot{x}_{j}(t)=-w_{j}^{2} B_{j} e^{i w t}$

ou na forma matricial:

$\mathbf{X}(\mathbf{t})=\mathbf{B} e^{i w t} \mathrm{e}$

$\ddot{\mathbf{X}}(\mathbf{t})=-w^{2} \mathbf{B} e^{i w t}$

que substituído em (4.9) conduz a:

$\left(-w^{2} \mathbf{M}+\mathbf{K}\right) \mathbf{B} e^{i w t}=\mathbf{0}$

Como o escalar $e^{i w t} \neq 0$ para todo valor de $t$, e para que haja deslocamento $\mathbf{B} \neq 0$, as freqüências $w$ devem satisfazer a equação:

$\left|-w^{2} \mathbf{M}+\mathbf{K}\right|=\mathbf{0}$

que no sistema que esta sendo analisando, se torna:

$\left|\begin{array}{cc}k_{1}+k_{2}-m_{1} w^{2} & -k_{2} \\ -k_{2} & k_{2}-m_{2} w^{2}\end{array}\right|=0$

Uma outra forma de se chegar a (4.15) é substituir (4.10) e (4.11) nas equações de movimento (4.5), agrupar as constantes $B_{\mathrm{j}}$ e suprimir o fator comum exponencial, obtendo-se: 


$$
\begin{array}{ccc}
\left(k_{1}+k_{2}-m_{1} w^{2}\right) B_{1} & -k_{2} B_{2} & =0 \\
-k_{2} B_{1} & +\left(k_{2}-m_{2} w^{2}\right) B_{2} & =0
\end{array}
$$

Excluindo a solução trivial com $B_{\mathrm{j}}=0$, o sistema de equações assim obtido deverá satisfazer as condições mostradas em (4.15).

Desenvolvendo o determinante de (4.15), obtém-se:

$m_{1} m_{2} w^{4}-\left(m_{1} k_{2}+m_{2} k_{2}+m_{2} k_{1}\right) w^{2}+k_{1} k_{2}=0$

que é denominada equação característica do sistema. As freqüências $w$ obtidas são denominadas freqüências características, naturais ou próprias do sistema.. Há casos em que duas ou mais freqüiências $w$ podem ser iguais, o que se constitui no fenômeno da degeneração [8]

Fazendo $W=w^{2}$ e resolvendo (4.17) obtém-se:

$$
w=+\sqrt{W=}+\sqrt{\frac{\left(m_{1} k_{2}+m_{2} k_{2}+m_{2} k_{1}\right) \pm \sqrt{\left(m_{1} k_{2}+m_{2} k_{2}+m_{2} k_{1}\right)^{2}-4 m_{1} m_{2} k_{1} k_{2}}}{2 m_{1} m_{2}}}
$$

Para simplificar esta análise, as constantes de mola $k_{1}$ e $k_{2}$ dos osciladores acoplados serão consideradas iguais a $k$, ou seja, $k=k_{1}=k_{2}$. Da mesma forma as massas $m_{1}$ e $m_{2}$ serão consideradas iguais a $m$, ou seja, $m=m_{l}=m_{2}$. Resolvendo para $w$ obtém-se:

$$
\begin{aligned}
& w_{1}=\sqrt{\frac{k}{m} \frac{(3+\sqrt{5})}{2}}=1,618033 \sqrt{\frac{k}{m}} \\
& w_{1}=\sqrt{\frac{k}{m} \frac{(3-\sqrt{5})}{2}}=0,618033 \sqrt{\frac{k}{m}}
\end{aligned}
$$

Pode-se então determinar as constantes B , ou utilizando as equações (4.16), ou utilizando as seguintes equações, obtidas de (4.13):

$$
\begin{aligned}
& \left(-w_{1}^{2} \mathbf{M}+\mathbf{K}\right) \mathbf{B}_{1} e^{i w_{1} t}=\mathbf{0} \\
& \left(-w_{2}^{2} \mathbf{M}+\mathbf{K}\right) \mathbf{B}_{2} e^{i w_{2} t}=\mathbf{0}
\end{aligned}
$$

Em geral, as equações (4.20) serão tantas quantas forem as freqüências $w$ existentes para o sistema.

Para o sistema analisado os valores encontrados para as constantes $\mathbf{B}_{1}$ e $\mathbf{B}_{2}$ foram: 


$$
\begin{aligned}
& \mathbf{B}_{1}=\left|\frac{1}{\frac{1+\sqrt{5}}{2}}\right|=\left|\begin{array}{c}
1 \\
1,618033
\end{array}\right| \\
& \mathbf{B}_{2}=\left|\frac{1-\sqrt{5}}{2}\right|=\left|\begin{array}{c}
1 \\
-0,618033
\end{array}\right|
\end{aligned}
$$

A solução para o sistema de equações acopladas pode ser construída a partir dos valores encontrados para $w_{j}$ e $\mathbf{B}_{\mathrm{j}}$ com:

$$
\mathbf{x}(t)=\mathbf{B}_{1} e^{-i w_{1} t}, \mathbf{B}_{1} e^{i w_{1} t}, \mathbf{B}_{2} e^{-i w_{2} t}, \mathbf{B}_{2} e^{i w_{2} t}
$$

A solução geral é dada então por:

$$
\mathbf{x}(t)=\left(a e^{-i w_{1} t}+b e^{i w_{1} t}\right) \mathbf{B}_{1}+\left(c e^{-i w_{2} t}+d e^{i w_{2} t}\right) \mathbf{B}_{2}
$$

que também pode ser escrita na forma

$$
\mathbf{x}(t)=A_{1} \operatorname{sen}\left(w_{1} t+\phi_{1}\right) \mathbf{B}_{1}+A_{2} \operatorname{sen}\left(w_{2} t+\phi_{2}\right) \mathbf{B}_{2}
$$

De uma maneira geral, o movimento da coordenada $x_{j}$ é composto pelos $n$ movimentos, correspondentes aos $n$ valores que a freqüência $w_{j}$ pode assumir.

Voltando ao sistema que está sendo analisado, verifica-se que este possui duas freqüências características, naturais ou próprias, e quatro constantes . Com isto a solução geral do problema será:

$$
\left.\begin{array}{l}
x_{1}(t)=e^{i w_{1} t}+e^{-i w_{1} t}+e^{i w_{2} t}+e^{-i w_{2} t} \\
x_{2}(t)=\left(\frac{1+\sqrt{5}}{2}\right) e^{i w_{1} t}+\left(\frac{1+\sqrt{5}}{2}\right) e^{-i w_{1} t}+\left(\frac{1-\sqrt{5}}{2}\right) e^{i w_{2} t}+\left(\frac{1-\sqrt{5}}{2}\right) e^{-i w_{2} t}
\end{array}\right\}
$$

com as freqüências características ou naturais $w_{1}$ e $w_{2}$ dadas por (4.19). O efeito do acoplamento em um sistema de dois graus de liberdade foi produzir duas freqüências características e dois modos de oscilação. O efeito do acoplamento em um sistema de $n$ graus de liberdade é produzir $n$ freqüências características e $n$ modos de oscilação.

Observar na solução acima que as coordenadas utilizadas estão acopladas, ou seja, as soluções são dependentes entre si.

Na próxima seção será mostrado um dos métodos utilizados para desacoplar as soluções, tornando-as independentes. 


\subsubsection{Coordenadas e Modos Normais}

Conforme o que foi visto na seção anterior (equação (4.7)) as equações de movimento de um sistema oscilante podem ser escritas na forma matricial como:

$$
\mathbf{M X}+\mathbf{K X}=\mathbf{0}
$$

As matrizes $\mathbf{M}$ e $\mathbf{K}$ especificam de que forma se acoplam os movimentos das distintas coordenadas [8]. Os termos não-diagonais não nulos de $\mathbf{M}$ indicam a proporcionalidade em que ocorre o acoplamento entre as coordenadas envolvidas na descrição do sistema. Já se $\mathbf{M}$ for diagonal ( $m_{j k} \neq 0$ para $j=k$, e $m_{j k}=0$ para $j \neq k$ ) a energia cinética do sistema será uma soma simples das energias cinéticas associadas às distintas coordenadas. Se $\mathbf{K}$ for diagonal, a energia potencial do sistema será uma soma simples das energias potenciais individuais. Quando M e $\mathbf{K}$ forem diagonais, cada coordenada se comportará de forma única, sofrendo oscilações com freqüência única e bem definida. As coordenadas que permitem que o sistema seja descrito desta forma única, e a mais compacta possível, são denominadas de coordenadas normais. E, para serem obtidas, o sistema deve sofrer uma mudança de coordenadas que diagonalize $\mathbf{M}$ e K simultaneamente. A análise modal [10], procedimento que será apresentado a seguir, tem como objetivo descrever o sistema em coordenadas normais, sistema este em que as soluções do sistema estejam desacopladas.

\subsubsection{Análise Modal}

A análise modal [10] , procedimento que será apresentado a seguir, tem como objetivo encontrar este novo sistema de coordenadas, as coordenadas normais $r(t)$, em que as soluções do sistema estejam desacopladas, isto é, cada equação que representa a solução de tal sistema dependa apenas de uma coordenada, de maneira que possam ser facilmente resolvidas e analisadas.

A análise modal pode ser feita em sistemas com múltiplos graus de liberdade, mas aqui será aplicada no mesmo sistema de dois osciladores harmônicos acoplados (ver Figura 4.1), já estudado na seção anterior.

Consideremos novamente a equação de movimento de tal sistema:

$$
\mathbf{M} \ddot{\mathbf{X}}+\mathbf{K X}=\mathbf{0}
$$

ou

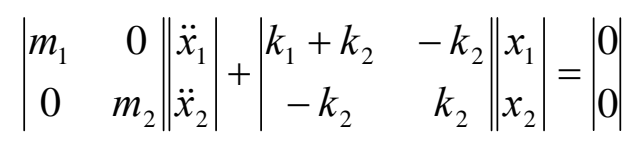


e as suas condições iniciais:

$\mathbf{X}(0)=\left|\begin{array}{l}x_{1}(0) \\ x_{2}(0)\end{array}\right|$
$\dot{\mathbf{X}}(0)=\left|\begin{array}{l}\dot{x}_{1}(0) \\ \dot{x}_{2}(0)\end{array}\right|$

Sendo $\mathbf{M}$ a matriz massa do sistema, define-se a matriz raiz quadrada $\mathbf{M}^{1 / 2}$, tal que:

$\mathbf{M}^{1 / 2} \mathbf{M}^{1 / 2}=\mathbf{M}$

e a sua inversa $\mathbf{M}^{-1 / 2}$. Seja

$\mathbf{X}(t)=\mathbf{M}^{-1 / 2} \mathbf{Q}(t)$

conseqüentemente

$\ddot{\mathbf{X}}(t)=\mathbf{M}^{-1 / 2} \ddot{\mathbf{Q}}(t)$

Substituindo (4.31) e (4.32) na equação (4.27) obtém-se

$\mathbf{M} \mathbf{M}^{-1 / 2} \ddot{\mathbf{Q}}(t)+\mathbf{K} \mathbf{M}^{-1 / 2} \mathbf{Q}(t)=\mathbf{0}$

e pré-multiplicando por $\mathbf{M}^{-1 / 2}$, tem-se que:

$\mathbf{M}^{-1 / 2} \mathbf{M} \mathbf{M}^{-1 / 2} \ddot{\mathbf{Q}}(t)+\mathbf{M}^{-1 / 2} \mathbf{K} \mathbf{M}^{-1 / 2} \mathbf{Q}(t)=\mathbf{0}$

mas como

$\mathbf{M}^{-1 / 2} \mathbf{M M}^{-1 / 2}=\mathbf{I}$

e

$\mathbf{M}^{-1 / 2} \mathbf{K} \mathbf{M}^{-1 / 2}=\tilde{\mathbf{K}}$

que fisicamente corresponde a distribuir a rigidez do sistema pela sua massa, fica-se com $\mathbf{I} \mathbf{Q}(t)+\tilde{\mathbf{K}} \mathbf{Q}(t)=\mathbf{0}$

que é a equação de movimento (4.27) descrita pelo novo sistema de coordenadas $\mathbf{Q}(t)$ sujeita as condições iniciais

$\mathbf{Q}(0)=\mathbf{M}^{1 / 2} \mathbf{X}(0)$

$\dot{\mathbf{Q}}(0)=\mathbf{M}^{1 / 2} \dot{\mathbf{X}}(0)$ 
Propondo novamente soluções da forma

$\mathbf{Q}(\mathbf{t})=\mathbf{V} e^{i w t}$

conseqüentemente

$\ddot{\mathbf{Q}}(\mathbf{t})=-w^{2} \mathbf{V} e^{i w t}$

onde $\quad \mathbf{V}$ é o vetor das constantes. Fazendo $\lambda=w^{2}$ e substituindo (4.39) e (4.40) em (4.37) tem-se que

$\tilde{\mathbf{K}} \mathbf{V}=\lambda \mathbf{V}$

O escalar $\lambda$ que satisfaz a esta equação para um correspondente autovetor $\mathbf{V}$ é denominado autovalor. Os autovetores $\mathbf{V}$ são os modos de vibração livre do sistema e os autovalores $\lambda \quad 0$ quadrado de suas freqüências naturais.

Os autovalores são obtidos do determinante de

$\operatorname{det}(\tilde{\mathbf{K}}-\mathbf{I} \lambda)=\mathbf{0}$

e os correspondentes autovetores de

$(\tilde{\mathbf{K}}-\mathbf{I} \lambda) \mathbf{V}=\mathbf{0}$

Neste ponto da análise tem-se as freqüências naturais $w_{\mathrm{j}}$ e os seus correspondentes vetores de constantes ou autovetores $\mathbf{V}_{j}$, com o que se poderia escrever a solução da equação de movimento (4.27) em coordenadas $\mathbf{Q}$, contudo estas ainda não são as coordenadas normais que desacoplam as soluções do sistema.

O próximo passo é normalizar os autovetores $\mathbf{V}_{j}$, o que é feito à partir de suas componentes através da condição de ortonormalização

$\sum_{1}^{n} \mathrm{v}_{j}^{2}=1$

obtendo-se $\tilde{\mathbf{V}}_{j}$, os autovetores normalizados de $\tilde{\mathbf{K}}$. Cada um destes autovetores formará uma coluna da matriz modal $\mathbf{P}$, ou seja

$\mathbf{P}=\mid \begin{array}{llll}\tilde{\mathbf{V}}_{1} & \tilde{\mathbf{V}}_{2} & \tilde{\mathbf{V}}_{3} & \cdots\end{array}$

onde n é o número de graus de liberdade do sistema. Agora faz-se

$\mathbf{Q}(t)=\mathbf{P R}(t)$ 
e substitui-se na equação (4.37), obtendo-se

$\mathbf{P} \ddot{\mathbf{R}}(t)+\tilde{\mathbf{K}} \mathbf{P R}(t)=\mathbf{0}$

Pré-multiplicando por $\mathbf{P}^{T}$ obtém-se

$\mathbf{P}^{T} \mathbf{P} \ddot{\mathbf{R}}(t)+\mathbf{P}^{T} \tilde{\mathbf{K}} \mathbf{P R}(t)=\mathbf{0}$

que pode ser simplificada para

$\mathbf{I} \ddot{\mathbf{R}}(t)+\Lambda \mathbf{R}(t)=\mathbf{0}$

já que

$\mathbf{P}^{T} \mathbf{P}=\mathbf{I}$

e

$$
\boldsymbol{\Lambda}=\operatorname{diag}\left(\lambda_{j}\right)=\mathbf{P}^{T} \tilde{\mathbf{K}} \mathbf{P}
$$

sendo $\Lambda$, a matriz diagonal cujos elementos são os autovalores $\lambda_{j}$ de $\tilde{\mathbf{K}}$, a matriz espectral de $\tilde{\mathbf{K}}$. Na forma matricial (4.49) é escrita como

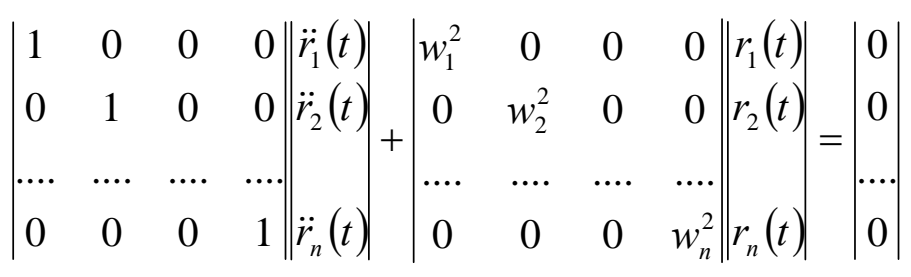

ou

$\left|\begin{array}{c}\ddot{r}_{1}(t)+w_{1}^{2} r_{1}(t) \\ \ddot{r}_{2}(t)+w_{2}^{2} r_{2}(t) \\ \ldots \ldots \ldots \\ \ddot{r}_{n}(t)+w_{n}^{2} r_{n}(t)\end{array}\right|=\left|\begin{array}{c}0 \\ 0 \\ \cdots \\ 0 .\end{array}\right|$

o que fornece $n$ equações desacopladas da forma

$\ddot{r}_{j}(t)+w_{j}^{2} r_{j}(t)=0$

sujeita as condições iniciais

$\mathbf{R}(0)=\mathbf{P}^{T} \mathbf{Q}(0)=\mathbf{P}^{T} \mathbf{M}^{1 / 2} \mathbf{X}(0)=\mathbf{S}^{-1} \mathbf{X}(0)$

e 
$\dot{\mathbf{R}}(0)=\mathbf{P}^{T} \dot{\mathbf{Q}}(0)=\mathbf{P}^{T} \mathbf{M}^{1 / 2} \dot{\mathbf{X}}(0)=\mathbf{S}^{-1} \dot{\mathbf{X}}(0)$

com n soluções desacopladas da forma

$r_{j}(t)=A_{j} \operatorname{sen}\left(w_{j} t+\phi_{j}\right)$

sendo $A_{j}$ e $\phi_{j}$ definidos a partir das condições iniciais do sistema.

Quando se expressa (a configuração de) um sistema em coordenadas normais, tanto a energia potencial como a cinética, se tornam diagonais simultaneamente [8]. Como são as componentes não diagonais de $\mathbf{M}$ e de $\mathbf{K}$, as que produzem o acoplamento entre as partículas, é evidente que utilizando coordenadas que façam diagonais a ambos os tensores, as coordenadas se desacoplarão, tornando o problema completamente separável nas componentes correspondentes aos movimentos independentes das coordenadas normais, cada uma das quais tendo a sua freqüência normal.

Com (4.55) obtém-se, no sistema de coordenadas físicas ou originais, que

$$
\mathbf{X}(t)=\mathbf{M}^{-1 / 2} \mathbf{Q}(t)=\mathbf{M}^{-1 / 2} \mathbf{P R}(t)=\mathbf{S R}(t)
$$

onde $\mathbf{S}=\mathbf{M}^{-1 / 2} \mathbf{P}$.

Como o princípio da superposição é aplicável às equações diferenciais que estão sendo consideradas (4.27) e (4.49), a solução geral, em coordenadas normais, pode ser escrita como uma combinação linear das soluções para cada um dos $n$ valores de $j$.

$$
\mathbf{R}(t)=\sum_{j=1}^{n} A_{j} \operatorname{sen}\left(w_{j} t+\phi_{j}\right)
$$

É possível, para condições iniciais quaisquer, $\quad \mathbf{X}_{j}(0)$ e $\dot{\mathbf{X}}_{j}(0)$, determinar um sistema de coordenadas normais com a propriedade de, cada uma delas variar harmonicamente com uma única freqüência $w_{j}$. Mas, em geral, nestas condições, as expressões para $\mathbf{R}(t)$ são complicadas. Já para o caso discutido aqui, em que o movimento do sistema ocorre nas proximidades da configuração de equilíbrio, ou seja, quando as coordenadas são deslocadas de sua posição de equilíbrio, e logo no instante $t=0$, são deixadas livres, estas expressões são como (4.59). Como o interesse nesta pesquisa, são pelos modos de vibração livre do sistema e suas freqüências naturais, fica justificado o uso desta abordagem.

A contribuição de cada modo na resposta total do sistema, em coordenadas físicas, pode ser observada na solução em série 
$\mathbf{X}(t)=\sum_{j=1}^{n} d_{j} \operatorname{sen}\left(w_{j} t+\phi_{j}\right) b_{j}$

sendo

$\mathbf{B}=\mathbf{M}^{-1 / 2} \mathbf{V}$

Devido à ortogonalidade dos modos de vibração, a condição inicial necessária para excitar um sistema em um único modo, o z-ésimo por exemplo, é que

$\mathbf{X}(0)=b_{z}$ e $\dot{\mathbf{X}}(0)=\mathbf{0}$

de forma que todos os coeficientes $d j$ na expressão (4.60) serão nulos exceto quando $j=z$.

\subsubsection{Análise Modal de Dois Osciladores Harmônicos Acoplados}

Para obter as coordenadas normais do sistema formado pelos dois osciladores harmônicos acoplados representados na Figura 4.1, que será utilizado como referência para a discussão de vibrações em sólidos, e do método de elementos finitos (MEF), será adotada uma metodologia que pode ser utilizada para sistemas com múltiplos graus de liberdade e que é adequada para a implementação em métodos numéricos, e com algumas simplificações, em métodos computacionais. Voltando as equações de movimento (4.6) e (4.7) escritas para tal sistema

$$
\left|\begin{array}{cc}
m_{1} & 0 \\
0 & m_{2}
\end{array}\right| \begin{gathered}
\ddot{x}_{1} \\
\ddot{x}_{2}
\end{gathered}|+| \begin{array}{cc}
k_{1}+k_{2} & -k_{2} \\
-k_{2} & k_{2}
\end{array}|| \begin{gathered}
x_{1} \\
x_{2}
\end{gathered}|=| \begin{aligned}
& 0 \\
& 0
\end{aligned} \mid
$$

ou

$$
\mathbf{M X}+\mathbf{K X}=\mathbf{0}
$$

Para simplificar esta análise, as constantes de mola $k_{1}$ e $k_{2}$ dos osciladores acoplados serão consideradas iguais a $k$, ou seja, $k=k_{1}=k_{2}$. Da mesma forma as massas $m_{1}$ e $m_{2}$ serão consideradas iguais a $m$, ou seja, $m=m_{1}=m_{2}$.

Passo 1 - Determinação de $\mathbf{M}^{-1 / 2}$, a inversa da matriz raiz quadrada de $\mathbf{M}$

$$
\mathbf{M}^{-1 / 2}=\left|\begin{array}{cc}
\frac{1}{\sqrt{m}} & 0 \\
0 & \frac{1}{\sqrt{m}}
\end{array}\right|
$$

Passo 2 - Determinação de $\tilde{\mathbf{K}}=\mathbf{M}^{-1 / 2} \mathbf{K} \mathbf{M}^{-1 / 2}$ 
$\tilde{\mathbf{K}}=\left|\begin{array}{cc}\frac{2 k}{m} & \frac{-k}{m} \\ \frac{-k}{m} & \frac{k}{m}\end{array}\right|$

Passo 3 - Determinação dos autovalores $\lambda_{j}=w_{j}^{2}$ e autovetores $\tilde{\mathbf{V}}_{j}$ de $\tilde{\mathbf{K}}$

$\operatorname{det}(\tilde{\mathbf{K}}-\mathbf{I} \lambda)=\mathbf{0}$

$\left|\begin{array}{cc}\frac{2 k}{m}-\lambda & \frac{-k}{m} \\ \frac{-k}{m} & \frac{k}{m}-\lambda\end{array}\right|=\mathbf{0}$

que leva aos dois autovalores

$\lambda_{1}=\frac{(3+\sqrt{5}) k}{2 m}$

$\lambda_{2}=\frac{(3-\sqrt{5}) k}{2 m}$

e às freqüências naturais

$$
\begin{aligned}
& w_{1}=\sqrt{\frac{(3+\sqrt{5}) k}{2 m}} \\
& w_{2}=\sqrt{\frac{(3-\sqrt{5}) k}{2 m}}
\end{aligned}
$$

Os autovetores são obtidos de

$(\tilde{\mathbf{K}}-\mathbf{I} \lambda) \mathbf{V}=\mathbf{0}$

com a condição de normalização do autovetor $\mathbf{V}_{j}$

$\left|\mathbf{v}_{1}\right|^{2}+\left|\mathbf{v}_{2}\right|^{2}=1$

Para o autovalor

$\lambda_{1}=\frac{(3+\sqrt{5}) k}{2 m}$

obtém-se 
$\tilde{\mathbf{V}}_{1}=\frac{k}{m}\left|\sqrt{\sqrt{\frac{5+\sqrt{5}}{10}}}\right|=\frac{k}{m}\left|\begin{array}{l}0,850650 \\ 0,525731\end{array}\right|$

Para o autovalor

$\lambda_{1}=\frac{(3-\sqrt{5}) k}{2 m}$

obtém-se

$\tilde{\mathbf{V}}_{2}=\frac{k}{m}\left|\sqrt{\frac{5-\sqrt{5}}{10}}\right|=\frac{k}{\frac{5+\sqrt{5}}{10}}\left|\begin{array}{l}0,525731 \\ 0,850650\end{array}\right|$

A Matriz Modal P será

$\mathbf{P}=\frac{k}{m}\left|\begin{array}{ll}0,850650 & 0,525731 \\ 0,525731 & 0,850650\end{array}\right|$

e a Matriz Espectral $\Lambda$ de $\tilde{\mathbf{K}}$ será

$$
\Lambda=\left|\begin{array}{cc}
\sqrt{\frac{(3+\sqrt{5}) k}{2 m}} & 0 \\
0 & \sqrt{\frac{(3-\sqrt{5}) k}{2 m}}
\end{array}\right|
$$

Assim as equações desacopladas, em coordenadas normais serão

$$
\mathbf{I} \mathbf{R}(t)+\Lambda \mathbf{R}(t)=\mathbf{0}
$$

$$
\left|\begin{array}{cc|}
1 & 0 \\
0 & 1|| \ddot{r}_{1}(t) \\
\ddot{r}_{2}(t)
\end{array}\right|+\left|\begin{array}{cc}
\frac{(3+\sqrt{5}) k}{2 m} & 0 \\
0 & \frac{(3-\sqrt{5}) k}{2 m}
\end{array}\right|\left|\begin{array}{c}
r_{1}(t) \\
r_{2}(t)
\end{array}\right|=\mathbf{0}
$$

Passo 4 - Cálculo das matrizes de transformação $\mathbf{S}^{-1}$ e $\mathbf{S}$

\section{Como}

$\mathbf{S}=\mathbf{M}^{-1 / 2} \mathbf{P}$

obtém-se 
$\mathbf{S}=\frac{k}{m \sqrt{m}}\left|\begin{array}{ll}0,850650 & 0,525731 \\ 0,525731 & 0,850650\end{array}\right|$

e, como

$\mathbf{S}^{-1}=\mathbf{P}^{T} \mathbf{M}^{1 / 2}$

obtém-se

$\mathbf{S}^{-1}=\frac{m \sqrt{m}}{k}\left|\begin{array}{ll}0,850650 & 0,525731 \\ 0,525731 & 0,850650\end{array}\right|$

Passo 5 - Determinação das condições iniciais nodais em coordenadas normais

$\mathbf{R}(0)=\mathbf{S}^{-1} \mathbf{X}(0)$

$\dot{\mathbf{R}}(0)=\mathbf{S}^{-1} \dot{\mathbf{X}}(0)$

sabendo-se que em coordenadas físicas

$$
\begin{aligned}
& \mathbf{X}(0)=\left|\begin{array}{l}
1 \\
0
\end{array}\right| m \\
& \dot{\mathbf{X}}(0)=\left|\begin{array}{l}
0 \\
0
\end{array}\right|
\end{aligned}
$$

Logo

$\mathbf{R}(0)=\frac{m \sqrt{m}}{k}\left|\begin{array}{l}0,850650 \\ 0,525731\end{array}\right|$

e

$\dot{\mathbf{R}}(0)=\mathbf{0}$

Passo 6 - Determinação das soluções desacopladas $\mathbf{R}(\mathrm{t})$

$$
\begin{aligned}
& r_{j}(t)=A_{j} \operatorname{sen}\left(w_{j} t+\phi_{j}\right) \\
& r_{1}(t)=\frac{m \sqrt{m}}{k} 0,850650 \times \operatorname{sen}\left(\sqrt{\frac{(3+\sqrt{5}) k}{2 m}} t+\frac{\pi}{2}\right)=\frac{m \sqrt{m}}{k} 0,850650 \times \cos 1,618033 t \sqrt{\frac{k}{m}} \\
& r_{j}(t)=\frac{m \sqrt{m}}{k} 0,525731 \times \cos 0,618037 t \sqrt{\frac{k}{m}}
\end{aligned}
$$


Passo 7 - Determinação das soluções em coordenadas físicas $\mathbf{X}(\mathrm{t})$

$$
\begin{aligned}
& \mathbf{X}(t)=\mathbf{M}^{-1 / 2} \mathbf{P R}(t)=\mathbf{S R}(t) \\
& \mathbf{X}(t)=\left|\begin{array}{l}
0,723606 \times \cos 1,618033 t \sqrt{\frac{k}{m}}+0,276393 \times \cos 0,618037 t \sqrt{\frac{k}{m}} \\
0,447273 \times \cos 1,618033 t \sqrt{\frac{k}{m}}+0,447213 \times \cos 0,618037 t \sqrt{\frac{k}{m}}
\end{array}\right|
\end{aligned}
$$

\subsubsection{Modos de Vibração Degenerados}

Os modos de vibração degenerados, ou seja, que não se pode distinguir, ocorrem em sistemas de dois ou mais osciladores acoplados que apresentam simetria. E, cada um dos modos degenerados corresponde a uma oscilação em oposição de fase. Deve-se salientar que os autovetores são apenas um dos conjuntos, entre outros infinitos conjuntos, que satisfazem as condições do problema. Contudo, todos estes autovetores representam alguma forma de oscilação em oposição de fase. [8]

\subsubsection{Modos de Vibrações e Freqüências Naturais em Sistemas Contínuos}

\subsubsection{Sistemas Contínuos Regulares}

A análise dinâmica de vibrações em sistemas contínuos que apresentam seção reta transversal regular ou, em alguns casos, variável, conduz a equação de onda [10].

$\frac{\partial^{2} w}{\partial t^{2}}=c^{2} \frac{\partial^{2} w}{\partial x^{2}}$

sendo $c$ a velocidade de propagação da onda no sistema em estudo.

O método usado para resolver a equação de onda é denominado separação de variáveis, e para que possa ser utilizado assumimos que o deslocamento $w(x, t)$ possa ser escrito como um produto de duas funções, uma dependente exclusivamente da ordenada $x$, e a outra exclusivamente do tempo $t$, ou seja,

$$
w(x, t)=X(x) T(t)
$$

Como a equação de onda é linear, qualquer combinação de soluções também é uma solução e, por isso, a solução geral pode ser dada por

$$
w(x, t)=\sum_{n=1}^{\infty} w_{n}(x, t)=\sum_{n=1}^{\infty} \operatorname{sen}\left(\lambda_{n} x\right)\left[A_{n} \operatorname{sen}\left(\lambda_{n} c t\right)+B_{n} \cos \left(\lambda_{n} c t\right)\right]
$$


onde $c$ é a velocidade de propagação da onda no sistema em estudo, $\lambda_{n}$ as suas freqüências naturais, e $A_{n}$ e $B_{n}$ são constantes determinadas pelas condições iniciais do problema $w(x, 0)=w_{0}(x)$

e

$\frac{\partial w}{\partial t}(x, 0)=v_{0 x}$

a partir das expressões

$B_{n}=\frac{2}{L} \int_{0}^{L} w_{0}(x) \operatorname{sen}\left(\frac{n \pi}{L} x\right) d x$

e

$A_{n}=\frac{2}{L \lambda_{m} c} \int_{0}^{L} v_{0}(x) \operatorname{sen}\left(\frac{n \pi}{L}\right) x d x$

para $m=1,2, \ldots \ldots$

O Tabela 4.1 sintetiza informações que fazem parte da análise dinâmica de quatro sistemas contínuos regulares. Entre estas informações estão a equação de onda, a velocidade de propagação $c$, e as condições de contorno usuais. 
Tabela 4.1 - Parâmetros fazem parte da análise dinâmica de quatro sistemas contínuos regulares.

\begin{tabular}{|c|c|c|c|c|}
\hline $\begin{array}{l}\text { Sistema } \\
\text { Oscilante }\end{array}$ & Corda & $\begin{array}{l}\text { Barra } \\
\text { Vibração } \\
\text { Longitudinal }\end{array}$ & $\begin{array}{l}\text { Barra } \\
\text { Vibração } \\
\text { Torcional }\end{array}$ & $\begin{array}{l}\text { Viga } \\
\text { Flexão }\end{array}$ \\
\hline $\begin{array}{l}\text { Equação de } \\
\text { Onda }\end{array}$ & $\frac{\partial^{2} w}{\partial t^{2}}=c^{2} \frac{\partial^{2} w}{\partial x^{2}}$ & $\frac{\partial^{2} w}{\partial t^{2}}=c^{2} \frac{\partial^{2} w}{\partial x^{2}}$ & $\frac{\partial^{2} w}{\partial t^{2}}=c^{2} \frac{\partial^{2} w}{\partial x^{2}}$ & $\frac{\partial^{2} w}{\partial t^{2}}=c^{2} \frac{\partial^{4} w}{\partial x^{4}}$ \\
\hline $\begin{array}{l}\text { Velocidade } \\
\text { de } \\
\text { Propagação }\end{array}$ & $c=\sqrt{\frac{\tau}{\rho}}$ & $c=\sqrt{\frac{E}{\rho}}$ & $c=\sqrt{\frac{G \gamma}{\rho J}}$ & $c=\sqrt{\frac{E I}{\rho A}}$ \\
\hline $\begin{array}{l}\text { Posição } \\
\text { Inicial }\end{array}$ & $w(x, 0)=w_{0}(x)$ & $w(x, 0)=w_{0}(x)$ & $\theta(x, 0)=\theta_{0}(x)$ & $w(x, 0)=w_{0}(x)$ \\
\hline $\begin{array}{l}\text { Velocidade } \\
\text { Inicial }\end{array}$ & $\frac{\partial w(x, 0)}{\partial t}=v_{0}(x)$ & $\frac{\partial w(x, 0)}{\partial t}=v_{0}(x)$ & $\frac{\partial \theta(x, 0)}{\partial t}=\dot{\theta}_{0}(x)$ & $\frac{\partial w(x, 0)}{\partial t}=v_{0}(x)$ \\
\hline $\begin{array}{l}\text { Extremidades } \\
\text { Fixas nos } \\
\text { Extremos }\end{array}$ & $\begin{array}{l}w(0, t)=0 \\
w(L, t)=0\end{array}$ & $\begin{array}{l}w(0, t)=0 \\
w(L, t)=0\end{array}$ & $\theta(L, t)=0$ & $\begin{array}{l}w(L, t)=0 \\
\frac{\partial w(L, t)}{\partial x}=0\end{array}$ \\
\hline $\begin{array}{l}\text { Extremidade } \\
\text { Livre }\end{array}$ & & $\begin{array}{l}E A \frac{\partial w(L, t)}{\partial x}=0 \\
\text { (tensão em } \mathrm{x}= \\
\text { L é nula) }\end{array}$ & $\begin{array}{l}G \gamma \frac{\partial \theta(L, t)}{\partial x}=0 \\
\text { (torque em } \mathrm{x}= \\
\text { L é nulo) }\end{array}$ & $\begin{array}{l}M_{\text {fletor }}=E I \frac{\partial^{2} w(L, t)}{\partial x^{2}}=0 \\
Q_{\text {cort }}=\frac{\partial}{\partial x}\left[E I \frac{\partial^{2} w}{\partial x^{2}}\right]=0\end{array}$ \\
\hline $\begin{array}{l}\text { Extremidade } \\
\text { Presa a uma } \\
\text { Mola }\end{array}$ & & $\begin{array}{l}E A \frac{\partial w(L, t)}{\partial x}= \\
=k w(L, t)\end{array}$ & $\begin{array}{l}G \gamma \frac{\partial \theta(L, t)}{\partial x}= \\
=k \theta\end{array}$ & \\
\hline $\begin{array}{l}\text { Extremidade } \\
\text { Presa a uma } \\
\text { Massa }\end{array}$ & & $\begin{array}{l}E A \frac{\partial w(L, t)}{\partial x}= \\
=-m \frac{\partial^{2} w(L, t)}{\partial t^{2}}\end{array}$ & $\begin{array}{l}G \gamma \frac{\partial \theta(L, t)}{\partial x}= \\
=-J_{M} \frac{\partial^{2} \theta(L, t)}{\partial t^{2}}\end{array}$ & \\
\hline
\end{tabular}

A determinação das freqüências naturais $w_{n}$, é feita a partir de parâmetros que dependem das condições iniciais do sistema. 


\subsubsection{Sistemas Contínuos Quaisquer}

A análise dinâmica de vibrações em sistemas contínuos, pode também ser realizada por métodos numéricos. Em muitos casos esta é a única forma de se realizar tais análises.

\subsection{Método de Elementos Finitos (MEF)}

Este conteúdo foi elaborado a partir das seguintes referências [10] [11] [12] [13] e do conteúdo do tutorial do programa de MEF utilizado (ANSYS).

\subsubsection{Resumo da Teoria}

Os métodos clássicos permitem o cálculo da resposta exata dos deslocamentos, deformações e tensões na estrutura em todos os seus pontos, isto é, nos seus infinitos pontos, porém estas soluções são conhecidas somente para alguns casos [13]. Por vezes, na análise do comportamento de elementos ou sistemas mecânicos sujeitos a alguma ação externa, são obtidas as equações diferenciais e as condições de contorno que descrevem esta iteração. Mas, mesmo quando estas equações são obtidas, nem sempre é possível uma solução analítica. Nestes casos se recorre à utilização de métodos numéricos, que possibilitam obter uma solução aproximada para o problema, e que podem ser aplicados em caráter geral, independentemente da forma da estrutura e das condições de carregamento, em geral, dentro da precisão aceitável para o problema.

O método dos elementos finitos (MEF) é uma destas técnicas de análise numérica utilizadas para a obtenção de soluções aproximadas para vários tipos de problemas, tais como: análise de tensões, transferência de calor, escoamento de fluidos, análise dinâmica entre outros.

Em todas estas análises, através da modelagem por elementos finitos, tenta-se representar o comportamento do material por meio de relações que levem em conta as principais propriedades dos materiais e a sua resposta às excitações externas.

De uma maneira geral, uma análise pelo MEF consiste das seguintes etapas:

- Discretização do domínio em elementos (malha);

- Cálculo das incógnitas do problema;

- Visualização e interpretação dos resultados.

O procedimento de discretização reduz o número de incógnitas existentes num problema contínuo, cuja variável de campo (pressão, temperatura, deslocamento ou outra quantidade) possui infinitos valores, a um número finito de incógnitas. 

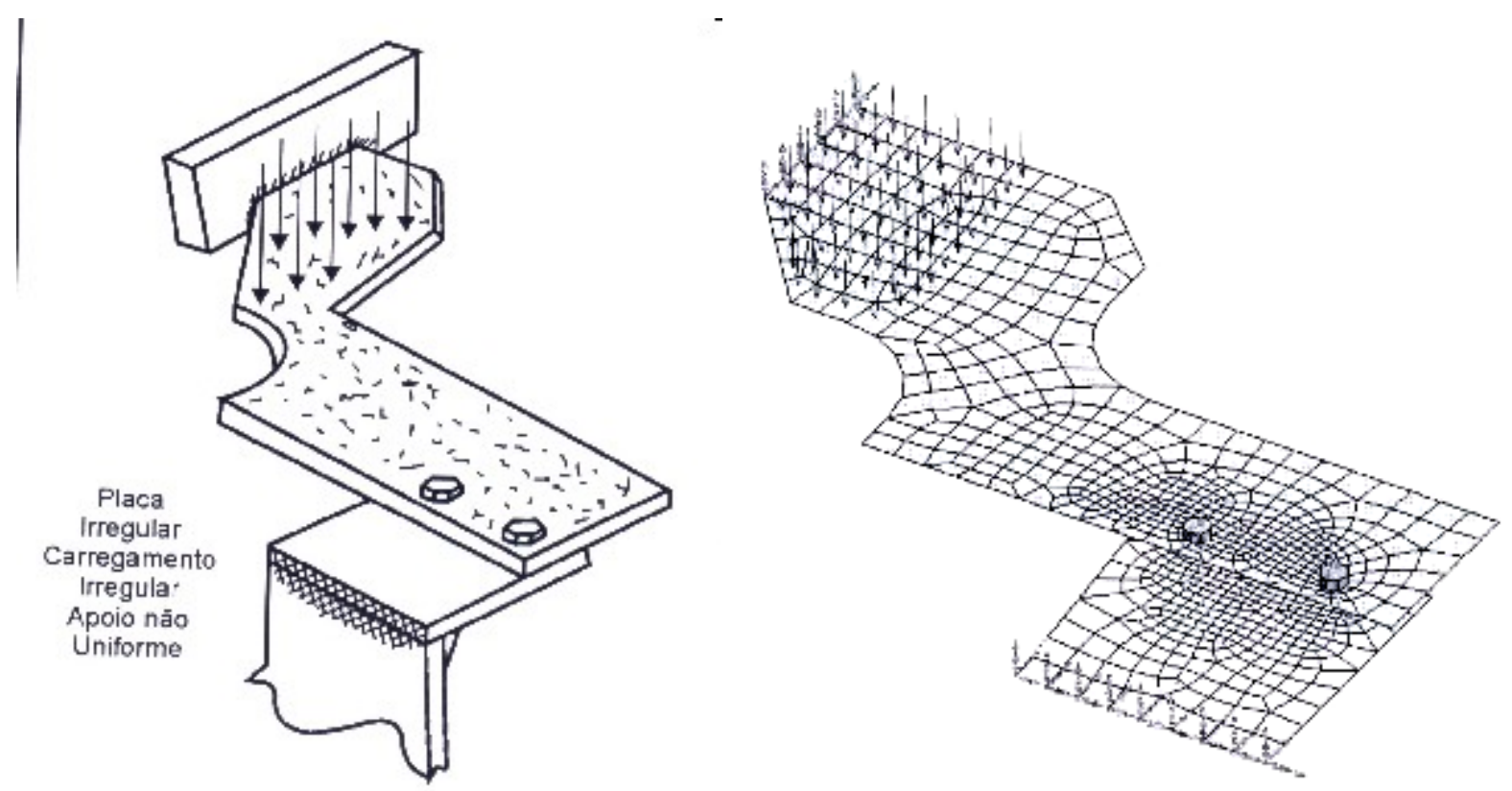

Figura 4.2 - (a) Estrutura de forma arbitrária. (b) Possível modelo de elementos finitos da estrutura [13].

A Figura 4.2(a) ilustra o conceito de discretização. Na figura é apresentada uma estrutura plana onde se quer determinar as regiões mais solicitadas do componente. A Figura 4.2(b) apresenta o modelo de elementos finitos obtido para a estrutura plana, que consiste de áreas planas quadrangulares interconectadas pelos pontos nodais ou nós. Além disso, pode-se verificar a partir das duas figuras que a força distribuída foi convertida em forças concentradas nos nós.

O número, tipo (i.e., linear, quadrático), forma (i.e., triangular, retangular), tamanho e densidade (i.e. refinamento da malha) dos elementos dependem de algumas considerações, tais como: discretizar, tão próximo quanto possível, o domínio exato do problema em questão com elementos apropriados; discretizar a região do domínio com elementos suficientemente pequenos, levando-se em consideração aspectos como precisão da solução, tempo computacional e custo. Geralmente, o refinamento da malha é requerido nos locais onde ocorre acentuada mudança: na geometria, nas condições de contorno, no carregamento, nas propriedades do material, ou em região de maior interesse para a solução [11].

Após a discretização do domínio em elementos, determina-se a matriz característica de cada elemento também denominada, nos problemas de mecânica estrutural, de matriz de rigidez. Essa matriz relaciona os deslocamentos nodais às forças nodais, conforme apresenta a seguinte equação: 
$\mathbf{K}_{\mathrm{e}} \mathbf{U}_{\mathrm{e}}=\mathbf{F}_{\mathrm{e}}$

onde:

$\mathbf{K}_{\mathrm{e}}$ é a matriz de rigidez do elemento;

$\mathbf{U}_{\mathrm{e}}$ é o vetor de deslocamentos nodais do elemento;

$\mathbf{F}_{\mathrm{e}}$ é o vetor de cargas do elemento.

Os deslocamentos dentro do elemento são interpolados dos deslocamentos nodais, conforme a seguinte equação:

$\mathbf{U}=\mathbf{N U}_{\mathbf{e}}$

onde:

$\mathbf{U}$ é o vetor de deslocamentos no interior do elemento;

$\mathbf{N}$ é a matriz das funções de interpolação;

$\mathbf{U}_{\mathrm{e}}$ é o vetor de deslocamentos nodais do elemento.

A especificação das propriedades do elemento, por intermédio da definição de sua matriz de rigidez é feita de forma aproximada. O procedimento de definição da matriz de rigidez de um elemento, por intermédio das funções de interpolação, define as propriedades do elemento com vistas a traduzir um dado comportamento físico, dentro das aproximações citadas.

A matriz de rigidez do elemento pode ser obtida de:

$\mathbf{K}_{\mathbf{e}}=\int_{V_{e}} \mathbf{B}^{T} \mathbf{D B} \mathrm{dV}$

onde:

$\mathbf{K}_{\mathrm{e}}$ é a matriz de rigidez do elemento;

B é a derivada da matriz das funções de interpolação $(\partial \mathrm{N})$;

$\mathbf{B}^{T}$ é a transposta da matriz $\mathbf{B}$;

D é a matriz tensão-deformação;

$V_{e}$ é o volume do elemento.

A matriz de rigidez e o vetor de cargas de cada elemento são usados para montar uma matriz de rigidez global e um vetor de cargas global para toda a estrutura, conforme a seguinte equação: 
$\mathbf{K}_{g} \mathbf{U}_{g}=\mathbf{F}_{g}$

onde:

$\mathbf{K}_{g}$ é a matriz de rigidez global;

$\mathbf{U}_{g}$ é o vetor de deslocamentos nodais global;

$\mathbf{F}_{g}$ é o vetor de cargas global.

O sistema de equações simultâneas é resolvido para os deslocamentos nodais. As demais variáveis (deformações, tensões, e outras) são calculadas a partir das relações deformaçãodeslocamento e tensão-deformação apresentadas na Equação (4.68) e na Equação (4.69) ou Equação (4.70) , respectivamente.

$\boldsymbol{\varepsilon}=\partial \mathbf{U}$

$\boldsymbol{\varepsilon}=\mathbf{C} \boldsymbol{\sigma}$

ou,

$\boldsymbol{\sigma}=\mathbf{D} \boldsymbol{\varepsilon}$

onde:

$\boldsymbol{\varepsilon}$ é o vetor de deformações;

U é o vetor de deslocamentos;

$\boldsymbol{\sigma}$ é o vetor de tensões;

D é a matriz tensão-deformação

C é a inversa da matriz tensão-deformação, ou seja $\mathbf{C}^{-1}=\mathbf{D}$

\subsubsection{Análise Modal Utilizando MEF}

Assim, o método de elementos finitos aproxima uma estrutura de duas formas distintas. A primeira aproximação feita na modelagem por elementos finitos consiste na divisão da estrutura em um número de partes menores e mais simples. Estas partes são chamadas de elementos finitos e o processo de divisão é chamado de discretização. Cada elemento é usualmente muito simples, como uma barra ou uma viga, o qual tem uma equação de movimento que pode ser facilmente resolvida ou aproximada. Cada elemento é limitado por pontos chamados nós, os quais o conecta aos outros elementos em sua vizinhança imediata. A coleção de elementos finitos e nós é chamada de malha de elementos finitos [10]. 
A equação de vibração de cada elemento finito individual é então determinada e resolvida. O que constitui a segunda forma de aproximação no método. As soluções das equações dos elementos são aproximadas por uma combinação linear de polinômios de baixa ordem. Cada uma destas soluções polinomiais individuais é tornada compatível com a solução adjacente nos nós comuns aos dois elementos (condições de continuidade). Estas soluções são reunidas em um procedimento, resultando em matrizes de massa e rigidez globais, as quais descrevem a vibração na estrutura com um todo. Este modelo global de massa e rigidez representa uma aproximação da estrutura que pode ser analisada e resolvida usando os métodos já analisados na Seção 4.1.6. O vetor $\mathbf{X}(t)$ dos deslocamentos, associado com a solução do modelo de elementos finitos global, corresponde ao movimento dos nós da malha de elementos finitos.

Um aspecto físico que pode ser salientado é que o MEF, ao tornar compatíveis as soluções polinomiais individuais e adjacentes dos nós comuns, respeitando assim as condições de continuidade entre os nós e elementos, utiliza os mesmos princípios e considerações feitas na análise de sistemas envolvendo osciladores harmônicos acoplados. A diferença é que no MEF os elementos são escolhidos entre uma variedade de tipos de elementos com diferentes números de nós e rigidez. Esta escolha deve levar em conta, como já foi mencionado, o domínio exato do problema em questão, a região da estrutura, a precisão da solução, o tempo computacional e o custo.

Os elementos tridimensionais são conectados por um conjunto de nós não coplanares. Eles são usados quando as tensões variam nas três dimensões [6]. Neste caso as deformações dos elementos pedem ser descritas apenas pelos movimentos translacionais $(x, y, z)$ de cada nó do elemento, como nos casos das simulações feitas neste estudo.

Desse modo, a modelagem de um sólido através de uma malha de elementos finitos, o torna semelhante a um conjunto numeroso de barras ou vigas acopladas.

Os softwares utilizam a formulação isoparamétrica em elementos finitos por simplificar e reduzir o volume de cálculo envolvido. Nesta a formulação da rigidez do elemento é desenvolvida essencialmente da mesma forma, exceto que um novo sistema de coordenadas é utilizado, o sistema de coordenadas naturais. Nesse novo sistema a localização de um ponto para o qual se deseja determinar o deslocamento não é referida ao tamanho físico dele, mas sim à sua posição relativa, isto é, se o ponto se encontra no meio do elemento, nas extremidades, etc. No sistema de coordenadas naturais, a idéia de posicionamento de um ponto é feita de forma admensional através de um parâmetro.[13]. Nos elementos isoparamétricos, a mesma função que interpola o campo de deslocamento entre os nós do elemento interpola também a geometria do elemento entre os nós, isto é, define a geometria do elemento. 
Genericamente a relação entre o comprimento $\partial x$ medido no sistema cartesiano e $\partial r$ medido no sistema de coordenadas naturais é efetuada pelo Jacobiano, ou seja

$\partial x=\mathrm{J} . \partial r$

Deste modo o operador Jacobiano pode ser considerado como um fator de escala que descreve a dimensão $\partial x$ associada à dimensão $\partial r$. Contudo, as expressões para o cálculo das deformações exigem que a matriz $\mathbf{J}$ possua inversa, não podendo ser singular, ou seja as deformações só podem ser calculadas se det $\mathbf{J} \neq \mathbf{0}$. Segundo [13] a matriz inversa do operador Jacobiano existe, se houver uma correspondência biunívoca entre o sistema natural de coordenadas e o sistema local de coordenadas do elemento. Quando o elemento finito é muito distorcido, essa relação única entre os sistemas de coordenadas não existe, acarretando singularidade do operador Jacobiano. Por exemplo, em um elemento na forma de quadrilátero, os ângulos interiores devem ser menores que $180^{\circ}$ para que o Jacobiano seja não singular. Os softwares de elementos finitos, que têm geradores de malha automáticos, utilizando uma geometria previamente definida como referência para gerar tais malhas, possuem critérios de avaliação que definem o grau de distorção do elemento finito gerado, verificando inclusive a situação extrema em que o ângulo entre dois lados do quadrilátero seja $180^{\circ}$.

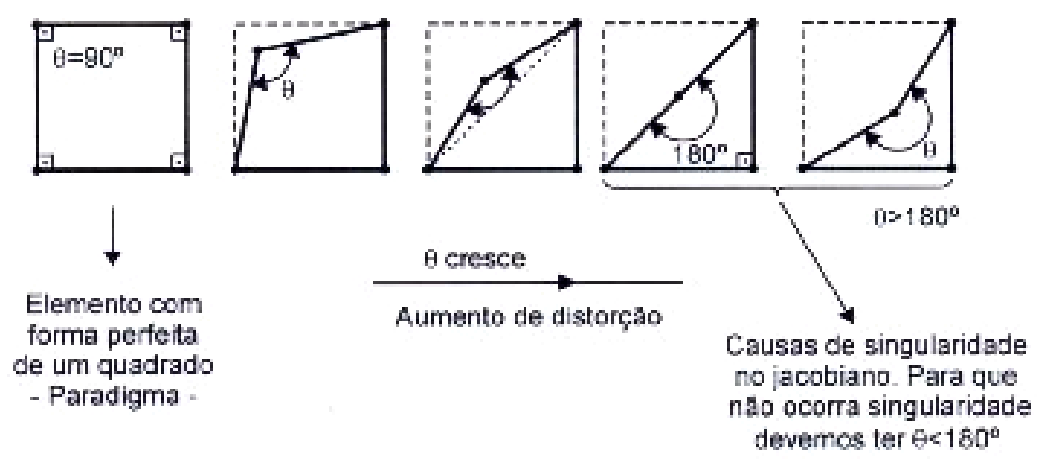

Figura 4.3: - Efeito do grau de distorção do elemento finito sobre a ocorrência de singularidade do operador Jacobiano [13]. 


\section{Capítulo 5}

\section{Estudo dos Casadores Mecânicos de}

\section{Impedância}

O detector de OG Mário Schenberg possui uma massa ressonante [14] [15] esférica de 1,15 toneladas, com 65 cm de diâmetro, que é feita de uma liga de cobre-alumínio [16] com 94\% Cu e 6\% Al. Esta grande massa esférica vibra quando uma OG passa através dela e o movimento produzido na sua superfície é monitorado por sensores de movimento, também chamados de transdutores, que transformam a oscilação mecânica em sinal elétrico [18] [19]. A distribuição destes transdutores na superfície da esfera é baseada no trabalho de Merkowitz e Johnson [28] [17], confirmado por Magalhães e colaboradores [22] [28]. O detector terá seis transdutores, localizados na superfície da esfera, como se estivessem no centro dos 6 pentágonos localizados na metade superior de um dodecaedro circunscrito à esfera.

Pela análise do sinal eletrônico destes sensores poderão ser obtidas a intensidade e a direção da onda gravitacional que está chegando [20] [21] [28]. O Schenberg terá freqüência ressonante em torno de 3,2 kHz com uma largura de banda próxima de $200 \mathrm{~Hz}$.

O grupo Brasileiro decidiu usar como sensores de movimento transdutores paramétricos de microondas, nos quais a cavidade supercondutora é bombeada com microondas ressonantes monocromáticas. Quando o tamanho da cavidade se modifica devido à vibração (uma das paredes da cavidade é conectada a esfera por um casador mecânico de impedância), ela cria duas bandas laterais no sinal de microondas que sai da cavidade. A amplitude destas bandas laterais é proporcional à vibração da esfera. Este tipo de transdutor permite o uso de vários formatos de casador de impedância. Um casador de impedância mecânico é um pequeno oscilador mecânico (ressonante, já que tem a mesma freqüência dos modos quadrupolares da esfera) que acopla os modos de vibração da esfera para o transdutor, fazendo também a amplificação mecânica da vibração da esfera. Esta amplificação varia com a raiz quadrada da razão entre a massa efetiva da esfera e a massa efetiva do oscilador (ressonador).

Um modelo completo do ruído para o detector Schenberg pode ser encontrado em [28] Espera-se que um transdutor com casador de impedância mecânico multimodo apresente mais vantagens que um transdutor de modo simples [23], sendo ele paramétrico, indutivo ou capacitivo. Por esta razão este tipo de casador de impedância é projetado para ser utilizado no Schenberg. 
Com o propósito de sugerir melhorias nos testes práticos do Schenberg, que devem começar em breve, procurou-se realizar simulações que permitissem estimar como mudanças nos parâmetros do casador de impedância mecânico influenciariam seu acoplamento com a antena.

Por simplicidade, nesta investigação optou-se por analisar casadores de impedância mecânicos de um modo. Foi feita uma série de estudos, utilizando o método de elementos finitos, de uma esfera conectada a ressonadores com formatos de "bico de passarinho” ("beak shape”) e “cogumelo” (“mushroom shape”), que operarão como casadores de impedância mecânicos entre a esfera e o transdutor, sendo ambos de um modo, mas com características de simetria diferentes. A procura por uma forma de casador de impedância mecânico que possa melhorar a performance do detector é descrita neste capítulo. Os resultados destes estudos são apresentados nas seções seguintes.

\subsection{Programas de MEF}

Foram analisados vários softwares que utilizam o "método de elementos finitos” (MEF), ou "finite element methods" (FEM), com o objetivo de avaliar as suas características de utilização, alguns com mais detalhe, outros sómente através de informações obtidas em consultas feitas.

Foi feita a opção em se utilizar o programa ANSYS 5.4, no qual se identificou a possibilidade de criação de macros e comandos dentro do próprio programa, além possuir ferramentas comuns aos outros programas deste tipo.

\subsection{Calibração do MEF Através da Simulação da Esfera do}

\section{Schenberg}

Após um período de estudo de MEF e do programa escolhido, quando se experimentou vários comandos, ferramentas, configurações e parâmetros relacionados com a geração da malha de elementos finitos, era necessário ser feita a calibragem do método para as análises pretendidas. Com este objetivo optou-se em utilizar uma esfera sólida de cobre-alumínio, similar à do Schenberg, que tem os modos quadrupolares em $3200 \mathrm{~Hz}$, para que os resultados obtidos pudessem ser comparados, verificando-se assim a adequação ou não das escolhas feitas na modelagem com o programa de MEF.

Desse modo, foi feita a simulação de uma esfera de 0,065 m de diâmetro, baseada na antena esférica Schenberg, que possuía as características mostradas na Tabela 5.1: 
Tabela 5.1: Propriedades do material da esfera e dos casadores de impedância

\begin{tabular}{lcl}
\hline \multicolumn{1}{c}{ Propriedade } & Designação & \multicolumn{1}{c}{ Valor } \\
\hline Material & & $94 \% \mathrm{Cu}-6 \% \mathrm{Al}$ \\
Massa específica & $\rho$ & $8077,5 \mathrm{~kg} / \mathrm{m}^{3}$ \\
Módulo de Young & $\mathrm{E}$ & $1,303 \times 10^{11} \mathrm{~Pa}$ \\
Coeficiente de Poisson & $v$ & 0,364 \\
\hline
\end{tabular}

Para a modelagem no ANSYS, além das características citadas, utilizou-se o elemento tetraédrico tridimensional "SOLID72”, os parâmetros de processamento utilizados pelo gerador automático da malha: $E S I Z E=0,060 \mathrm{~m}$ (“element size”, usado pelo programa como comprimento de referência do elemento) e $L V L=6$ (“smart level”, que define um grupo de parâmetros responsáveis pelo grau de refinamento da malha). A malha gerada para a esfera possuía 1960 nós e 9746 elementos tetraédricos tridimensionais “SOLID72”.

As freqüências encontradas para os cinco modos quadrupolares foram (em Hz) 3189,7 ; 3190,0 ; 3190,8 ; 3191,2 e 3192,1. Obtendo-se assim uma freqüência média de 3190,8 Hz, com desvio padrão de $1 \%$. Os modos torsionais da esfera foram encontrados em uma freqüência em torno de $2990 \mathrm{~Hz}$.

Apesar destes valores sugerirem que os modos não são perfeitamente degenerados, na prática pode-se assumir que eles são, e com uma freqüência igual a freqüência média de 3190,8 Hz, porque as pequenas diferenças nas freqüências são provavelmente devido às limitações da modelagem com MEF (imprecisões intrínsecas do método numérico).

Como mencionado na Seção 2.1.1, de acordo com a Teoria Geral da Relatividade espera-se que os modos quadrupolares da esfera sejam excitados pelo sinal da OG e, teoricamente, eles são exatamente degenerados [17].

O movimento resultante da simulação em uma das freqüências está ilustrado na Figura 5.1 . 


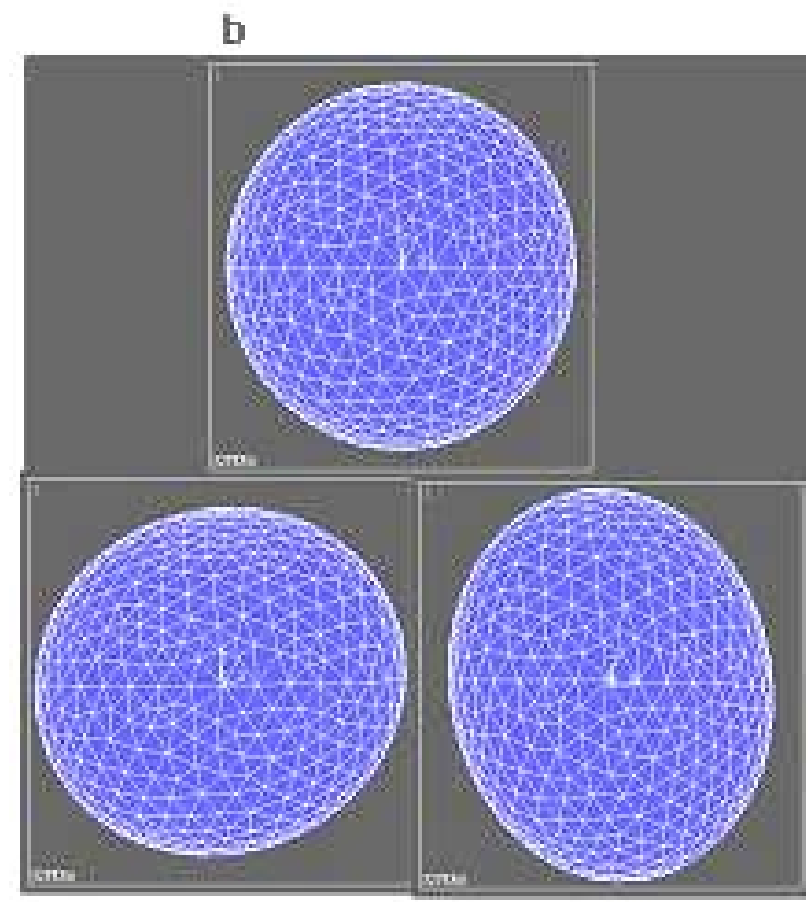

a

c

Figura 5.1: Instantâneos do movimento da esfera sómente à freqüência do modo quadrupolo de 3190,0 Hz . A esfera oscila de (b) para (a) para (b) para (c) e então move de volta, modificando o formato da esfera em repouso para este de um elipsóide.

A mudança na forma da esfera para um elipsóide está presente em todas as freqüências do modo quadrupolo, como previsto pela teoria [24].

Os modos da esfera do Schenberg estão publicados em [25] e eles foram medidos após a usinagem dos furos para alojar a suspensão e os futuro transdutores. Os valores encontrados foram (em Hz) 3172,5 ; 3183,0 ; 3222,9 e 3240,0 . Eles forneceram uma média de 3206,4 Hz .

Comparando-se estes valores com os obtidos na simulação feita aqui, é razoável se especular que a baixa freqüência média obtida nas simulações é devido ao fato de nenhum dos furos terem sido considerados na modelagem da esfera. Em um futuro trabalho estes furos serão incluídos. Todavia, as freqüências simuladas e as reais estão próximas uma da outra, em torno de $3200 \mathrm{~Hz}$, o que nos permite concluir que as escolhas e o método utilizado são adequados para a análise pretendida.

\subsection{Modelagem e Simulação com os Casadores de Impedância}

\subsubsection{Formatos Inicialmente Pesquisados}

Antes de se pesquisar os formatos de casadores de impedância que serão abordados nas seções seguintes, alguns formatos foram modelados e simulados. A intenção inicial era se obter, com um casador de impedância de apenas um modo, uma grande amplificação do movimento da 
superfície da esfera. Por isso o formato inicial tinha a forma de uma barra curva e tão longa quanto a sua calibração permitisse. Contudo foram abandonados por razões que serão abordadas a seguir.

- Mais de um dos modos de vibração do casador de impedância ocorria abaixo de $2900 \mathrm{~Hz}$ , ou seja, antes dos modos torsionais da esfera. Aparentemente havia um excesso de massa nestes casadores de impedância, o que conduziu a se tentar formatos mais leves, mas que tivessem uma boa rigidez à flexão, garantida pela forma do perfil de sua seção transversal;

- O primeiro modo normal de vibração do casador de impedância ainda ocorria em freqüência abaixo da freqüência de trabalho da antena, e a tentativa de redimensionar para calibrá-lo, ainda introduzia outros modos no casador de impedância (torsionais, por exemplo), os quais impediriam a calibração do transdutor paramétrico de microondas. A distribuição eqüitativa de massa ao longo da extensão destes formatos mantinha-os excessivamente pesados na extremidade em balanço. Também havia a necessidade de aumentar a rigidez na extremidade oposta, próxima união com a esfera. Estas constatações conduziram a se tentar formatos que apresentassem uma redução gradativa, mas significativa, em sua seção transversal, à medida que esta se afasta de sua base cilíndrica. Simultaneamente deveria se aumentar as dimensões nas proximidades do cilindro de união. Estas diretrizes conduziram aos formatos que serão discutidos nas próximas seções.

A Figura 5.2 mostra alguns destes formatos que foram anteriormente analisados. 

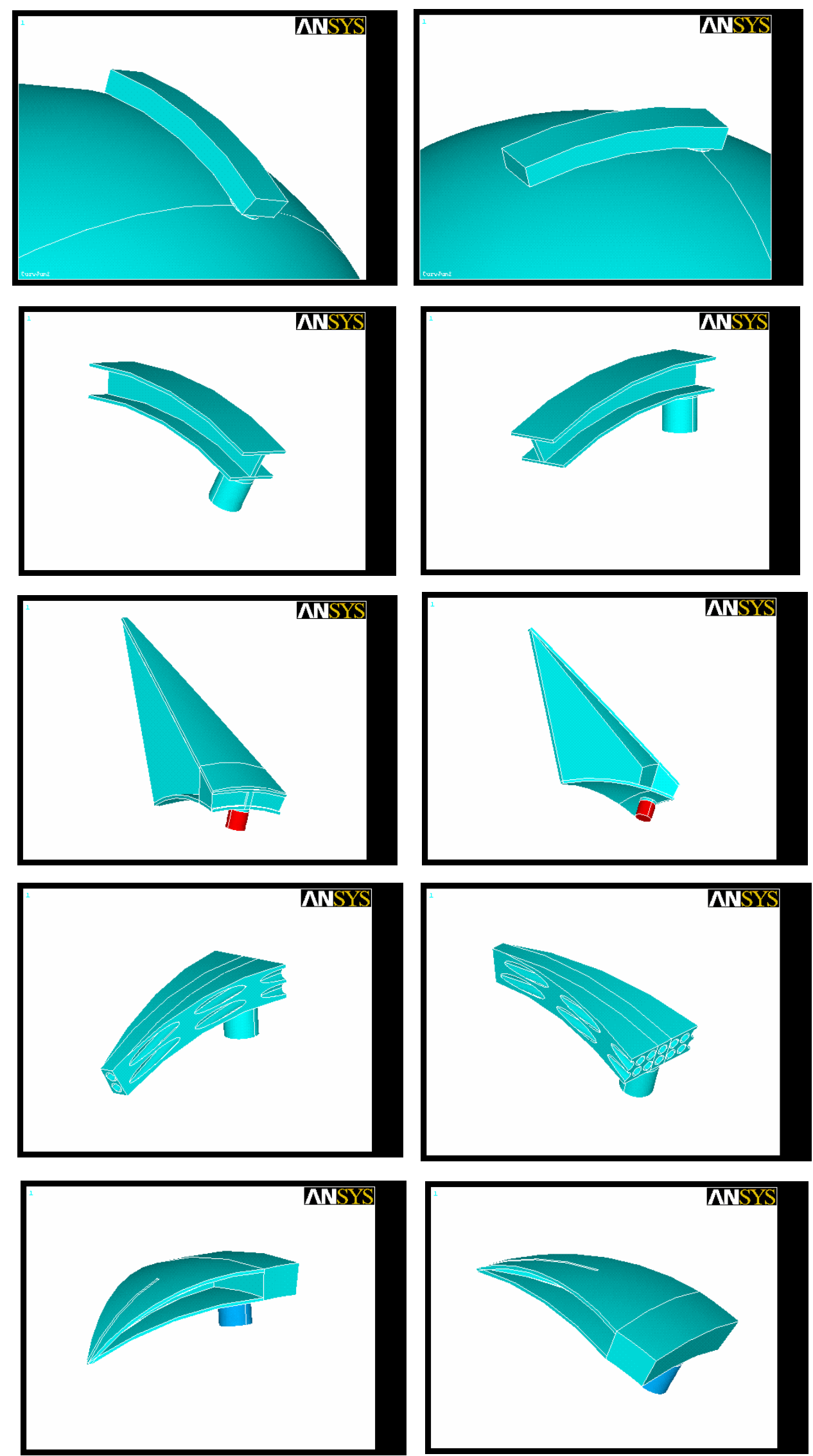

Figura 5.2: Alguns formatos de casadores de impedância testados no início desta pesquisa 


\subsubsection{Casadores de Impedância com Formato "Bico de Passarinho”}

\section{("beak shape")}

Uma vista em 3-D de um casador de impedância analisado neste trabalho pode ser vista na Figura 5.3 , onde a parte inferior do cilindro será conectada a um furo da esfera.
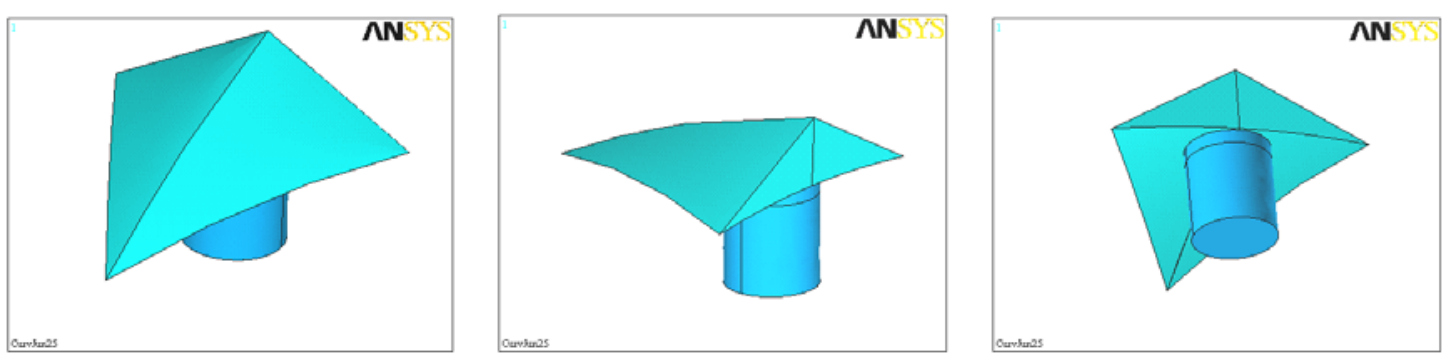

Figura 5.3 : Três vistas do casador de impedância mecânica. A vista mais a esquerda mostra em destaque a barra que vibra. A vista central e a da direita destacam o cilindro que conecta esta peça na esfera.

A outra extremidade está conectada a uma barra, a qual vibrará com uma freqüência ressonante com os modos quadrupolares da esfera. O cilindro e a barra formam uma peça maciça, sem descontinuidade.

Neste estudo se considera que uma cavidade de microondas aberta (como a utilizada em [29]) pode ser montada na extremidade da barra, a qual possui comprimento de aproximadamente 10 cm. Um desenho com as dimensões principais deste casador de impedância pode ser visto na Figura 5.4 . 

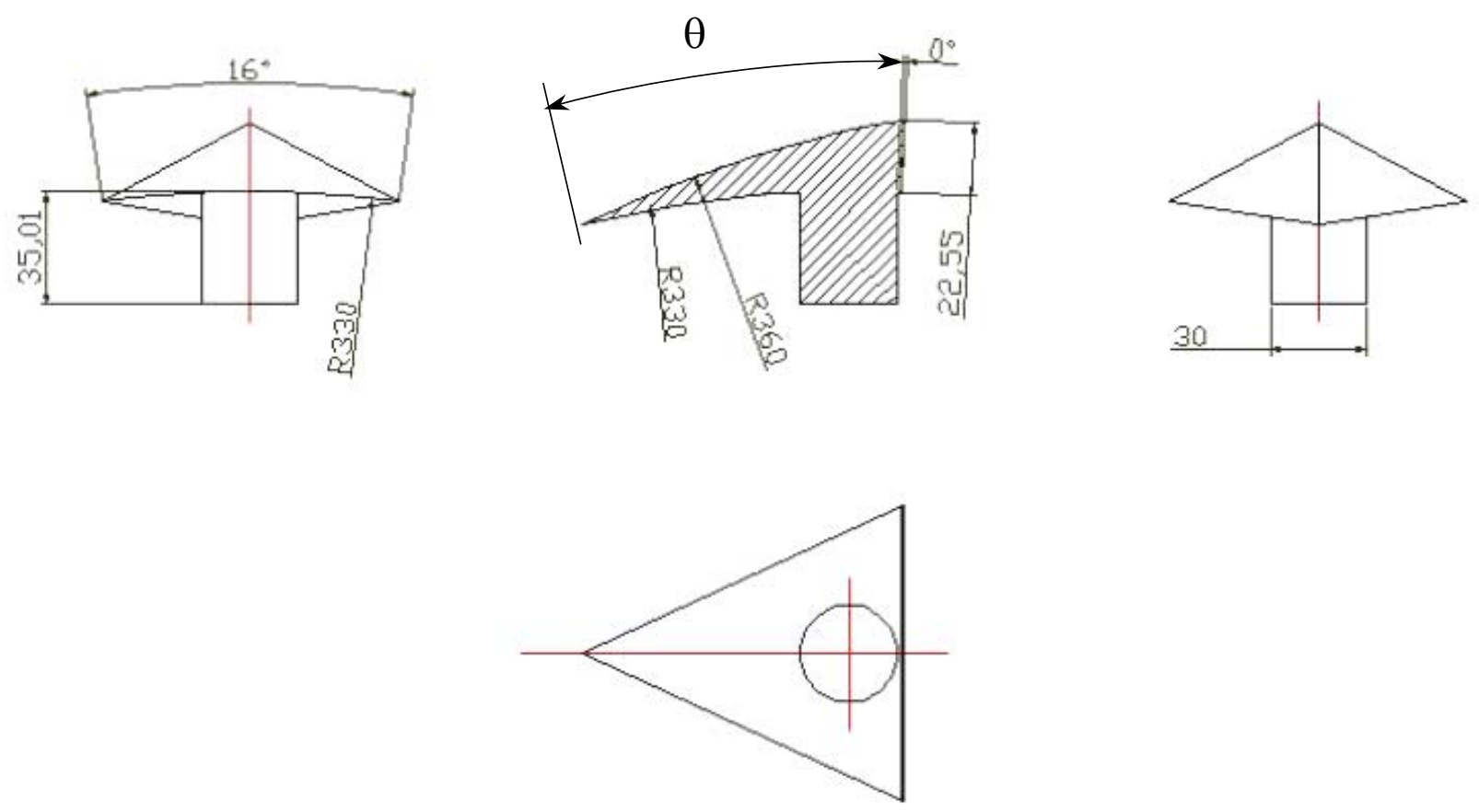

Figura 5.4: Desenho cotado do casador de impedância mecânico. O ângulo $\theta$ que define a sua extensão foi alterado para cada modelo utilizado nas simulações. Os ângulos e raios utilizam como referência o centro da esfera de $0,65 \mathrm{~m}$ com a qual os casadores de impedância serão unidos, com exceção do arco com raio de $360 \mathrm{~mm}$ que é construído entre pontos definidos pelas outras dimensões. A extremidade livre do cilindro da base será introduzida $25 \mathrm{~mm}$ no furo de fixação na esfera. As dimensões estão em mm.

Este formato de casador de impedância foi estudado na tentativa de otimizar o espaço interno da câmara experimental (criogênica), tendo-se em mente que é necessário medir as vibrações da esfera em locais próximos ao seu equador. Se este tipo de casador de impedância se mostrar aproveitável, ele pode ser montado próximo ao equador da esfera com a barra apontando para o seu pólo superior, permitindo o uso de uma esfera maior no mesmo espaço experimental.

\subsubsection{As Simulações da Esfera com um Casador de Impedância "Bico} de Passarinho"

Foram realizadas 13 simulações em que apenas um casador de impedância mecânico, com formato de "Bico de Passarinho", estava unido à esfera. Durante estas tentativas houve necessidade de se alterar a estratégia na escolha das dimensões do modelo que se testava devido 
às dificuldades que surgiram durante este processo de dimensionamento, o que é relatado nas subseções seguintes.

\subsubsection{Primeira Estratégia}

O objetivo inicial nesta fase foi calibrar o casador de impedância para que seu primeiro modo fosse ressonante com a freqüência de trabalho do detector. Isto foi tentado em cada dimensionamento e simulação realizados, alterando-se o ângulo $\theta$ (mostrado na Figura 5.4) que define o comprimento em balanço, e as dimensões da parte posterior do casador de impedância. Constatou-se que, além do ângulo $\theta$, poucas alterações poderiam ser implementadas, isto devido às limitações de espaço impostas pela câmara criogênica

Os movimentos ou oscilações do casador de impedância nos outros modos da esfera também foram analisados, pois poderiam influenciar na calibração do transdutor de microondas e no sinal eletrônico gerado.

Percebeu-se que a freqüência do casador de impedância era muito influenciada pelo ângulo $\theta$. Além disto, o pequeno espaço disponível dentro da câmara experimental obrigava o casador de impedância a ter dimensões reduzidas, o que fazia com que a banda de detecção ficasse muito estreita (em torno de $40 \mathrm{~Hz}$ ), e nenhuma maneira foi encontrada para melhorar esta largura de banda.

\subsubsection{Segunda Estratégia}

Tentou-se modelar o casador de impedância com exatamente a mesma freqüência de um dos modos quadrupolares da esfera. Inicialmente adotou-se o modo quadrupolar identificado como “charuto-panqueca”, que apesar de não ser excitado pela OG, pode ser facilmente identificado entre os demais modos. O procedimento seguido é descrito a seguir:

- Escolha de uma das freqüências obtidas para um dos modos quadrupolares, entre as obtidas na última simulação feita.

- Comparação deste valor de freqüência com a obtida para o casador de impedância.

- A partir da diferença entre estas freqüências estimar a alteração que deveria ser feita no ângulo $\theta$ utilizando processo de interpolação linear,

- Alteração do modelo, confecção da nova malha e realização de nova simulação,

- Avaliação dos resultados obtidos, e dependendo da necessidade repetir o procedimento desde o seu início. 
Nestas simulações, ao variar $\theta$ entre $17,3^{\circ}$ e $19,41^{\circ}$, o que é equivalente a se variar o comprimento do arco entre $100 \mathrm{~mm}$ e $110 \mathrm{~mm}$, a freqüência do primeiro modo do casador de impedância variou entre 3546,8 Hz e $2850,5 \mathrm{~Hz}$.

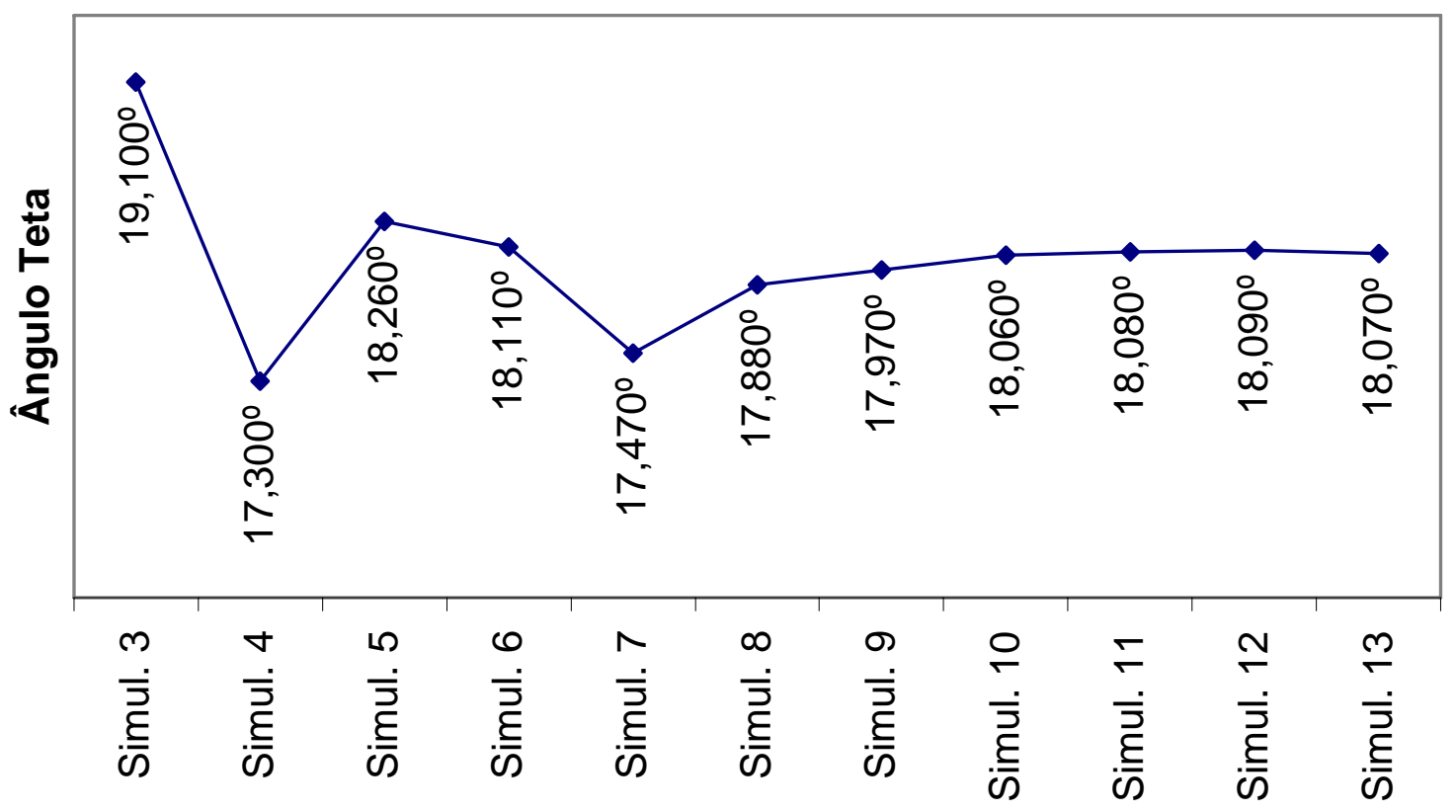

Figura 5.5: Gráfico dos valores obtidos para $\theta$ nas simulações feitas com um casador de impedância com formato "Bico de Passarinho" conectado à esfera.

Tabela 5.2: Freqüências obtidas nas simulações 1 a 5 da esfera com um casador de impedância "bico de passarinho".

\begin{tabular}{cccccc}
\hline & Simul. 1 & Simul. 2 & Simul. 3 & Simul. 4 & Simul. 5 \\
\hline Ângulo (graus) & & & $19,100^{\circ}$ & $17,300^{\circ}$ & $18,260^{\circ}$ \\
\hline Comprimento arco (mm) & 100,0000 & 110,0000 & 110,0000 & 100,0000 & 105,2000 \\
\hline Casador de Impedância & & 2452.1 & & & \\
Casador de Impedância & & 2489.9 & 2850.5 & & 2982.7 \\
Modo Torsional & 2987.1 & 2992.0 & 2982.3 & 2982.9 & 2986.9 \\
Modo Torsional & 2989.6 & 2995.9 & 2987.1 & 2987.0 & 2989.5 \\
Modo Torsional & 2991.1 & 2998.0 & 2989.4 & 2989.5 & 2991.3 \\
Modo Torsional & 2991.8 & 3004.9 & 2991.1 & 2991.3 & 2991.4 \\
Modo Torsional & 3183.4 & 3010.2 & 2991.6 & 2991.5 & 3148.3 \\
Casador de Impedância & & & & & 3183.3 \\
Modo Quadrupolar & 3186.8 & 3213.4 & 3181.5 & 3179.8 & 3183.5 \\
Modo Quadrupolar & 3187.4 & 3215.6 & 3183.4 & 3183.3 & 3185.1 \\
Modo Quadrupolar & 3188.8 & 3217.3 & 3183.4 & 3183.5 & 3185.9 \\
Modo Quadrupolar & 3189.5 & 3221.1 & 3185.7 & 3185.5 & 3192.0 \\
Modo Quadrupolar & & 3222.5 & 3185.9 & 3186.0 & 3546.8 \\
Casador de Impedância & 3897.9 & & & CuvJun25 & CuvJun26 \\
\hline Referência & CuvJun18 & CuvJun23 & CuvJun24 & \\
\hline
\end{tabular}


O programa de elementos finitos não foi capaz de fornecer a freqüência desejada. Ele apenas calculava estes modos em uma freqüência, ou superior, ou inferior às dos modos quadrupolares (quintupleto), o que pode ser observado na Tabela 5.2 nas simulações identificadas como Simulações 1, 2, 3, 4 e 5.

\subsubsection{Terceira Estratégia}

Diante da instabilidade verificada na estratégia anterior, em certo ponto foi feita uma escolha: adotar-se como freqüência de referência para o cálculo do ângulo $\theta$, a menor freqüência de um dos quintupletos obtidos até então. Com esta opção obtiveram-se as freqüências identificadas como Simulação 6 na Tabela 5.3 .

Foram obtidos os modos do casador de impedância acoplados com os quadrupolos da esfera nas freqüências de: 3155,0 ; 3183,4 ; 3183,5 ; 3185,2 ; 3185,9 e 3194,2 Hz , entretanto o casador de impedância também acoplou com o modo torsional a 2991,4 Hz . A Figura 5.6 exibe um quadro da animação do conjunto na freqüência de 2991,4 Hz (modo torsional da esfera), feita pelo programa de elementos finitos, em um instante em que apresentava pouca deformação. 
Tabela 5.3: Freqüências obtidas nas simulações 6 a 13 da esfera com um casador de impedância "bico de passarinho".

\begin{tabular}{|c|c|c|c|c|c|c|c|c|}
\hline & Simul. 6 & Simul. 7 & Simul. 8 & Simul. 9 & Simul. 10 & Simul. 11 & Simul. 12 & Simul. 13 \\
\hline Ângulo (graus) & $18,110^{\circ}$ & $17,470^{\circ}$ & $17,880^{\circ}$ & $17,970^{\circ}$ & $18,060^{\circ}$ & $18,080^{\circ}$ & $18,090^{\circ}$ & $18,070^{\circ}$ \\
\hline Comprimento arco (mm) & 104,3740 & 100,6310 & 103,0000 & 103,4990 & 104,0181 & 104,1333 & 104,1909 & 104,0757 \\
\hline \multicolumn{9}{|l|}{ Casador de Impedância } \\
\hline \multicolumn{9}{|l|}{ Casador de Impedância } \\
\hline Modo Torsional & 2982.7 & 2982.8 & 2982.7 & 2982.8 & 2982.7 & 2982.7 & 2982.8 & 2982.8 \\
\hline Modo Torsional & 2986.9 & 2987.4 & 2987.3 & 2987.4 & 2986.9 & 2986.9 & 2987.0 & 2986.9 \\
\hline Modo Torsional & 2989.5 & 2989.3 & 2989.2 & 2989.3 & 2989.5 & 2989.5 & 2989.5 & 2989.5 \\
\hline Modo Torsional & 2991.3 & 2991.0 & 2991.0 & 2991.0 & 2991.3 & 2991.3 & 2991.3 & 2991.3 \\
\hline Modo Torsional & 2991.4 & 2991.6 & 2991.6 & 2991.6 & 2991.5 & 2991.5 & 2991.5 & 2991.5 \\
\hline Casador de Impedância & 3155.0 & & & & & & 3144.2 & 3168.3 \\
\hline Modo Quadrupolar & 3183.4 & 3181.5 & 3179.9 & 3173.1 & 3167.5 & 3172.5 & 3183.4 & 3183.4 \\
\hline Modo Quadrupolar & 3183.5 & 3185.1 & 3185.1 & 3185.1 & 3183.3 & 3183.4 & 3183.5 & 3183.5 \\
\hline Modo Quadrupolar & 3185.2 & 3185.5 & 3185.5 & 3185.5 & 3183.5 & 3183.5 & 3185.0 & 3185.3 \\
\hline Modo Quadrupolar & 3185.9 & 3187.5 & 3187.5 & 3187.3 & 3185.3 & 3185.3 & 3185.9 & 3185.9 \\
\hline Modo Quadrupolar & 3194.2 & 3187.6 & 3187.6 & 3187.7 & 3185.9 & 3185.9 & 3190.1 & \\
\hline Casador de Impedância & & 3473.7 & 3302.4 & 3215.8 & 3206.4 & 3222.2 & & 3208.2 \\
\hline Referência & CuvJun27 & CuvJun28 & CuvJun29 & CuvJun30 & CuvJun31 & CuvJun32 & CuvJun33 & CuvJun34 \\
\hline
\end{tabular}

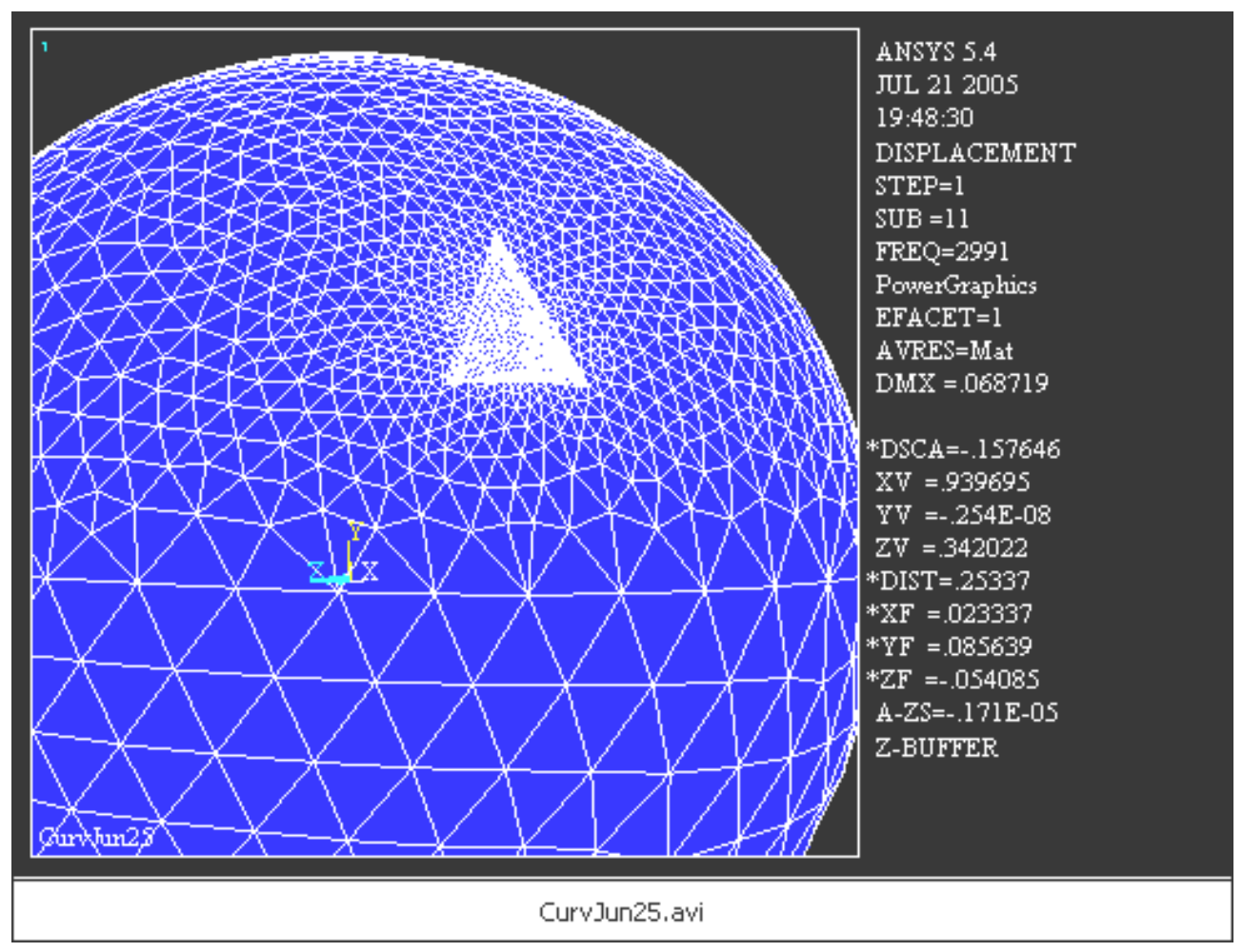

Figura 5.6: Um quadro da animação gerada pelo programa de MEF na freqüência de 2991,4 Hz (modo torsinal da esfera) apresentando pouca deformação. 
A Figura 5.7 mostra quadros deste modo de vibração, onde a oscilação do casador de impedância pode ser vista facilmente. O movimento torsional também pode ser visto na malha que parece distorcida de um quadro para outro. Este acoplamento é indesejável, pois ele cria outro modo no casador de impedância, que gera sinal eletrônico em uma freqüência diferente dos modos de interesse da esfera, além de dissipar energia da banda de freqüência de detecção. Como a banda de detecção (40 Hz) é pequena, quando comparada com a distância entre os modos torsionais e quadrupolares $(165 \mathrm{~Hz})$, o acoplamento teria de ser menor.

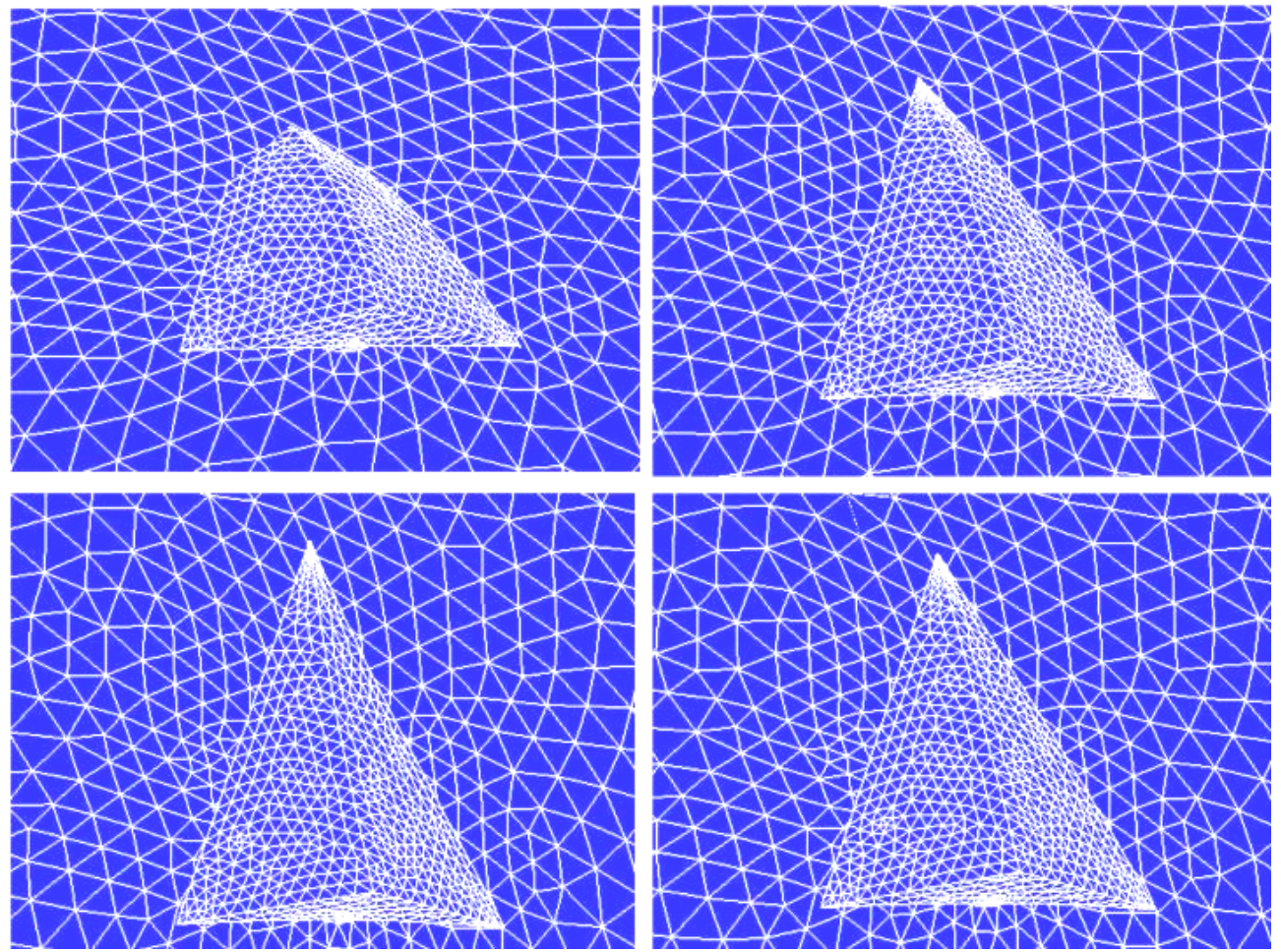

Figura 5.7: Quadros da animação do modo torsional em 2991,4 Hz .

Em outra tentativa de calibração do casador de impedância, em que foi utilizada uma freqüência um pouco maior que a ressonante, esta situação foi bastante melhorada. Neste caso, que é identificado como Simulação10 na Tabela 5.3, foram encontrados seis modos, que são nitidamente combinações do primeiro modo do casador de impedância e do modo quadrupolar da esfera, com as seguintes freqüências (em Hz): 3167,5 ; 3183,3 ; 3182,5 ; 3185,3 ; 3185,9 e 3206,4 . A amplificação no movimento do modo torsional foi muito pequena, neste caso.

$\mathrm{Na}$ última simulação feita com este formato de casador de impedância, identificada com Simulação 13 na Tabela 5.3 , também foram nitidamente observadas combinações do primeiro modo do casador de impedância e do modo quadrupolar da esfera, nas seguintes freqüências (em Hz): 3168,3 ; 3183,4 ; 3183,5; 3185,3 ; 3185,9 e 3208,2 . Neste caso o acoplamento do casador de impedância com a esfera “espalhou” menos estas freqüências. 


\subsubsection{Duas Simulações da Esfera com Três Casadores de Impedância “Bico de Passarinho”}

Em todas as simulações realizadas com apenas um casador de impedância conectado à esfera o casador de impedância acoplou com o modo torsional da esfera, o que variou de uma simulação para outra foi o quanto o movimento torsional foi amplificado. Mas não se sabia ainda a influencia que um sistema com mais simetria poderia produzir neste comportamento.

Foram selecionados dois dos casadores de impedância já utilizados nas simulações feitas: os casadores de impedância das Simulações 8 e 10 . Esta escolha considerou o comportamento dos casadores de impedância ao acoplarem com os modos torsionais da esfera e sua influência sobre o sinal eletrônico gerado pelo transdutor de microonda. Considerou-se também a freqüência em que foram calibrados e a largura de banda..

Considerando que a origem dos eixos de referência está localizada no centro da esfera, como é mostrado na Figura 5.8 , as posições dos casadores de impedância podem ser definidas de acordo com os ângulos $\phi$ (no plano $x y$, iniciando em $x$ e aumentando na direção positiva de y) e $\theta$ (no plano $y z$, iniciando em $y$ e aumentando na direção positiva de $z$ ). Os ângulos $\phi$ e $\theta$ utilizados na distribuição destes casadores de impedância na superfície da esfera estão relacionados na Tabela 5.4 .

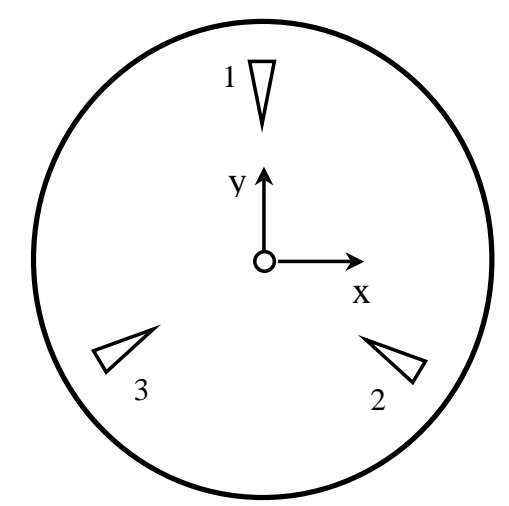

Figura 5.4: Posição dos três casadores de impedância utilizados na simulação relativa à superfície de uma esfera.

Tabela 5.4: Posição de cada casador de impedância na superfície da esfera.

\begin{tabular}{cccc}
\hline Casador de Impedância & 1 & 2 & 3 \\
\hline$(\phi, \theta)$ (graus) & $(90 ; 25,6000)$ & $(330 ; 25,6000)$ & $(210 ; 25,6000)$ \\
\hline
\end{tabular}


Após as duas simulações, o casador de impedância que apresentar melhor performance será escolhido e usado em uma simulação posterior em que seis destes casadores serão conectados à esfera, nas mesmas posições utilizadas pelo detector Schenberg.

Tabela 5.5: Freqüências obtidas nas duas simulações em que três casadores de impedância foram unidos à esfera.

\begin{tabular}{ccc}
\hline & Simul. 14 & Simul. 15 \\
\hline Ângulo (graus) & $17,880^{\circ}$ & $18,060^{\circ}$ \\
\hline Comprimento arco (mm) & 103 & 104,0181 \\
Modo Torsional & 2980.6 & 2980.5 \\
Modo Torsional & 2983.1 & 2983.2 \\
Modo Torsional & 2984.1 & 2984.2 \\
Modo Torsional & 2989.0 & 2989.3 \\
Modo Torsional & 2989.8 & 2989.7 \\
Modo Quadrupolar & 3176.8 & 3156.4 \\
Modo Quadrupolar & 3177.0 & 3160.6 \\
Modo Quadrupolar & 3182.8 & 3180.2 \\
Modo Quadrupolar & 3183.7 & 3183.6 \\
Modo Quadrupolar & 3183.8 & 3184.3 \\
\hline $1^{\text {o }}$ Casador de Impedância & 3280.5 & 3185.0 \\
$2^{\circ}$ Casador de Impedância & 3286.3 & 3201.6 \\
$3^{\circ}$ Casador de Impedância & 3305.1 & 3210.0 \\
\hline Modo Superior Esfera & 4377.9 & 4377.9 \\
\hline & TriCJ29 & TriCJ31 \\
\hline
\end{tabular}

A Tabela 5.5 apresenta as freqüências obtidas nas duas simulações com três casadores de impedância unidos à esfera. Em ambas as configurações os casadores de impedância acoplaram com o modo torsional na maioria das freqüências, contudo as amplificações observadas foram semelhantes entre si e comparáveis às obtidas nas simulações com apenas um casador de impedância unido à esfera. Avaliando-se os parâmetros mostrados na Tabela 5.6, observa-se que:

- As freqüências médias obtidas no modo torsional foram semelhantes (2985,32 e 2985,38 Hz),

- Os desvios padrão das freqüências no modo torsional também foram semelhantes $(3,94677$ e 3,99962 Hz),

- A freqüência média obtida para a freqüência no modo quadrupolar da Simulação 14 (3180,82 Hz) foi mais próxima da freqüência de trabalho de $3200 \mathrm{~Hz}$ (diferença de 19,18 Hz), do que a da Simulação 15 (3173,02 Hz, com diferença de 26,98 Hz),

- A diferença nos desvios padrão foi significativa (3,60 e 13,42), sendo o menor deles o calculado para a Simulação 14 . Pode-se considerar, com pouco erro, o valor médio das 
freqüências do modo quadrupolar desta simulação, como sendo a freqüência do modo quadrupolar degenerado.

Considerando o que foi discutido com relação aos modos de vibração e acoplamentos, da esfera e dos casadores de impedância, e que a média obtida para a freqüência no modo quadrupolar da Simulação 14 foi mais próxima da freqüência de trabalho, além de seu desvio padrão ter sido significativamente menor, o casador de impedância da Simução 14 foi escolhido para a próxima simulação utilizando seis deste casdores de impedância.

Tabela 5.6: Parâmetros calculados a partir das freqüências obtidas nas Simulações 14 e 15

\begin{tabular}{ccc}
\hline & Simul. 14 & Simul. 15 \\
\hline Média do modo torsional & 2985,32 & 2985,38 \\
\hline Desvio Padrão do modo torsional & 3,9467708 & 3,999625 \\
\hline Média do modo quadrupolar & & \\
\hline Dexvio Padrão do modo quadrupolar & 3180,82 & 3173,02 \\
\hline Diferença: 3200,00 Hz - MédiaModoQuadrupolar & 19,18 & 26,98 \\
\hline
\end{tabular}

\subsubsection{Simulação da Esfera com Seis Casadores de Impedância “Bico de} Passarinho"

Nesta simulação utilizou-se seis casadores de impedância do mesmo tipo utilizado na Simulação 14. Eles foram posicionados na superfície da esfera como se estivessem no centro dos seis pentágonos localizados na metade superior de um dodecaedro circunscrito à esfera, na mesma distribuição utilizada no detector Schenberg, e considerando o mesmo sistema de referência adotado na seção anterior (ver Figura 5.4). A atual distribuição é mostrada na Figura 5.5 .

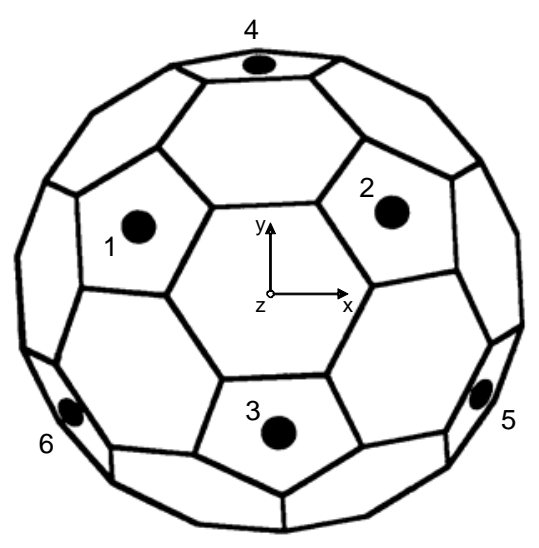

Figura 5.5: Posição dos seis casadores de impedância utilizados na simulação relativa à superfície de um icosaedro truncado. 
Os ângulos $\phi$ e $\theta$, utilizados para determinar a posição de cada casador de impedância na distribuição sobre a superfície da esfera, estão relacionados na Tabela 5.7 .

Tabela 5.7: Posições dos seis casadores de impedância simulados simultaneamente com a esfera. Os ângulos estão em graus.

\begin{tabular}{ccccccc}
\hline $\begin{array}{c}\text { Casador de } \\
\text { Impedância }\end{array}$ & 1 & 2 & 3 & 4 & 5 & 6 \\
\hline$(\phi, \theta)$ (graus) & $(150 ; 52,6225)$ & $(30 ; 52,6225)$ & $(270 ; 52,6225)$ & $(90 ; 10,8122)$ & $(330 ; 10,8122)$ & $(210 ; 10,8122)$ \\
\hline
\end{tabular}

A Figura 5.6 mostra a malha gerada pelo programa de elementos finitos para o sistema que está sendo analisado.

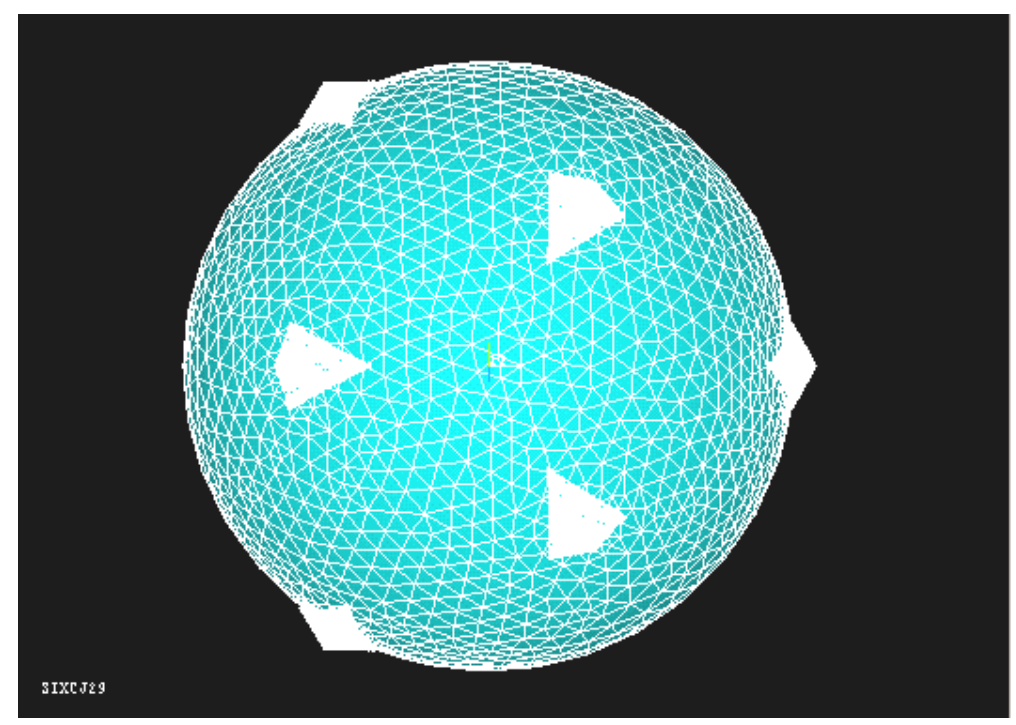

Figura 5.6: Vista superior com os seis casadores de impedância "Bico de Canário" unidos à esfera e a malha gerada pelo programa de elementos finitos.

Mais uma vez os casadores de impedância acoplaram com o modo torsional da esfera. Este acoplamento foi nítido nas freqüências de 2978,0 ; 2978,5 ; 2979,1 e 2979,9 Hz , sendo que em 2979,9 Hz foi observada a maior amplificação do movimento.

Foram encontrados onze modos, que são nitidamente combinações do primeiro modo do casador de impedância e do modo quadrupolar da esfera, com as seguintes freqüências (em Hz): 3162,8 ; 3163,3 ; 3164,1 ; 3166,6 ; 3167,2 ; 3225,7 ; 3233,3 ; 3243,6 ; 3247,2 ; 3250,7 e 3253,8 . Em todas as freqüências do modo quadrupolar observou-se pequena deformação da esfera. Em várias das freqüências os movimentos dos casadores de impedância apresentaram sincronismo em suas oscilações, algumas vezes dois a dois, outras vezes três a três, e em metade das freqüências alguns dos casadores de impedância oscilavam com uma amplitude nitidamente maior que os demais.

Era esperado [27] que o sistema esfera mais os seis casadores de impedância tivesse 11 modos formando dois quintupletos e um singleto. No modo individual (singleto) a esfera deveria permanecer em repouso enquanto os transdutores se movem. 
No caso em análise a distribuição das freqüências (em Hz) seria:

Primeiro quintupleto: 3162,8 ; 3163,3 ; 3164,1 ; 3166,6 ; 3167,2 ;

Singleto: 3225,7 ;

Segundo quintupleto: 3233,3 ; 3243,6 ; 3247,2 ; 3250,7 e 3253,8.

As freqüências do primeiro quintupleto podem ser consideradas degeneradas já que elas possuem pequeno desvio padrão de 1,9836 do valor médio de 3164,8 Hz .

Já as freqüências do segundo quintupleto possuem desvio padrão de 7,9219 do valor médio de 3245,72 Hz , não podendo ser consideradas degeneradas.

A Figura 5.7 mostra as amplitudes máximas do movimento dos casadores de impedância devido ao acoplamento com o modo torsional da esfera em uma freqüência de 2979,9 Hz. A Figura 5.8 mostra as amplitudes máximas do movimento em um dos quintupletos em uma freqüência de 3253,8 Hz.
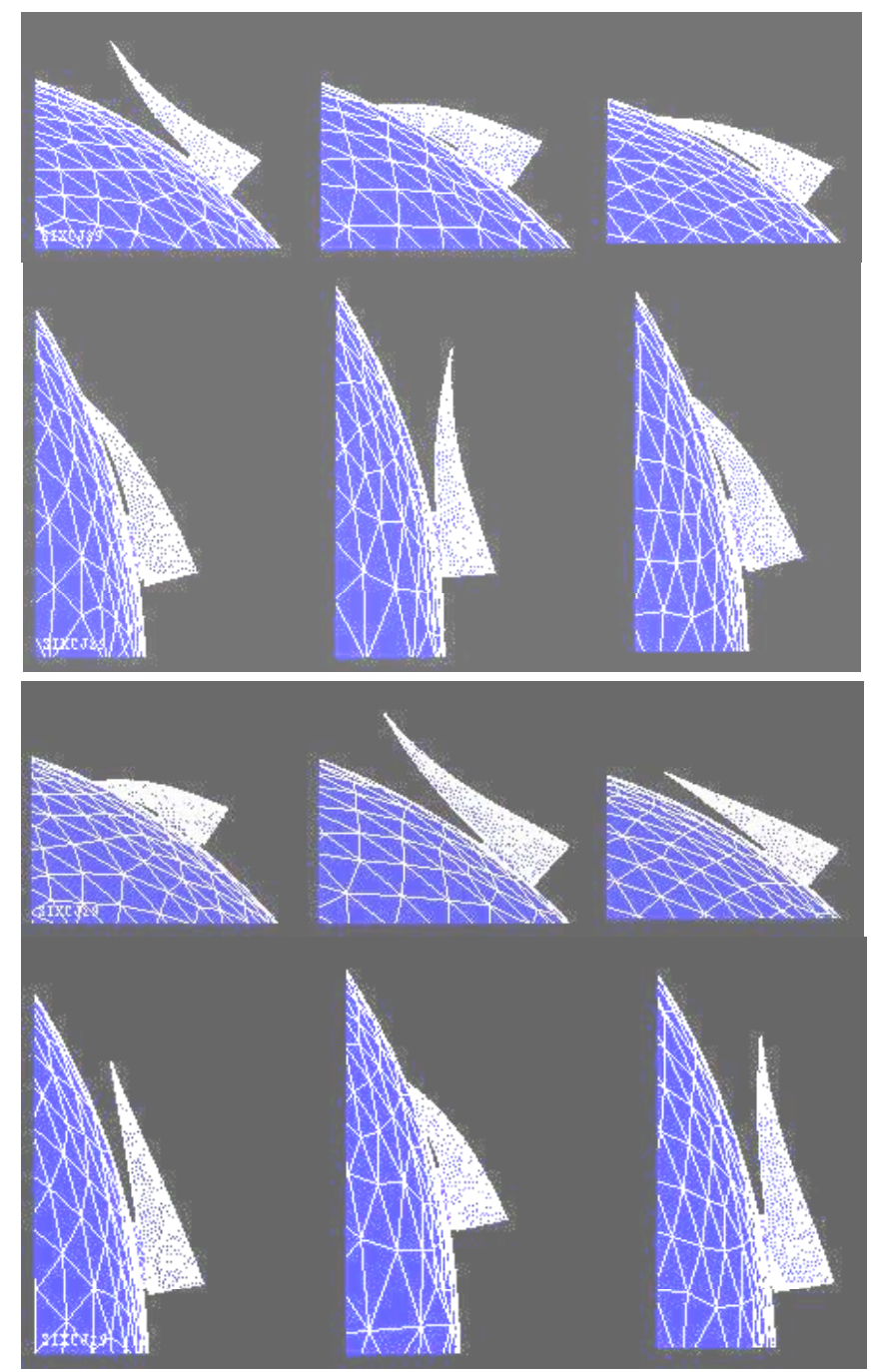

Figura 5.7: As figuras superior e inferior mostram as amplitudes máximas do movimento dos casadores de impedância, devido ao acoplamento com o modo torsional da esfera, em uma freqüência de 2979,9 Hz. O movimento ocorre entre estas amplitudes máximas. 

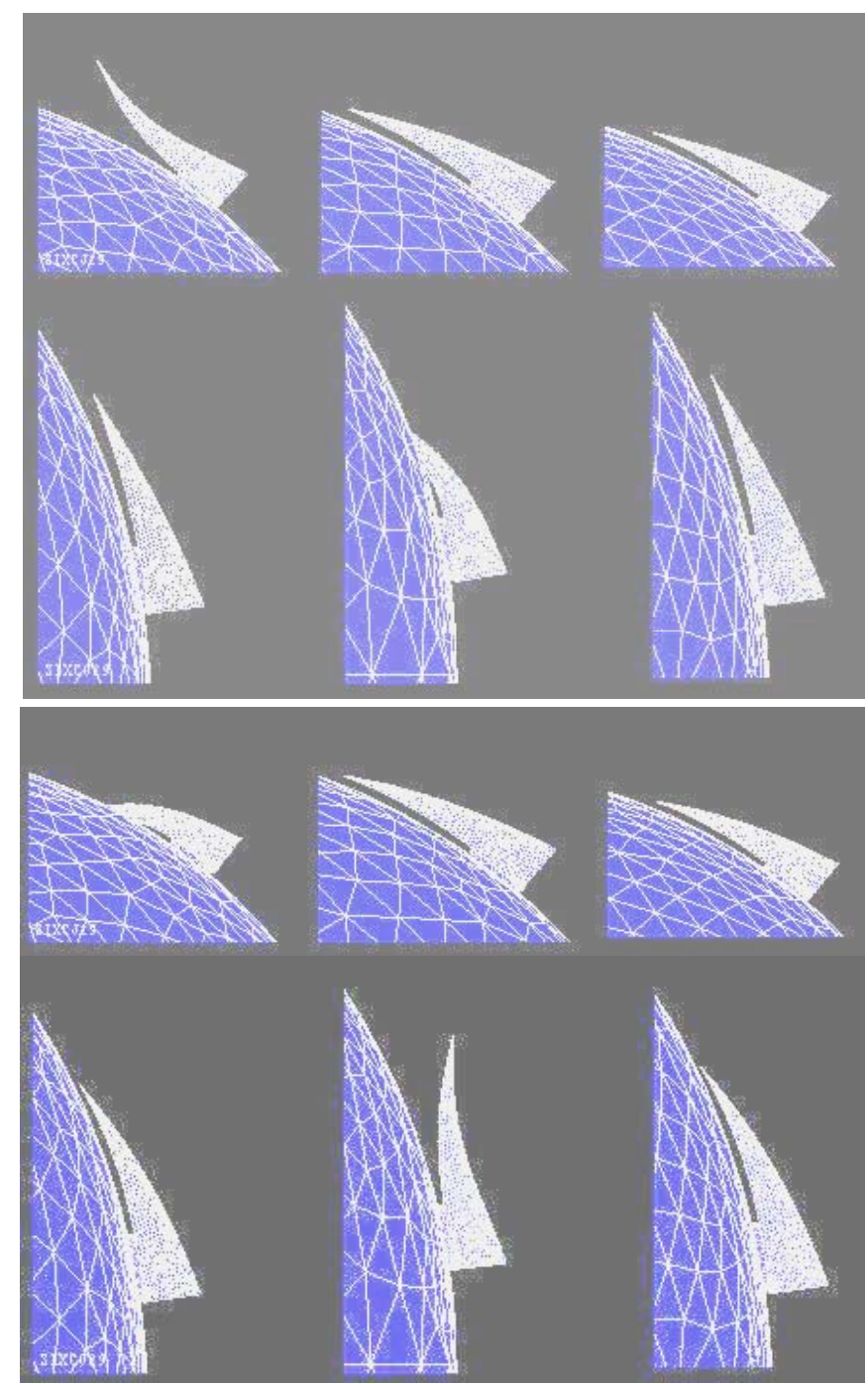

Figura 5.8: As figuras superior e inferior mostram as amplitudes máximas do movimento dos casadores de impedância em um dos modos quintupleto em uma freqüência de 3253,8 Hz. O movimento ocorre entre estas amplitudes máximas. Nos modos quintupleto a esfera e os casadores se movem, mas esperava-se que um casador se movesse mais que os outros. Este fato ocorreu em outras freqüências deste modo.

Através da análise destas simulações pode-se verificar que haveria acoplamento entre o modo vibracional principal dos casadores de impedância com os modos torsionais da esfera, isto na maioria das freqüências. Uma conseqüência deste fato é que as deformações decorrentes deste acoplamento gerariam um sinal eletrônico em uma freqüência diferente da de trabalho, não permitindo uma boa identificação dos modos quadrupolares da esfera através do sinal vindo dos transdutores durante a utilização da antena.

\subsubsection{As Simulações da Esfera com um Casador de Impedância com Formato "Cogumelo" ("mushroom shape")}

A escolha do casador de impedância com o formato de "Cogumelo”, que será estudado aqui, teve duas razões. Era importante que o tipo de casador de impedância escolhido resultasse em um 
modelo simples com o programa de elementos finitos, e que os parâmetros pudessem ser facilmente modificados.

Este formato consiste de um diafragma em forma de disco com um cilindro no centro que conecta o diafragma à esfera. Embora este não tenha o mesmo formato que o transdutor real utilizado no detector Schenberg, para a esfera ele é fisicamente similar, modelado por molas e massas [17].

Uma vez definido o formato do casador de impedância, determinaram-se as dimensões do diafragma e do cilindro central.

Por simplicidade, apenas um casador de impedância foi unido à esfera na primeira série de simulações. A intenção era sintonizar o casador de impedância na mesma freqüência dos modos quadrupolares da esfera, de modo que trabalhasse como um transdutor ressonante.

A estimativa inicial para as dimensões do casador de impedância mecânico foi baseada em um cálculo descrito no livro de Blevins [26], que considera o cogumelo conectado a uma massa infinita. Segundo esta fonte, para o formato de cogumelo a freqüência do movimento é dada pela fórmula:

$f_{i j}=\frac{\lambda_{i j}^{2} t}{4 \pi a^{2}}\left(\frac{E}{3 \rho\left(1-v^{2}\right)}\right)^{\frac{1}{2}}$

Os subíndices ij referem-se ao modo de interesse, que neste caso é 00 . A constante $\lambda_{00}$ depende da razão $b / a$, onde $b$ é o diâmetro do cilindro central e $a$ é o diâmetro do diafragma. Alguns valores de $\lambda_{00}{ }^{2}$ são mostrados na Tabela 5.8. A espessura do diafragma é dada por $t$, enquanto $E, \rho$ e $v$ foram definidos na Tabela 5.1 , na seção 5.2 .

Tabela 5.8: Valores da constante $\lambda_{00}{ }^{2}$ para o modo de interesse do casador de impedância [26].

\begin{tabular}{cc}
\hline$b / a$ & $\lambda_{0,0}{ }^{2}$ \\
\hline 0,1 & 4,23 \\
0,3 & 6,66 \\
0,5 & 13,06 \\
0,7 & 37,00 \\
\hline
\end{tabular}

Como tentativa inicial foram adotados $b=30 \mathrm{~mm}, a=100 \mathrm{~mm}$ e a freqüência $f_{00} \approx 3200 \mathrm{~Hz}$. $\mathrm{O}$ objetivo era determinar $\mathrm{t}$. As tentativas seguintes foram estimadas levando-se em conta as freqüências obtidas e o comportamento do casador de impedância. Com alguns ajustes este procedimento forneceu as dimensões apresentadas na Tabela 5.9. 
Tabela 5.9: Dimensões dos casadores de impedância testados em cada simulação. A ordem das simulações está indicada no topo da tabela. As freqüências se referem ao sistema esfera com um casador de impedância.

\begin{tabular}{lccccccc}
\hline \multicolumn{1}{c}{ Característica } & Variável & Simul. 1 & Simul. 2 & Simul. 3 & Simul. 4 & Simul. 5 & Simul. 6 \\
\hline Diâmetro do diafragma (mm) & $a$ & 100 & 100 & 100 & 100 & 50 & 50 \\
Diâmetro do cilindro central (mm) & $b$ & 30 & 30 & 30 & 10 & 10 & 10 \\
Espessura do diafragma (mm) & $t$ & 6,1 & 5,9 & 5,2 & 9,5 & 1,9 & 1,6 \\
Freqüência média do quintupleto (Hz) & & 3182,5 & 3180,8 & 3186,8 & 3186,0 & 3185,8 & 3182,1 \\
Freqüência do singleto (Hz) & & 3328,6 & 3284,5 & 3035,2 & 3388,9 & 3590,7 & 3199,9 \\
\hline
\end{tabular}

A Figura 5.9 mostra os cincos primeiros modelos de casadores de impedância simulados. Os desenhos estão em escala.

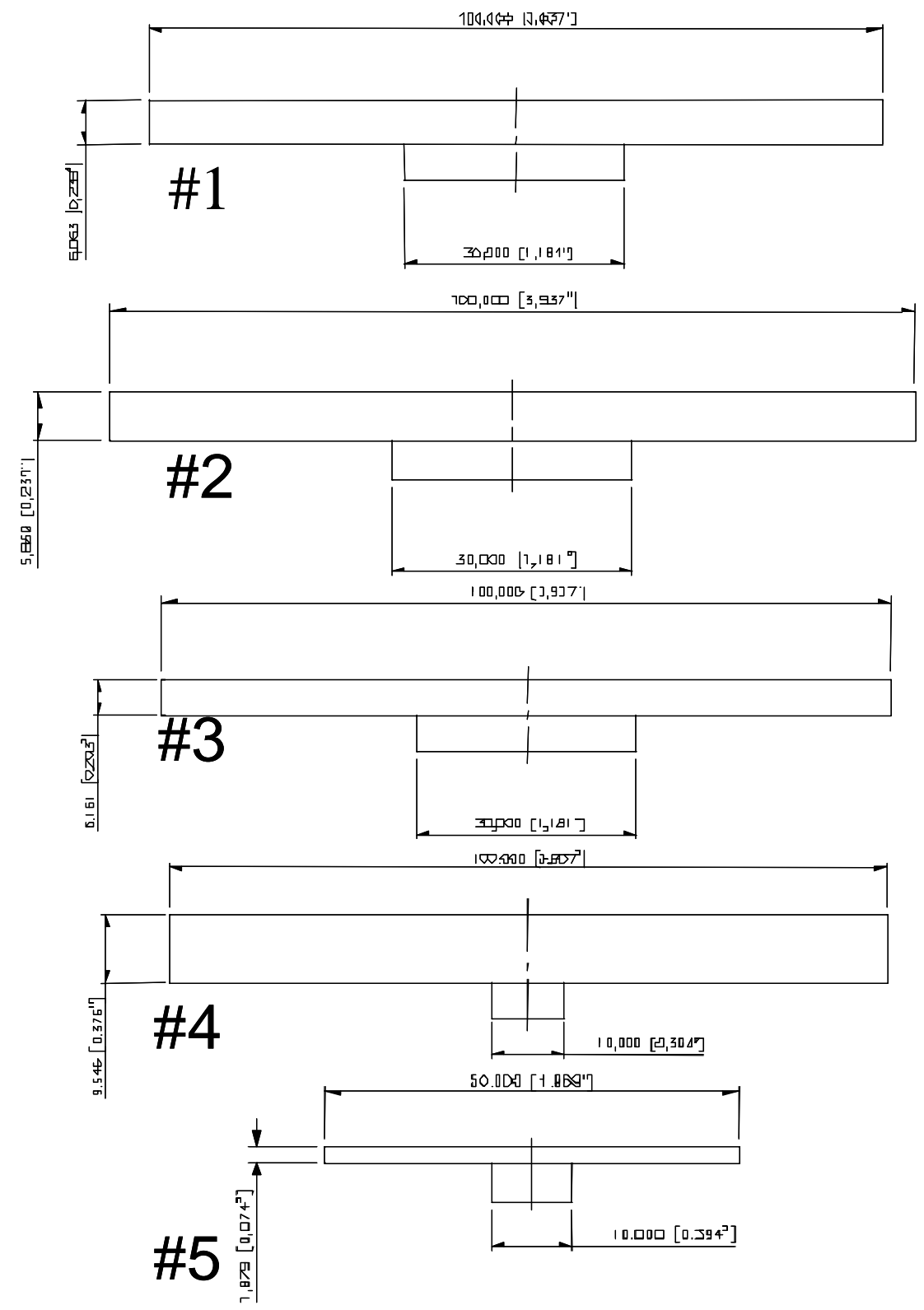

Fig5.9: Desenhos dos casadores de impedância utilizados nas Simulações de \#1 a \#5. Cotas em mm e polegadas. 


\subsubsection{As Primeiras Três Simulações}

As dimensões utilizadas para o casador de impedância para cada simulação realizada encontramse na Tabela 5.9 .

Como previsto pela teoria [27], o sistema esfera mais um casador de impedância produziu um total de seis modos. Cinco destes modos estão muito próximos em freqüência (pela teoria eles deveriam ser degenerados, formando um quintupleto), e o outro afastado (o singleto) tem uma freqüência diferente dos outros.

Os valores obtidos para estas freqüências são identificados como Simul. 1 na Tabela 5.10 , que mostra a média das freqüências do quintupleto, seu desvio padrão e a sua banda.

Tabela 5.10: Freqüências (em Hz) obtidas nas seis primeiras simulações da esfera unida a um casador de impedância. Também é mostrada a média das freqüências do quintupleto, seu desvio padrão e a sua banda.

\begin{tabular}{|c|c|c|c|c|c|c|c|}
\hline & Modos & Simul. 1 & Simul. 2 & Simul. 3 & Simul. 4 & Simul. 5 & Simul. 6 \\
\hline \multirow{5}{*}{ 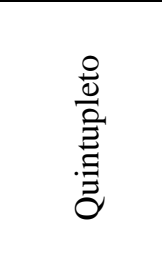 } & 1 & 3170,0 & 3164,7 & 3183,5 & 3180,9 & 3183,8 & 3174,7 \\
\hline & 2 & 3183,5 & 3183 & 3185,4 & 3183,7 & 3185,0 & 3183,0 \\
\hline & 3 & 3185,4 & 3184,8 & 3186,3 & 3186,6 & 3185,9 & 3183,8 \\
\hline & 4 & 3186,3 & 3185,5 & 3187,0 & 3186,6 & 3186,5 & 3184,1 \\
\hline & 5 & 3187,1 & 3186,2 & 3192,0 & 3192,1 & 3187,6 & 3184,8 \\
\hline Singleto & 6 & 3328,6 & 3284,5 & 3035,2 & 3388,9 & 3590,7 & 3199,9 \\
\hline \multicolumn{2}{|c|}{ Média do Quintupleto } & 3182,5 & 3180,8 & 3186,8 & 3186,0 & 3185,8 & 3182,1 \\
\hline \multicolumn{2}{|c|}{ Desv Padrão Quintup } & 7,1 & 9,1 & 3,2 & 4,2 & 1,4 & 4,2 \\
\hline \multicolumn{2}{|c|}{ Desv Pad \% } & $0,22 \%$ & $0,29 \%$ & $0,10 \%$ & $0,13 \%$ & $0,05 \%$ & $0,13 \%$ \\
\hline \multicolumn{2}{|l|}{ Banda } & 17,1 & 21,5 & 8,5 & 11,2 & 3,8 & 10,1 \\
\hline \multicolumn{2}{|l|}{ Banda \% } & $0,54 \%$ & $0,68 \%$ & $0,27 \%$ & $0,35 \%$ & $0,12 \%$ & $0,32 \%$ \\
\hline
\end{tabular}

Estes modos de freqüência estão dentro dos limites da largura de banda do detector Schenberg, como é pretendido.

O refinamento do projeto do casador de impedância foi feito a partir da inspeção do seu movimento, obtido da simulação feita e que pode ser observado na Figura 5.10 . Percebe-se que a forma como o diafragma oscila em cada modo não é muito uniforme. Este tipo de uniformidade é uma propriedade desejável quando se tem que calibrar mais de um transdutor ao mesmo tempo, como ocorrerá quando o detector Schenberg estiver em plena operação. Esta propriedade também favorece a geração de um sinal forte em transdutores capacitivos ou indutivos. 

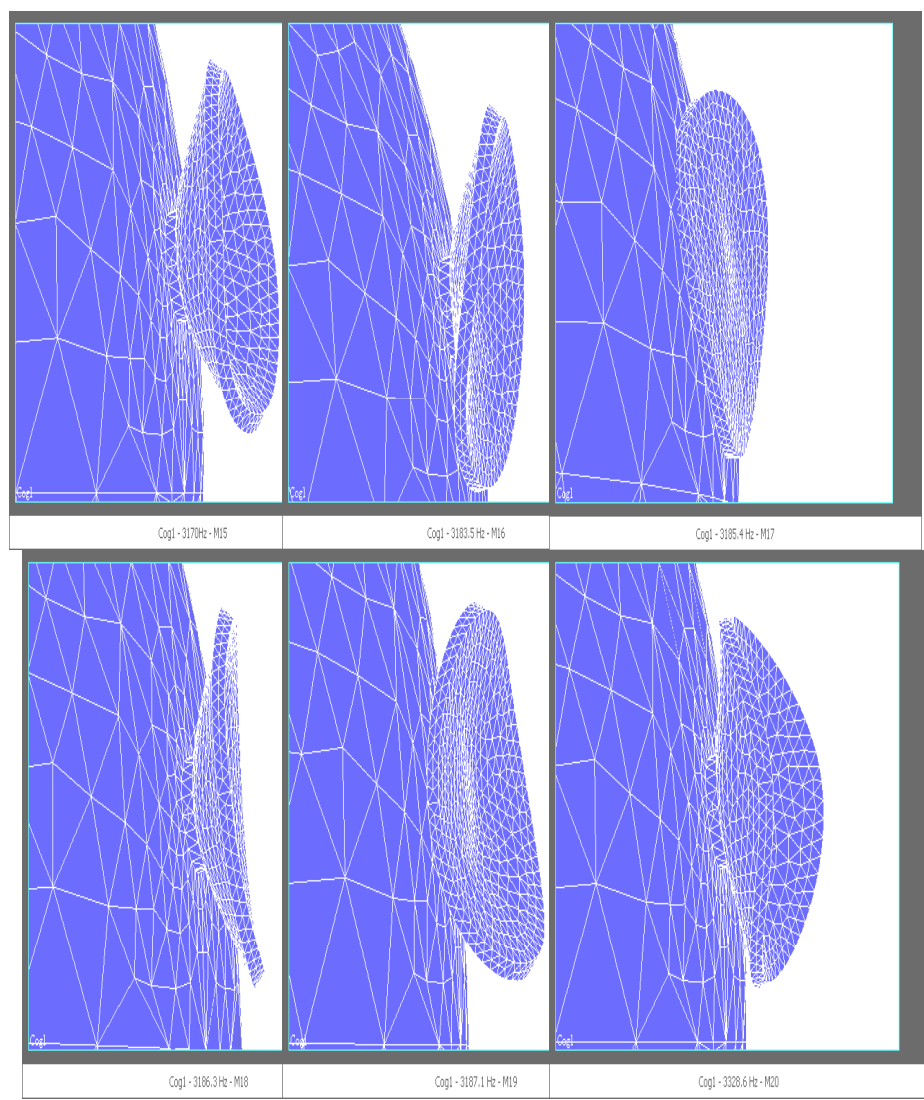

Figura 5.10: Instantâneos do movimento do casador de impedância utilizados na Simulação 1 em cada um dos seis modos do sistema esfera com um casador de impedância. O modo singleto é mostrado no quadro inferior direito.

Com o objetivo de tornar estes modos de vibração mais uniformes, foram modificadas as dimensões do casador de impedância, iniciando-se pela redução da espessura do diafragma, conforme Tabela 5.9 . Com as novas dimensões foi realizada a Simulação 2 e as freqüências obtidas para os modos de interesse são mostradas na Tabela 5.10. Após analisar diversas das animações geradas para o quintupleto, singleto e para o modo torsional, foi selecionada a seqüência de imagens mostrada na Figura 5.11 , que mostra o comportamento do casador de impedância nas freqüências obtidas para o quintupleto e para o singleto. Pode ser observado dos cinco primeiros quadros que o casador de impedância vibra mais uniformemente no quintupleto desta simulação. Mas no singleto, mostrado no quadro inferior direito, apresenta um formato do tipo borboleta enquanto se move, formato este impróprio para o uso com transdutores do tipo indutivo, capacitivo e paramétrico. 

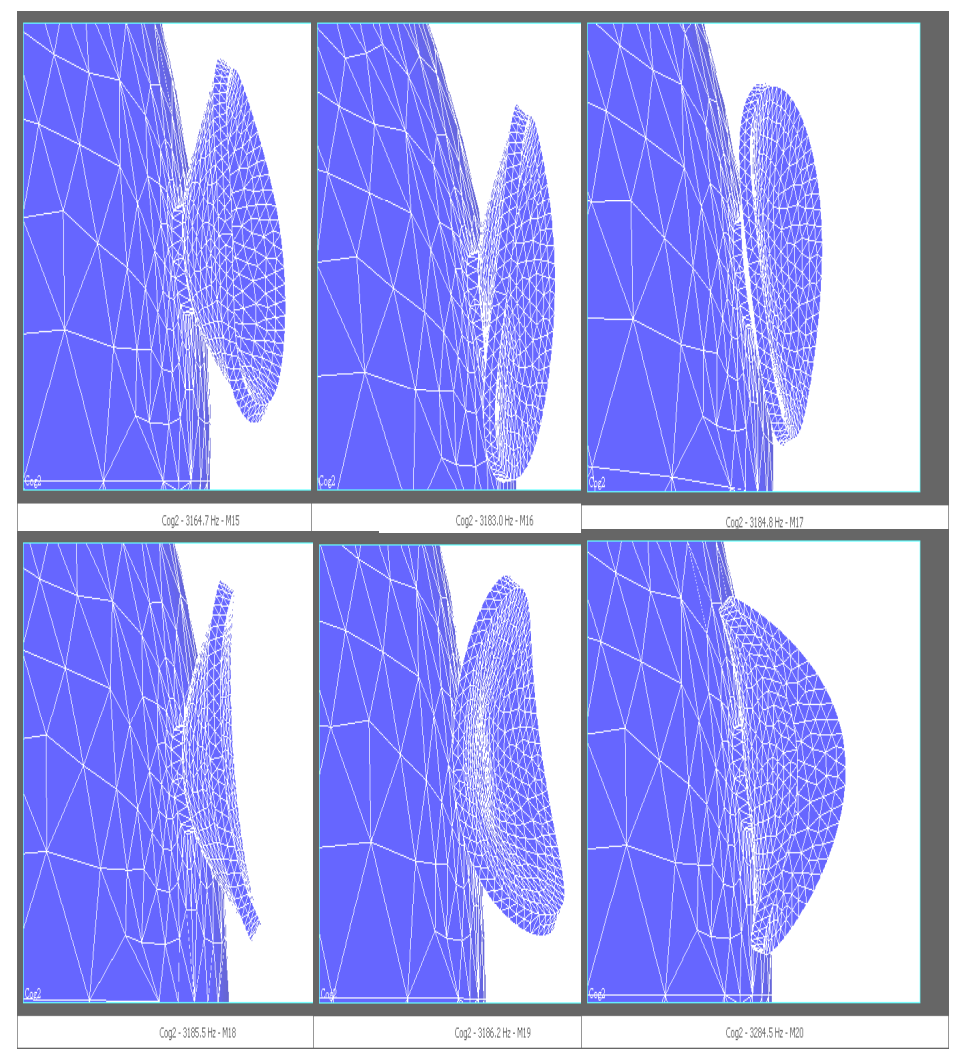

Figura 5.11: Instantâneos do movimento do casador de impedância obtidos na Simulação 2 para os seis modos do sistema esfera com um casador de impedância. O modo quintupleto é mostrado nos cinco primeiros quadros e o modo singleto no quadro inferior direito.

Para obter-se o formato utilizado na Simulação 3 , a espessura do diafragma foi reduzida ainda mais, o que pode ser verificado na Tabela 5.9 . As freqüências obtidas após esta simulação encontram-se na Tabela 5.10 . Após a análise das novas animações foram selecionados os instantâneos mostrados na Figura 5.12. Do segundo ao sexto quadros da figura verifica-se que nesta simulação o casador de impedância oscilou ainda mais uniformemente no quintupleto do que na Simulação 2. Entretanto, no singleto, que é mostrado no quadro superior esquerdo, o casador de impedância também teve a sua forma distorcida, ainda que em freqüência próxima do quintupleto, criando dificuldades na sua calibração e gerando um sinal pior nos transdutores indutivos ou capacitivos.

Suspeitou-se que os modos que apresentaram forma distorcida apareceram porque a base do casador de impedância foi deformada de tal modo, que amplificava o movimento diferencial da superfície da esfera. Na tentativa de corrigir esta distorção diminui-se o diâmetro do cilindro base, como é apresentado na próxima seção. 

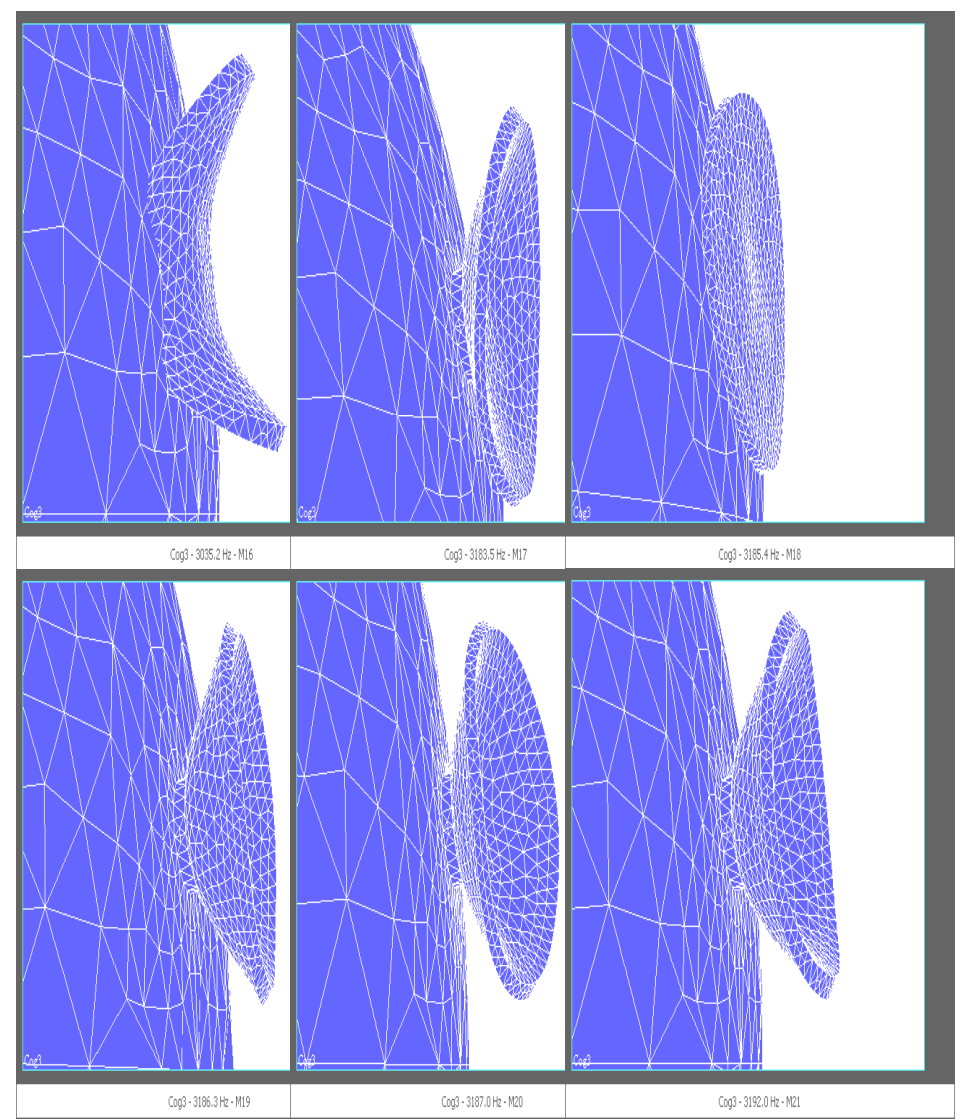

Figura 5.12: Instantâneos do movimento do casador de impedância utilizado na Simulação 3 para os seis modos do sistema esfera com um casador de impedância. Seu modo singleto é mostrado no desenho superior esquerdo.

\subsubsection{A Quarta e Quinta Simulações}

Para a Simulação 4 modificaram-se as dimensões do casador de impedância como mostrado na Tabela 5.9 . As freqüências obtidas para os modos são mostradas na Tabela 5.10 . Após a análise das animações geradas constatou-se que esta tentativa mostrou ser inadequada, porque a freqüência do modo de interesse do "cogumelo", cujo movimento foi mostrado claramente na linha inferior da Figura 5.12, tornou-se muito próxima da freqüência de um modo inconveniente, a do seu modo torsional, como é mostrado na Figura 5.13. 


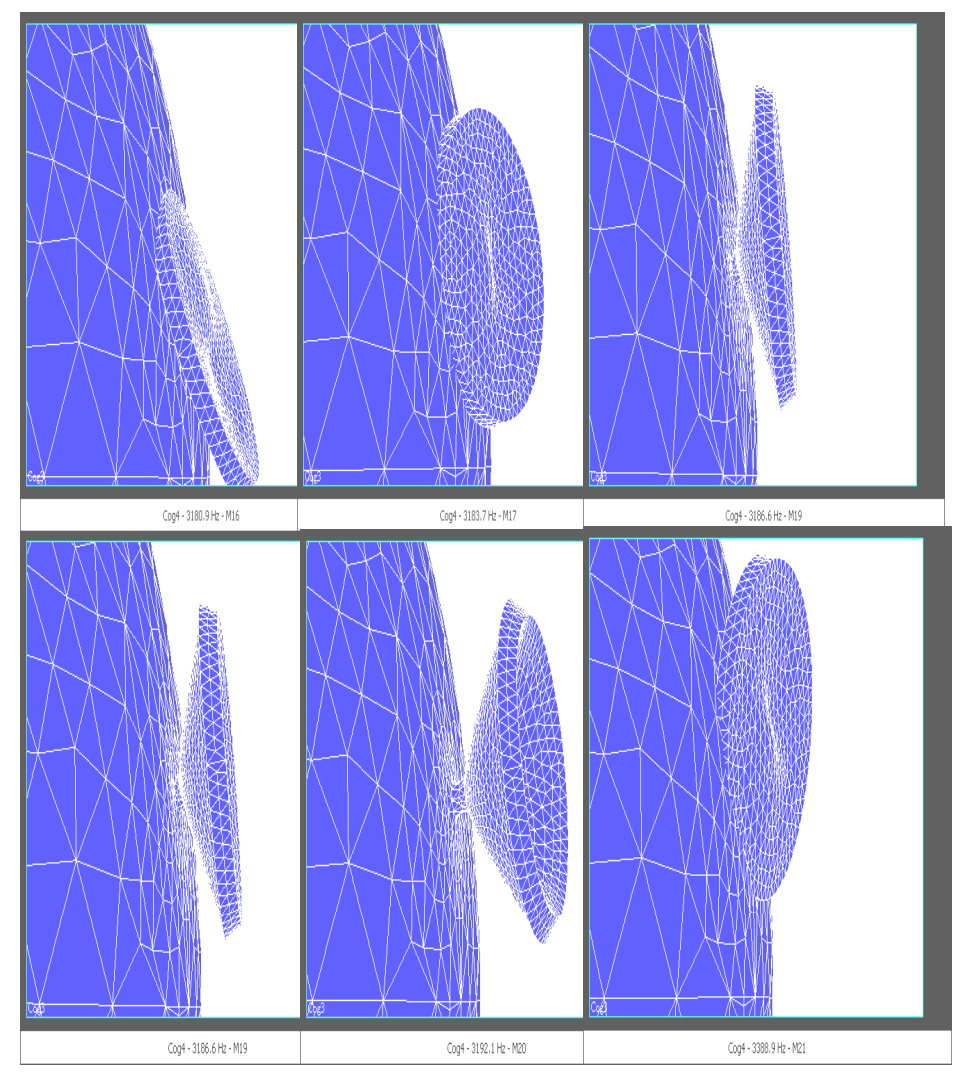

Figura 5.13: Instantâneos do movimento do casador de impedância utilizado na Simulação 4 para os seis modos de interesse do sistema esfera com um casador de impedância. O modo torsional do casador de impedância está evidente nos desenhos superior esquerdo, superior central e inferior direito.

Na tentativa de calibrar o casador de impedância para que o seu modo de interesse fosse ressonante com o modo quadrupolar da esfera, diminuiu-se a espessura do diafragma e se gerou o modelo utilizado na Simulação 5 , cujas dimensões são mostradas na Tabela 5.9 . As freqüências obtidas para os modos são mostradas na Tabela 5.10 e os instantâneos selecionados para a análise, mostrando o movimento resultante do casador de impedância, são mostrados na Figura 5.14.

A ocorrência do modo torsional foi eliminada. Em todos os modos os casadores de impedância apresentaram deformação próxima ao formato desejado. Embora ainda existissem algumas diferenças, estas foram menores que nas simulações anteriores. Decidiu-se fazer novas modificações e tentativas. 


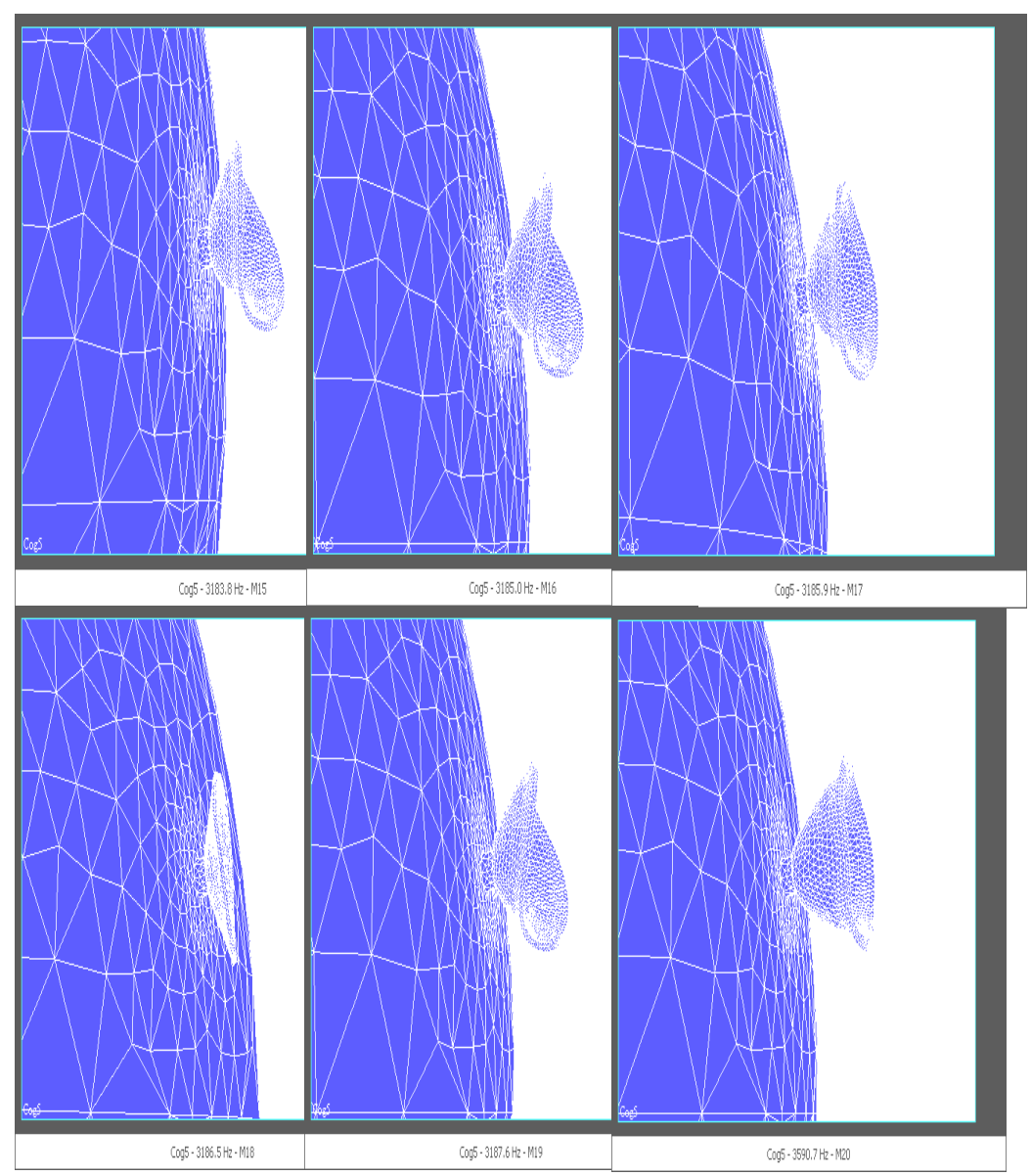

Figura 5.14: Instantâneos do movimento do casador de impedância utilizado na Simulação 5 para os seis modos de interesse do sistema esfera com um casador de impedância. O modo singleto é mostrado no desenho inferior direito.

\subsubsection{A Sexta Simulação}

No modelo utilizado na Simulação 6 os diâmetros do diafragma e do cilindro central não foram alterados, mas a espessura do diafragma foi reduzida, como é mostrado na Figura 5.15 .

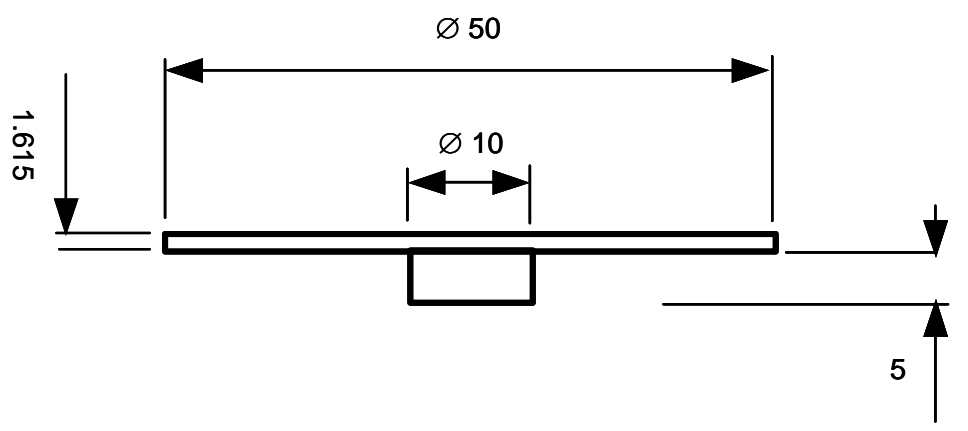

Figura 5.15: Desenho do casador de impedância utilizado na Simulação 6 . As dimensões estão em milímetros.

Como são mostradas na Tabela 5.10 , as freqüências do singleto e do quintupleto estão dentro dos limites da largura de banda do detector. Da Figura 5.16 , que mostra instantâneos do movimento do sistema em estudo, pode-se constatar que, com as dimensões utilizadas, o mesmo 
modo do casador de impedância, com o mesmo tipo de movimento, ocorreu em todos os modos de interesse do sistema, como era pretendido. Estes modos terão poucos problemas de calibração e espera-se que gerem um sinal significativo nos transdutores capacitivos ou indutivos.
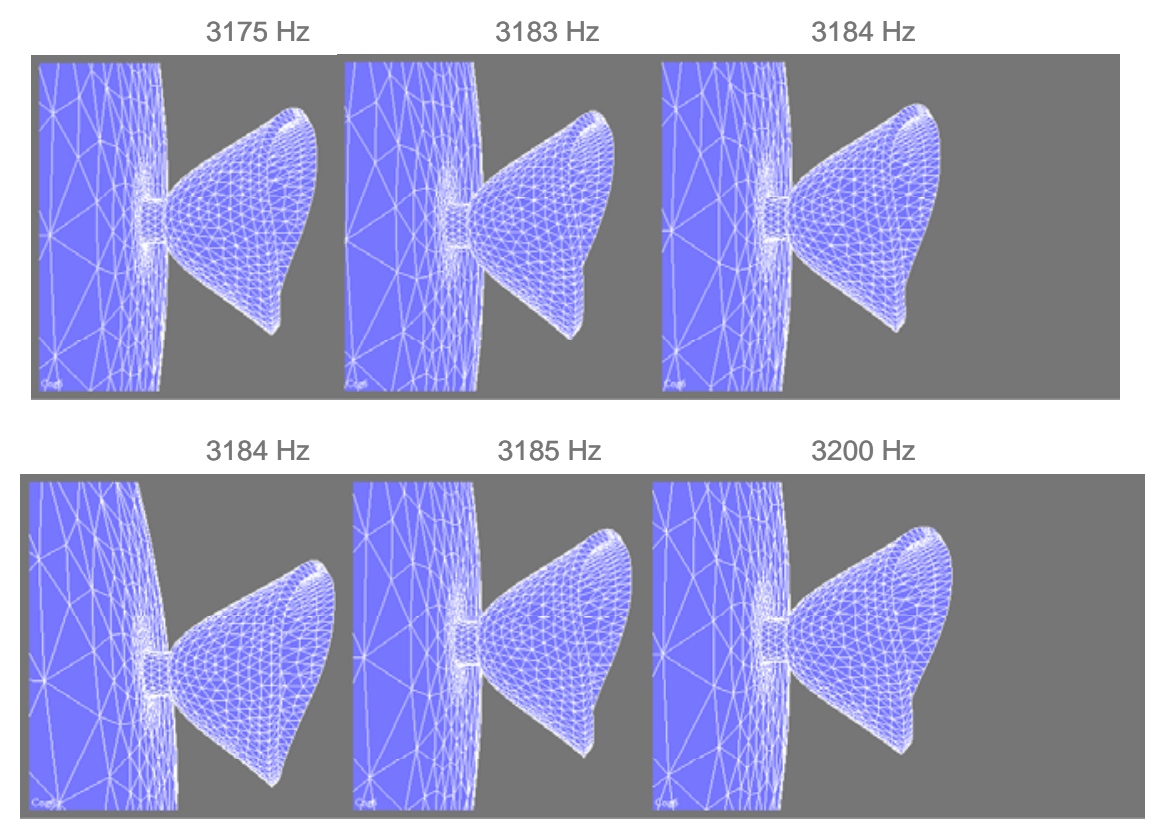

Figura 5.16: Instantâneos do movimento do casador de impedância utilizado na Simulação 6 nos seis modos do sistema esfera com casador de impedância. O modo singleto é mostrado no quadro inferior direito.

\subsubsection{Simulação da Esfera com Seis Casadores de Impedância “Cogumelo"}

Uma vez obtida a calibração em um sistema com apenas um casador de impedância unido à esfera, o que foi conseguido na Simulação 6, a continuação natural desta pesquisa foi conectar seis casadores de impedância do mesmo tipo deste à superfície da esfera, seguindo a distribuição utilizada no detector Shenberg.

Eles foram posicionados de acordo com uma distribuição em um semi-dodecaedro. Esta distribuição é a mesma utilizada e descrita na Seção 5.3.5, lembrando que os ângulos $\phi$ e $\theta$, utilizados para determinar a posição de cada casador de impedância na distribuição sobre a superfície da esfera, estão relacionados na Tabela 5.7 .

Estudou-se o comportamento dos casadores de impedância acoplados aos modos quadrupolares e torsionais da esfera.

Verificou-se que o sistema esfera mais os seis ressonadores tinha 11 modos, formando basicamente dois quintupletos e um singleto, como era esperado [27]. A Tabela 5.11 mostra as freqüências obtidas para estes modos. 
Tabela 5.11: Freqüências obtidas para os modos de interesse na simulação da esfera unida a seis casadores de impedência com formato de Cogumelo.

\begin{tabular}{|c|c|c|c|c|c|c|}
\hline Modos & Freqüências & Média & Desv padrão & Desv padrão \% & Banda & Banda \% \\
\hline & 3164 & & & & & \\
\hline & 3168 & & & & & \\
\hline \multirow[t]{3}{*}{ quintupleto } & 3171 & 3169,2 & 3,2711 & 0,103 & 8 & $0,25 \%$ \\
\hline & 3171 & & & & & \\
\hline & 3172 & & & & & \\
\hline \multirow[t]{3}{*}{ singleto } & 3187 & & & & & \\
\hline & 3194 & & & & & \\
\hline & 3196 & & & & & \\
\hline \multirow[t]{3}{*}{ quintupleto } & 3204 & 3203,00 & 8,4261 & 0,263 & 21 & $0,66 \%$ \\
\hline & 3206 & & & & & \\
\hline & 3215 & & & & & \\
\hline Média & 3186,18 & & & & & \\
\hline Desv. padrão & 17,84 & & & & & \\
\hline Desv. padrão \% & $0,56 \%$ & & & & & \\
\hline Banda & 51,00 & & & & & \\
\hline Banda \% & $1,60 \%$ & & & & & \\
\hline
\end{tabular}

As freqüências dos quintupletos podem ser consideradas degeneradas já que elas possuem pequeno desvio padrão do valor médio de 3169,2 Hz (primeiro quintupleto) e 3203,0 Hz (segundo quintupleto). Contudo, é importante se notar que, a largura de banda coberta pelo segundo quintupleto é 2,6 vezes maior que a coberta pelo primeiro quintupleto.

As freqüências do primeiro quintupleto são basicamente degeneradas. Elas possuem pequeno desvio padrão do valor médio de 3169,2 Hz comparado à sua distância de 17,8 Hz do modo singleto ao centro da banda.

Por outro lado, as freqüências do segundo quintupleto não podem ser consideradas degeneradas já que o desvio padrão do seu valor médio de 3203,0 Hz é comparável à distância de 16 Hz ao modo central, como é evidente pela Figura 5.17 .

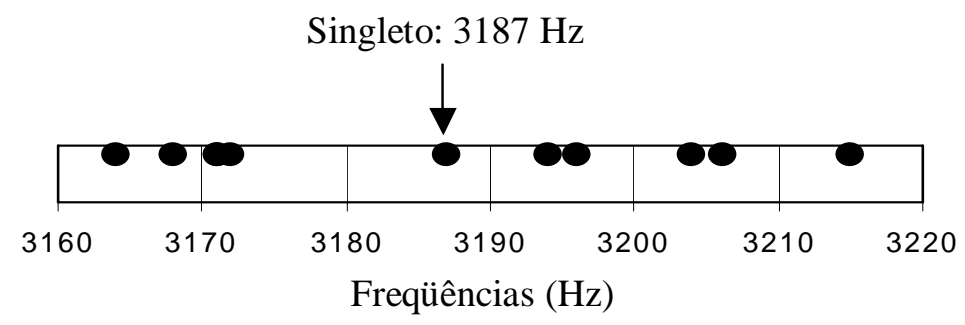

Figura 5.17: Freqüências de acoplamento do sistema esfera com os seis casadores de impedância. A degenerescência é mais afetada no quintupleto com maiores freqüências. Notar que a freqüência $3171 \mathrm{~Hz}$ é repetida. 
No modo singleto a esfera permanece em repouso enquanto os transdutores se movem, como é mostrado na Figura 5.18 .

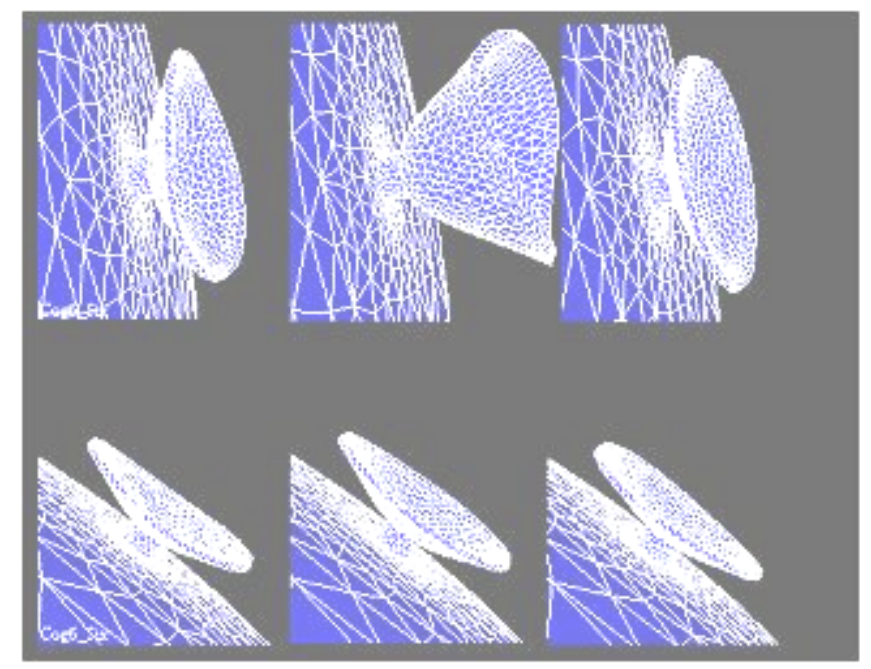

Figura 5.18: Instantâneos da simulação do movimento dos casadores de impedância no modo singleto do sistema esfera com seis casadores, onde todos os casadores se movem enquanto a esfera permanece em repouso. A amplitude máxima do movimento é mostrada na imagem superior central.

Os outros dez modos possuem um transdutor que se move mais intensamente que os outros, um comportamento que é ilustrado na Figura 5.19..

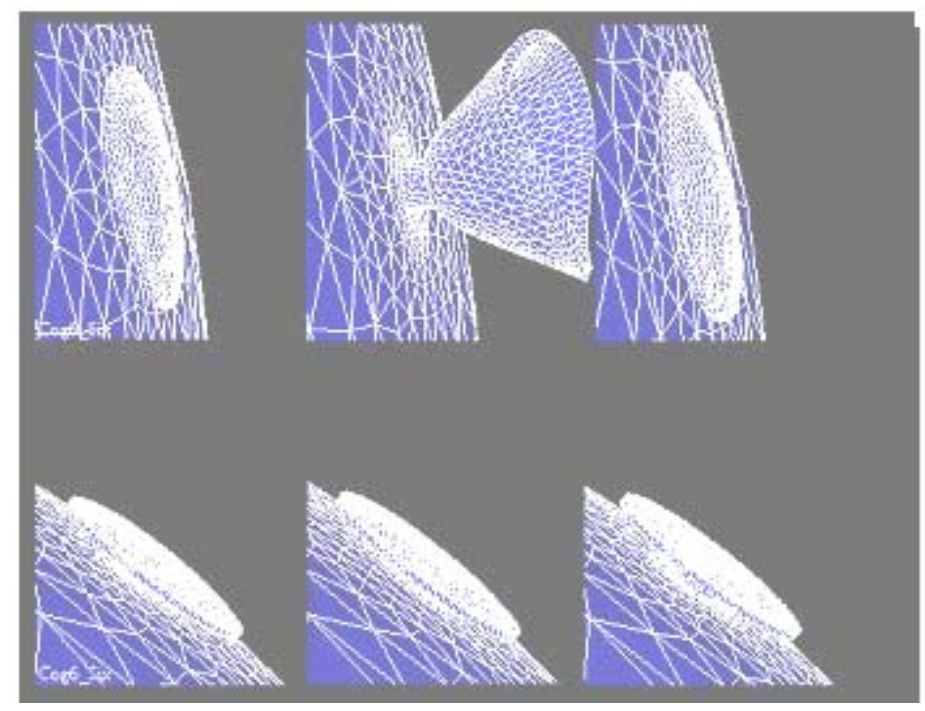

Figura 5.19: Instantâneos dos movimentos simultâneos dos casadores de impedância no modo com freqüência de $3164 \mathrm{~Hz}$ do sistema esfera com seis casadores de impedância. Nos modos quintupleto a esfera e os casadores se movem mas um casador se move mais que os outros, como é evidente pelas figuras, a amplitude máxima do movimento é mostrada na imagem superior central. 


\section{Capítulo 6}

\section{Conclusões}

Com a intenção de obter uma melhor amplificação da oscilação da esfera em seu modo quadrupolar com um casador de impedância mecânico de apenas um modo, e com a limitação de que este tinha que caber dentro da câmara experimental, foi proposto um formato original de casador de impedância aqui denominado "bico de passarinho", que não se mostrou satisfatório. O projeto deste tipo de casador de impedância com o transdutor parece ser muito delicado. Uma pequena alteração na sua dimensão angular $\theta$, utilizado para calibrar sua freqüência de vibração, pode alterar como este casador de impedância acopla com os modos quadrupolares e torsionais da esfera. Mas ele pode ser projetado para ter modos melhores.

Vale a pena lembrar que quando o transdutor é bombeado com o sinal de microondas, a freqüência é deslocada para um valor mais abaixo. Isto pode fazer este tipo de casador de impedância inadequado para o uso neste tipo de detector.

Contudo existem observações que devem ser mencionadas em relação ao formato "bico de passarinho":

- O fato do procedimento utilizado para estudar o comportamento da união dos casadores de impedância investigados com a esfera, utilizando um programa de MEF, ter mostrado de forma bastante clara que uma escolha inadequada do formato deste casador de impedância é aparente na investigação (fornece resultados coerentes com a má escolha do formato)

- Apesar de não possuir um formato tão simples quanto se desejava, o formato "bico de passarinho” permitia que com o controle de apenas um parâmetro, o seu ângulo $\theta$, se alterasse seu tamanho, já que várias dimensões eram alteradas por serem dependentes deste ângulo.

- O procedimento utilizado na escolha da melhor calibração para o casador de impedância, no caso deste formato, mostrou que era visível uma tendência para o valor deste parâmetro.

No estudo do casador de impedância com formato "cogumelo", depois de uma série de mudanças nas suas dimensões obteve-se uma configuração na qual todos os modos do sistema esfera mais ressonadores possuem formatos similares e podem ser calibrados da mesma maneira. Os ressonadores com melhor performance, entre todas as simulações, foram os menores e mais leves 
Tinham uma razão relativamente alta entre o diâmetro do diafragma e o diâmetro da base, e um diafragma fino.

Este resultado sugere que é importante manter o contacto entre a membrana e a esfera tão pequeno quanto possível, enquanto se mantém a membrana grande e fina.

Determinou-se também os onze modos normais do sistema esfera com seis destes ressonadores com formato de cogumelo.

Quando estes casadores foram conectados à esfera nas posições adequadas percebeu-se que os modos quintupletos apresentaram larguras de banda diferentes.

Foi identificado que o posicionamento dos casadores de impedância afetam o comportamento geral do sistema.

O fato de todos os transdutores estarem localizados na mesma metade da esfera cria uma assimetria em sua distribuição na superfície da esfera. Da experiência que foi acumulada durante este estudo, acredita-se que tal assimetria pode ter influenciado a resposta dos modos. Por esta razão, a falta da degenerecência no segundo quintupleto pode ser devido à assimetria criada pela presença dos ressonadores em apenas um dos hemisférios da esfera. A mesma constatação pode ser feita analisando-se as freqüências dos casadores de impedância mecânicos "bico de passarinho".

Destes resultados presume-se que os transdutores reais para o detector "Mário Schenberg” precisam ter uma membrana grande e fina para terem uma boa performance. Quer dizer: grande quando comparada com seus conectores.

É provável também que os modos quintupletos não sejam igualmente espalhados em torno do valor médio, o maior deles teria uma banda mais larga.

Ficou claro ao final desta pesquisa, que neste tipo de estudo, feito a partir dos valores das freqüências obtidas para os modos, a análise dos movimentos gerados pelo programa de MEF, nem sempre é simples e clara.

Aparentemente os erros inerentes ao programa de MEF utilizado não impediram e nem alteraram as possíveis conclusões cabíveis neste estudo. Por isso, os resultados das simulações feitas nesta pesquisa, poderiam ser considerados como resultados experimentais, e serem analisados como tais.

Foi mostrado que obter um oscilador mecânico com uma freqüência próxima de um dos modos quadrupolares de uma esfera, e que trabalhe como um bom casador de impedância para um detector de ondas gravitacionais esférico, não é simples ou direto. 


\subsection{Sugestões para Trabalho Futuro}

A distribuição das freqüências nos modos quintupleto em torno do seu valor médio, denotando uma assimetria, poderia afetar a análise de dados. É recomendável portanto se investigar em que grau esta caracterítica afeta a análise de dados.

Como uma continuação natural deste trabalho seria feita uma simulação da esfera com os furos que serão utilizados para conectar os transdutores, e outra simulação adicionando a estes o furo da suspensão da esfera.

A simulação de um casador de impedância multimodo, objetivando uma investigação mais próxima do transdutor real de dois modos projetado para ser utilizado no Schenberg, seria um avanço importante em uma futura pesquisa. 


\section{Bibliografia}

[1] Frajuca, C. Otimização de transdutores de dois modos mecânicos para detectores de ondas gravitacionais. São Paulo. 97 p. Tese (Doutorado em Física) - Universidade de São Paulo, 1996.

[2] Andrade, Luiz A. - Desenvolvimento de um Oscilador em 10 GHz de Ultrabaixo Ruído de Fase e a Análise de seu Desempenho nos Transdutores Paramétricos do Detector de Ondas Gravitacionais Mário Schenberg. São José dos Campos. 173p. Tese (Astrofísica) Instituto Nacional de Pesquisas Espaciais, 2004.

[3] Jackson, John David. Classical Eletrodynamics. New York: Wiley, 1999, 808p.

[4] Ribeiro, Kilder L. Estudo do Sistema de Transdução Paramétrica para Detectores de Ondas Gravitacionais. São José dos Campos. 92p. Tese (Ciência Espacial / Astrofísica) Instituto Nacional de Pesquisas Espaciais, 2003.

[5] J.Weber, (1960). Detection and Generation of Gravitational Waves, Phys.Ver., 117, 306.

[6] Melo, José L. Estudo do Sistema de Isolamento Vibracional da Suspensão para o Protótipo de um Detector de Ondas Gravitacionais. São José dos Campos. 111p. Dissertação (Ciência Espacial / Astrofísica) - Instituto Nacional de Pesquisas Espaciais, 2001.

[7] Richard, J. P. Wide-band bar detectors of gravitational radiation. Physical Review Letters, v. 52, n. 3, p. 165-167, Jan. 1984.

[8] Marion, Jerry B. Dinamica Clasica de lás Particulas y Sistemas. Barcelona: Reverte, 1975, $653 p$.

[9] J.P. Richard, (1079) A Multimode Antenna for the Detection of Short Pulses of Gravitational Waves, em Proceeding of the Second Marcel Grossmann Meeting on General Relativity, editado por R.Ruffini, (North-Holland, Amsterdam). 
[10] Walter, C. ; Sampaio, R. ; Cataldo, E., Vibrações Mecânicas - Resumo da teoria e exercícios, RJ: PUC-Rio e AEB (Agência Espacial Brasileira), 1998

[11] Pimentel, Karla C. A. , Tubulações Pressurizadas em Aterros Reforçados com

Geossintéticos, Brasília: 271p. (Dissertação em Geotecnia) - Universidade de Brasília, 2003

[12] Bathe, Klaus-Jürgen , Finite Element Procedures, New Jersey: Prentice Hall, 1996.

[13] Avelino Alves Filho, Elementos Finitos, São Paulo: Érica, 2000

[14] O. D. Aguiar et. al, Class. Quantum Grav.22, $209\{2005\}$

[15] C. Frajuca, K.L.Ribeiro, O.D.Aguiar, L. A Andrade, P.J.Castro, N.S.Magalhaes and R. M. Marinho Jr,Class. Quantum Grav. 21, $1107\{2004\}$

[16] G. Frossati, Proceedings of the First International Workshop for an Omnidirectional Gravitational Radiation Observatory, W. F. Velloso, Jr., O. D. Aguiar and N. S. Magalhaes, editors (Singapore, World Scientific, 1997).

[17] C. Frajuca, K. L. Ribeiro, L. A. Andrade, W. F. Velloso Jr, J. L. Melo, O. D. Aguiar and N. S. Magalhaes, Class. Quantum Grav. $\{19\}\{1961\}\{2002\}$

[18] C. Frajuca, O. D. Aguiar, N. S. Magalhaes, K. L. Ribeiro and L. A Andrade, Proc. 3rd Edoardo Amaldi Conference on Gravitational Waves (Pasadena, USA, July 1999). AIP Conf. Proc. 523 (New York, AIP) p.417.

[19] S. M. Merkowitz and W. W. Johnson, Journal\{Phys. Rev. Lett. $\}\{70\}\{2367\}\{1993\}$

[20] N. S. Magalhaes, O.D. Aguiar, W.W. Johnson and C.Frajuca, Journal\{Gen. Relat. Grav.\}, 29,1511\{1997\}

[21] N. S. Magalhaes, W. W. Johnson, C. Frajuca and O. D. Aguiar, MNRAS, 274, 670,\{1995\}

[22] N. S. Magalhaes, W. W. Jonhson, C. Frajuca and O D. Aguiar, \Journal\{Astrophysical Journal $\}\{475\}\{462\}\{1997\}$

[23] O. D. Aguiar et al., Journal \{Class. Quantum Grav. $\}\{23\}\{239\}\{2006\}$

[24] N. S. Magalhaes, W. W. Johnson, C. Frajuca and O. D. Aguiar, \Journal\{Astroph. J.\} \{475\} $\{462\}\{1997\}$

[25] O. D. Aguiar et al., Journal $\{$ Class. Quantum Grav. $\}\{21\}\{459\}\{2004\}$

[26] R. D. Blevins, Formulas for Natural Frequency and Shape, (Malabar, Krieger Publ., 1979).

[27] S. M. Merkowitz and W. W. Johnson, Journal \{Phys. Rev. D\} \{56\}\{7513\}\{1997\} 
[28] C. Frajuca, F. S. Bortoli and N. S. Magalhaes, "Studying a new shape for the impedance matchers in Mario Schenberg Transducers". In: 6th Edoardo Amaldi Conference on Gravitational Waves, 2005, Nago, Okinawa,Japão. Abstract booklet. Tokio : Organizing comitte, 2005.

[29] C. Frajuca, F.S. Bortoli; N. S. Magalhães. Resonant tranducers for spherical gravitational wave detectors. Brazilian Journal of Physics, São Paulo, SP, v. 35, n. 4B, p. 1201-1203, 2005.

[30] “Sky \& Telescope”, october, 2000.

[31] Sérgio Ricardo Furtado. Estudo de Técnicas de Resfriamento Rápido de Antenas Esferoidais Utilizadas em Detectores de Ondas Gravitacionais. São José dos Campos, Dissertação (Mestrado em Astrofísica), INPE - Divisão de Astrofísica, 2006. 